\title{
Treatment technologies for urban solid biowaste to create value products: a review with focus on low- and middle- income settings
}

\author{
Christian Riuji Lohri • Stefan Diener - Imanol Zabaleta • \\ Adeline Mertenat $\cdot$ Christian Zurbrügg
}

Published online: 10 February 2017

(C) The Author(s) 2017. This article is published with open access at Springerlink.com

\begin{abstract}
Treatment of biowaste, the predominant waste fraction in low- and middle-income settings, offers public health, environmental and economic benefits by converting waste into a hygienic product, diverting it from disposal sites, and providing a source of income. This article presents a comprehensive overview of 13 biowaste treatment technologies, grouped into four categories: (1) direct use (direct land application, direct animal feed, direct combustion), (2) biological treatment (composting, vermicomposting, black soldier fly treatment, anaerobic digestion, fermentation), (3) physico-chemical treatment (transesterification, densification), and (4) thermo-chemical treatment (pyrolysis, liquefaction, gasification). Based on a literature review and expert consultation, the main feedstock requirements, process conditions and treatment products are summarized, and the challenges and trends, particularly regarding the applicability of each technology in the
\end{abstract}

Electronic supplementary material The online version of this article (doi:10.1007/s11157-017-9422-5) contains supplementary material, which is available to authorized users.

C. R. Lohri $(\bowtie) \cdot$ S. Diener · I. Zabaleta ·

A. Mertenat · C. Zurbrügg

Department of Sanitation, Water and Solid Waste for

Development (Sandec), Eawag: Swiss Federal Institute of

Aquatic Science and Technology, Überlandstrasse 133,

8600 Dübendorf, Switzerland

e-mail: christian.lohri@eawag.ch urban low- and middle-income context, are critically discussed. An analysis of the scientific articles published from 2005 to 2015 reveals substantial differences in the amount and type of research published for each technology, a fact that can partly be explained with the development stage of the technologies. Overall, publications from case studies and field research seem disproportionately underrepresented for all technologies. One may argue that this reflects the main task of researchers - to conduct fundamental research for enhanced process understanding-but it may also be a result of the traditional embedding of the waste sector in the discipline of engineering science, where socio-economic and management aspects are seldom object of the research. More unbiased, wellstructured and reproducible evidence from case studies at scale could foster the knowledge transfer to practitioners and enhance the exchange between academia, policy and practice.

Keywords Municipal solid waste management . Organic waste $\cdot$ Recycling $\cdot$ Valorization $\cdot$ Developing countries

\section{Introduction}

The generation of solid waste has been increasing on a worldwide scale, mainly driven by growing global population, urbanization and economic growth, coupled with changing production and consumption 
behavior (Karak et al. 2012). Ensuring adequate solid waste management is acknowledged as one of the key challenges of the twenty-first century and considered a fundamental element for sustainable development (Scheinberg et al. 2010; Wilson 2015). Opportunities for improvement remain particularly pronounced in urban low- and middle-income settings, where solid waste management is characterized by low waste collection coverage, lack of treatment and inadequate disposal. Many appropriate solutions are hindered given the fast and unregulated growth of settlements in topographically often challenging areas, lack of financial resources, ineffective organizational structures, lack of viable business models, low political priority setting by governments and minimal enforcement of policy and legislation (Marshall and Farahbakhsh 2013; Zurbrügg 2013). Adverse effects on human health, the environment, and social and economic development are the consequence (Guerrero et al. 2013).

In low- and middle-income settings, a predominant characteristic of municipal solid waste-defined as non-liquid waste from households, small businesses and institutions (Wilson 2015) - is the high fraction of organic, hence biodegradable matter (=biowaste). This fraction often constitutes more than $50 \%$ of the total waste generated and can be as high as $80 \%$ (Troschinetz and Mihelcic 2009; Wilson et al. 2012). Biowaste is comprised of food and kitchen waste (e.g. from households, restaurants, hotels, schools, hospitals), market waste, yard and park waste, and residues from food and wood processing industries (Hoornweg and Bhada-Tata 2012). Unmanaged biowaste poses a considerable threat to public and environmental health as it impacts through olfactory nuisance, attracts insects, rodents and other disease vectors, and generates leachate that may contaminate surface and groundwater supplies (Reddy and Nandini 2011). Moreover, uncontrolled disposal of biowaste emits methane, a major greenhouse gas (Bogner et al. 2008).

Advancing on biowaste management is an ideal entry point for overall municipal solid waste management improvements (Srivastava et al. 2014; Wilson 2015). Besides reducing public health threats (Ahmad et al. 2007) and environmental burden (Friedrich and Trois 2011), returning resource value of waste into the economy reflects the paradigm shift towards a circular economy focused on 'closing loops' through recovery, while at the same time considering new business opportunities and economic growth (Ghisellini et al. 2016; Witjes and Lozano 2016). Biowaste treatment in a circular economy addresses resource scarcity, for instance the depleting nutrients stocks such as phosphorus (Zabaleta and Rodic 2015). It can also act as driving force for overall waste management when, for instance, the economic value of biowaste-derivedproducts incentivizes waste collection or the new revenue opportunities enhance financial sustainability of the system (Lohri et al. 2014).

Biowaste treatment and its benefits has attracted considerable interest of researchers worldwide (e.g. Polprasert 2007; Yang et al. 2015b). Many publications, however, either include liquid biowaste or then emphasize only certain waste treatment options without allowing a comparison among them. A comprehensive overview of a wide range of different biowaste treatment technologies is still lacking. This article attempts to fill this gap by reviewing the state-ofresearch and research challenges for a wide range of biowaste treatment technologies. It puts a special focus on the applicability of these treatment approaches for low- and middle-income settings where the need for solutions is most evident. The way this review is structured it: (1) provides a systematic, descriptive overview of the main treatment technologies for urban biowaste, (2) compares the state-of-research of these biowaste treatment technologies by examining the type of research published in scientific articles from 2005 to 2015, and (3) investigates if and how scientific publications address the issue of biowaste treatment specific to low- and middle-income settings.

Source-segregated solid biowaste is considered as feedstock of the presented treatment technologies. Thus, the review does not look into treatment options for mixed municipal waste streams, such as mechanical-biological treatment (MBT) with refuse/solid derived fuel (RDF/SDF) production (Di Lonardo et al. 2012; Velis et al. 2010), incineration (Astrup et al. 2009) or landfill treatment (Hashisho and ElFadel 2014).

\section{Methodology}

This review of biowaste treatment technologies for low- and middle-income settings is based on a 
comprehensive scientific literature review and expert consultation. In expert group dialogs a simplified, structured overview of the selected treatment technologies was developed. The technologies reviewed are grouped according to their principal conversion processes and show the corresponding treatment products and their potential end-uses.

Each reviewed biowaste treatment technology is briefly summarized according to the following structure: (1) introduction including a brief historical background, (2) input material (feedstock specifications and pre-treatment requirements), (3) conversion process and main technologies, (4) output (product characteristics, post-processing requirements and enduses), and (5) critical review of challenges and trends in low- and middle-income settings. Citation of scientific key literature allows access to more detailed information on each technology.

The Scopus search engine and database, an abstract and citation database of peer-reviewed literature, was used for the state-of-research analysis. The search was conducted for the publication period of 2005 until and including 2015, and was performed between 2nd June and 7th July 2016. Three search levels were applied consecutively. At each level a specific set of search terms was adopted as shown in Fig. 1. The search results of each level were then used as a basis to apply the search terms of the next level. The comprehensive listing of all applied search terms at each level with the specific search codes can be found in the supplementary material.

Search level 1 After consultation of waste experts in a focus group discussion, search terms of each specific treatment technology descriptor, process and corresponding treatment as well as their synonyms were defined. These search terms (connected with the Boolean "OR") were used in the search categories "article title" and "keywords" (authors keywords as well as the indexed keywords). Other technologies descriptors were excluded using the Boolean "AND NOT" feature in the "article title" category. This "AND NOT" feature was not applied to the "keywords" category to retain publications that comparatively discuss different treatment technologies. This process was repeated for each technology and the results were analyzed in terms of frequency of publication.

Search level 2 This level then used terms describing the feedstock for treatment-solid waste and its synonyms-to filter the results from search level 1 . The "AND NOT" Boolean was used in the "article title" category to exclude articles related to other waste which is not considered relevant for this review.

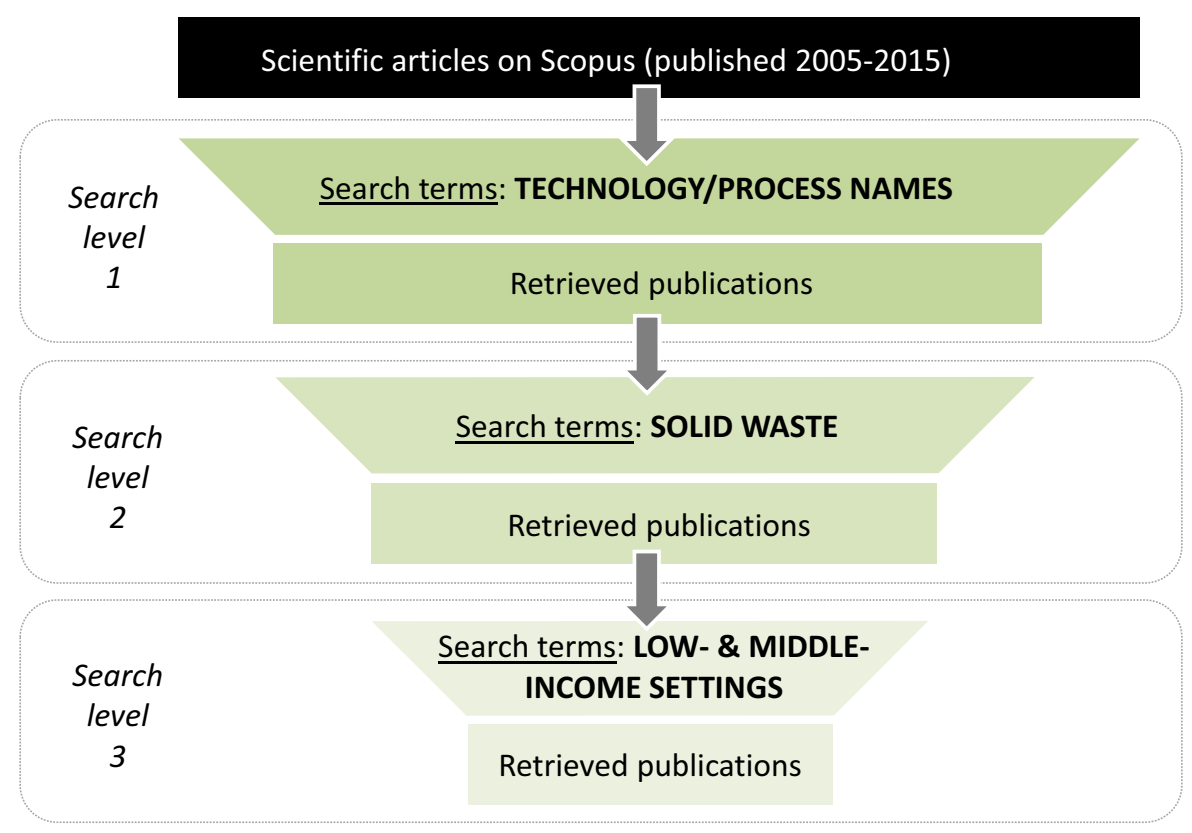

Fig. 1 Levels of scientific literature search and corresponding search term categories 
Feedstock terms such as wastewater, sludge, faeces, urine, sewage, manure, livestock waste, dairy waste, tire, e-waste, medical waste, are examples of such exclusion (see supplementary material). Results were analyzed regarding frequency of publication for each technology and then analyzed in more detail to assess the type of research conducted. Three research type categories were established:

1. Process engineering Articles of laboratory/bench scale work with a technical focus on the basic fundamentals to understand and optimize the process

2. Implementation Pilot/demonstration scale or case studies discussing the field application

3. Sustainability aspects Financial, social, environmental aspects, models and simulations, theoretical evaluation, potential analysis, decision support tools

From the search level 2 results for each technology (=population size), a representative sample size was calculated based on an error margin of $5 \%$, a confidence level of $95 \%$, using a conservative response distribution of $50 \%$. Then $20 \%$ was added to this calculated sample size to account for potential non-target articles in the selection. The calculated number of publications was then randomly extracted from the results of search level 2. Each author of the present article then individually classified each selected article into the three research type categories, whereby articles could fit in one, two or all three categories. The research type classifications for each treatment technology were then compared to each other.

Search level 3 This level then filtered the results of search level 2 to extract those articles that relate to low- and middle-income settings. Besides using a defined list of search terms to capture this aspect (see supplementary material) all 105 country names which are classified as low-income, lower-middle income, or upper-middle income countries (World Bank 2015) were included. Furthermore, eight countries classified with a low or middle Human Development Index (HDI) (United Nations Development Programme 2015 ), and two countries with $<60 \%$ of the population served by waste collection services (UNEP 2011) were added to the list. In total 126 search terms were thus used for the search categories "article title" and "keywords". The results were analyzed in terms of frequency of publication for each technology as well as the trend of publication frequency over 5 year periods.

\section{Overview of biowaste treatment technologies/ processes}

In this context biowaste treatment technologies are defined as processes that convert discarded biowaste into new products with potentially some value. Treatment technologies for urban solid biowaste are grouped into four main categories: (1) direct use, (2) biological treatment, (3) physico-chemical treatment, and (4) thermochemical treatment (Fig. 2).

Sustainable waste recycling requires a supply of adequate waste materials as input, and the market demand for the output products (Vergara and Tchobanoglous 2012). For biowaste such markets will depend on the intended end-use of the outputs, which can roughly be clustered into three end-use groups:

Animal husbandry Biowaste-derived products can be used as animal feed. This will continue being of increasing relevance considering the major global shift towards diets with increased consumption of animal products. The demand for meat and milk is expected to be 58 and $70 \%$ higher in 2050 than in 2010, with low- and middle-income countries significantly contributing to this increase (FAO 2011). A growing demand for animal products requires increasing amounts of feed. Rising prices of conventional feed resources such as soy-and fishmeal, the risk of future unavailability and the current associated negative environmental impacts in production of such conventional feed are triggering innovation and alternative feed. Protein products derived from waste, such as insects or worms, are increasingly being considered as possible alternative option (Makkar et al. 2014).

Agriculture Biowaste, a source of carbon and plant nutrients, can be processed into different type of soil amendments with benefit for both crops and soils. These biowaste-derived soil amendments (e.g. compost, digestate) are by many customer groups perceived as low value products (Gilbert 2015). However, with increasingly intense agricultural practices, soils are progressively vulnerable, especially in the tropics. Rapid carbon turnover (3-5 times faster than in 


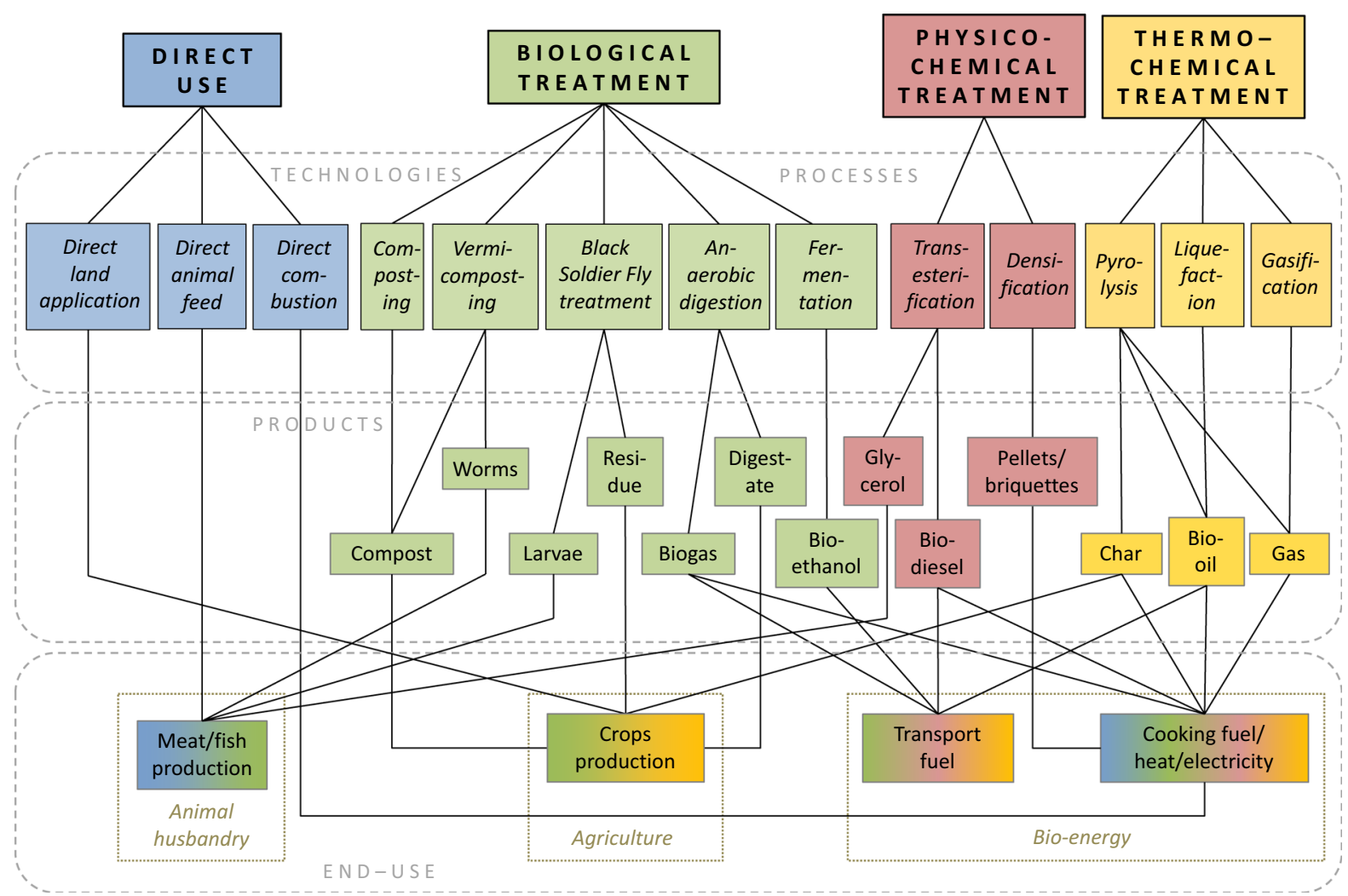

Fig. 2 Overview of biowaste treatment technologies as presented in this review with the respective products generated from waste and their end-use

temperate regions) and extraction, decreasing nutrient retention and water storage capacity, and decreasing erosion resistance are highlighting the need of carbon and plant nutrient replenishment. This can be achieved by recycling organic waste into agriculture (Smith et al. 2015).

Bio-energy The energy contained in waste biomass has received increased attention. Considering the growing energy demand, 1.2 billion people (17\% of the global population) without electricity and 2.7 billion people (38\% of the global population) still relying on unsustainably harvested wood for cooking (OECD/IEA 2015), biowaste-derived energy products are of high interest (Lohri et al. 2016). In addition, the increasing global mobility combined with the world's dwindling petroleum reserves raise the interest for technologies to convert (and upgrade) biowastederived products into transportation fuels.

\subsection{Direct use}

The direct use of biowaste is an ancient form of waste treatment/disposal. It is associated with low costs and simplicity. Included in this category of 'direct uses' are direct land application, waste fed directly to animals and direct open combustion. The risks of such practices depend on the composition of the biowaste. Contamination can easily jeopardize human, animal and environmental health. Direct biowaste use on land and for feed is still practiced today, mainly in rural settings. In urban settings, characterized by high population density and increasing waste complexity, this practice is less frequent.

\subsubsection{Direct land application}

Introduction Direct land application, also called landspreading, refers to the practice of raw waste 
dispersal onto fields. Literature on land application of waste typically describes the spread of raw agricultural waste (manure and/or crop residue) onto fields. However, literature tagged with this terms may also comprise studies on use of composted material, digestate, faecal sludge or wastewater. In this study the term is used in a strict sense only considering the practice when no actual treatment phase is involved, with the exception of segregation. Direct land application is particularly relevant for crops that require large quantities of organic nutrients (Dulac 2001).

Input material Direct land application should focus only on pure organic waste (Gendebien et al. 2001) as non-biodegradable waste fractions or pollutants would affect soil and crop quality or endanger farmers health. A study conducted for the EU Commission came to the conclusion that more than $90 \%$ of the waste spread on European land is agricultural waste, mainly animal manure. The remaining 10\% is food waste (Gendebien et al. 2001). When considering urban organic waste, studies have shown the potential benefit of using yard waste (Hegberg et al. 1990) and municipal organic waste (EPA 2004) that can enhance organic matter levels, total nitrogen and available phosphorous in soils.

Conversion process With direct land application, raw organic waste undergoes natural aerobic biodegradation after it is spread onto the field. Degradation mobilizes nutrients and increases organic matter content of soil. However, degradation may also cause a nitrogen competition in soil, when the microbial population outcompetes the crop in the use of nitrogen for their own metabolism, with the result that the crop shows signs of nitrogen deficiency. Smith et al. (2015) estimate that untreated waste application results in a $66 \%$ decrease of the nitrogen available for crop growth. On the other hand, raw biowaste consisting of very nutrient rich materials may result in leaching of nutrients into groundwater or surface water or the volatilization as ammonia.

Products and uses The main output of direct land application of waste is a soil amendment with high organic matter content. Organic matter plays a threefold role in soil by (1) biologically acting as nutrient and energy supply for microbes, (2) chemically buffering changes in soil pH capacity, and (3) physically influencing soil structure and associated properties. Direct land application of waste is, in a strict sense, not a treatment process and might negatively impact on plants and soil. As waste is likely to contain a certain level of pathogens or trace elements, these can bio-accumulate in plants and soil (Olowolafe 2008). This may result in health threats from food contamination or pollution of water courses from runoff (Smith et al. 2015). According to Dulac (2001), landspreading of raw organic matter is specifically beneficial for degraded soils in arid areas. But the same studies highlight the risk of lower availability of micro-nutrients necessary for plant growth when applying non-stable organic material (Dulac 2001). Landspreading of raw organic waste must therefore be subject to restrictions and control to avoid environmental and human health risks (EPA 2004; Dulac 2001). One control measure is to ensure sufficient time between application of waste and the subsequent crop planting and harvesting (Dulac 2001).

Critical review of challenges and trends in low-and middle-income settings Landspreading of raw organic waste is still a common practice in rural areas of low-and middle-income countries for improving soil nutrients content. The potential benefits and risks of this practice is closely linked to quality of the waste. Landspreading does not ensure pathogen removal. Thus, spreading of plant disease to plants and farming workforce related health is threatened. If the waste is contaminated with inorganic compounds (e.g. heavy metals), these may accumulate in soils or crops. Research on direct land application of biomass puts a focus on these risk aspects, evaluating the impact of specific organic residues on soil and/or crop characteristics in terms of fertility, structure and trace element content (Hegberg et al. 1990; Olowolafe 2008; Walsh and McDonnell 2012). Organic residue properties are highly variable as are soil and crop response. Therefore, it remains a challenge to assess the impact of landspreading on soil. Gendebien et al. (2001), in the European survey of wastes spread on land, highlighted the need of preventive measures such as chemical and physical analysis of waste and field trials prior to any direct application of raw waste. Alvarenga et al. (2007) claim that eco-toxicity tests combined with chemical analysis allow a good environmental risk assessment of direct land application for evaluating contaminant bioavailability, 
mobility and toxicity. The time period between landspreading and planting of crop should be sufficiently long to ensure minimal risk for soil and plants. In urban settings with intensive use of agricultural land, this recommendation may, however, be difficult to follow. Overall, to avoid negative side effects, it is recommended to avoid direct land application but rather include a treatment process (e.g. through composting) before spreading the waste onto the field. This ensures a hygienization phase and the conversion of nutrients into a more readily available form for the plants.

\subsubsection{Direct animal feed}

Introduction A simple way to recover value from biowaste is to feed it to animals. Humans have been feeding biowaste to animals since the beginning of animal domestication. In countries such as South Korea, Taiwan and Japan, 38.4, 22.1 and $11.5 \%$ of biowaste respectively, is processed into swine, poultry and fish feeds to partly substitute the conventional feed ingredients (Cheng and Lo 2016).

Input material Quality of the waste is again a key issue and source-separated biowaste from vegetable and fruit markets can be a suitable feed for animals. In general, animal feed should contain an adequate amount of carbohydrates, amino acids, minerals, vitamins, essential nutrients, fibers and fats (Lardinois and van De Klundert 1993) and minimize pollutants which endanger the animal or the meat quality. The largest risk lies in the substances contained in the waste. To mitigate the potential risks or to enhance its nutritive value, biowaste is often treated before being fed to animals. The benefit of waste as feed heavily depends on the animals' digestive systems. Ruminants with complex digestive systems can digest materials containing mainly cellulose (e.g. straw, grass), whereas the digestive system of pigs cannot digest straw or low-quality fodder. Completely rotten items should not be used for animal feed (Lardinois and van De Klundert 1993). When biowaste contains meat or has been in contact with meat, there may be risk of animal infection which then may transmit diseases to humans (e.g. salmonellosis), or to other animals (e.g. swine fever or bovine spongiform encephalopathy, BSE) (Lardinois and van De Klundert 1993). After first reports of BSE cases, very stringent legislation regarding the use of animal byproducts as animal feed (e.g. the feed ban) were implemented (EU 1994; Onodera and Kim 2006). Other compounds of concern are heavy metals (Cheng et al. 2016a, b), polycyclic aromatic hydrocarbons (PAH) (Cheng et al. 2015a) and organochlorine pesticides (Cheng et al. 2014), mainly studied in aquaculture.

Conversion process Direct animal feeding with waste can be applied on a decentralized-household level for self-production of animal protein. It can also be performed in a more centralized way, where the biowaste may undergo processing, such as grinding or drying, and can then be fed pure to animals or in a mixed form with other feedstuffs. Once consumed, the biowaste is metabolized by the animals contributing to their physiological needs, an increase in their body mass, and ultimately, into the targeted value products (e.g. meat, eggs, milk).

Products and uses Animal production yields high value products, such as meat, eggs, milk, leather, etc. The largest risk, as highlighted above, is to ensure good quality of waste used in direct animal feed. Although research has shown that the taste of meat and dairy products is not affected when animals are fed with biowaste (Kwak and Kang 2006; Lardinois and van De Klundert 1993), biowaste containing fish was reported to cause minor taste changes in pork meat (Márquez et al. 2011). In other studies improved meat qualities (Cheng et al. 2015b; Mo et al. 2014) and milk qualities (Angulo et al. 2012) were reported when using biowaste-based diets.

Critical review of challenges and trends in low-and middle-income settings The extent to which biowaste is fed to animals is currently largely unknown. Existing information is limited to Asian industrialized countries, such as Japan, Hong Kong, Taiwan and South Korea (Cheng and Lo 2016). Although not published, one can assume that in rural areas direct animal feeding with agricultural waste is with certainty widely practiced. In the urban context, biowaste from certain sources (e.g. restaurants, markets) are often observed to be collected and paid for by livestock holders.

Direct animal feeding diverts considerable amounts of biowaste from the main waste stream, thereby saving costs and infrastructure to waste managers. In 
Nouakchott, Mauritania, $40 \%$ (on wet weight basis) of household waste is used as animal feed. This results in an organic fraction of only $5 \%$ at the point of collection (Alouéimine et al. 2006). Research to quantify this practice in cities and countries would help to better understand how direct feeding impacts on the solid waste management system, and how such practices might be used elsewhere. As animal protein intake by humans is foreseen to increase especially in transition countries where meat consumption has been growing at 5-6\% per year and dairy products at $3.4-3.8 \%$ per year (FAO 2003), using waste for direct feed might be an interesting option. The same applies for fish consumption, where the expected expansion in production would be in aquaculture (FAO 2016). Nevertheless, the practice of direct animal feed with biowaste also poses risks as contaminants in waste (microbial pathogens, packaging hardware, mercury, polycyclic aromatic hydrocarbons, organochlorine pesticides) may not only endanger the health of the animals but also of humans by consumption of products derived from these animals (Cheng et al. 2014, 2015b, 2016b). Ensuring good quality waste feedstock is required if direct animal feeding is to be implemented in a centralized manner. Properly designed source separation strategies and supply chains can be a way to ensure such feedstock quality. Most of the literature published on this topic deals with animal health and nutrition issues, fish rearing being the most frequently studied case (Cheng et al. 2015a; Mo et al. 2014, 2015), followed by swine (Esteban et al. 2007; Kwak and Kang 2006), cattle (Angulo et al. 2012; Froetschel et al. 2014) and poultry husbandry (Rizal et al. 2015). Many of the publications conclude that food waste can be satisfactorily recycled by converting it into animal feed. In contrast, further research on indirect impact on human health as consumer is needed.

The so-called food waste hierarchy prioritizes efforts to feed food waste to animals over other technologies such as composting and anaerobic digestion (Papargyropoulou et al. 2014). This approach is of particular interest for low- and middle-income settings, where other biowaste treatment options have failed in the past or are still inexistent.

\subsubsection{Direct combustion}

Introduction Direct combustion, also known as open burning, refers to a wide range of uncontrolled waste combustion practices including burning of waste in backyards or dump sites. The associated benefits are a reduction of waste volume and the hygienization of the waste. On the downside, however, uncontrolled open burning without use of an adequate stack, duct or chimney may directly emit harmful combustion products into the local environment (Estrellan and Iino 2010). This waste management technique is unfortunately one of the primary practices applied in low- and middle-income settings worldwide as it requires very little technical knowledge and minimal costs, and is the easiest way to get rid of litter which was not collected (Smith et al. 2015; UNEP 2007). Open burning is practiced by municipal employees and landfill workers to diminish the waste volume at dump sites, by informal recycling sectors to recover valuable products (e.g. scrap metals), and by individuals who lack waste collection services and want to reduce their waste amounts or require a cheap heating and/or cooking fuel. Despite its extensive use worldwide, open burning is considered an illegal practice in most countries and has been declared an "environmentally unacceptable process" by the Stockholm Convention due to the generation of harmful pollutant products from incomplete combustion (UNEP 2007). For this reason, this review only describes this practice briefly and emphasized the challenges of open burning.

Critical review of challenges and trends in low-and middle-income settings Open burning is not considered an acceptable solid waste management although it is still widely practiced in urban low- and middleincome settings. It poses a substantial threat to human and environmental health from emissions of mixed waste burning and/or incomplete combustion. Open burning has the main objective of waste reduction and does not recover energy nor nutrients.

Analysis of the research conducted over the last 10 years on open burning reveals that the main focus has been on assessing the emissions and the related environmental and health impacts (Babel and Vilaysouk 2016; Nagpure et al. 2015; Prasad Raju and Partheeban 2014; Zhang et al. 2011). Although most of the research so far has focused on emission of nitrogen oxides and complex organic compounds, in the last decade there has been increased interest in the emission and impacts of short-lived climate pollutants (SLCPs). Black carbon receives considerable attention as a SLCP (Stohl et al. 2015) and it is reported that the 
impact of black carbon from burning waste is still not well documented Bond et al. (2013). The task of assessing the impacts on public health and the environment at local, regional and national scales is a challenging endeavor as open burning relates to a dispersed non-point emissions. Research on open burning impacts helps provide evidence to policymakers to enforce strict regulations and control mechanisms (Forbid et al. 2011; Park et al. 2013). Thus, there is a need for further research aiming at (1) improved quantifying the amplitude of this practice at a local, regional and national scale, and (2) for enhanced emission assessment and controlling and evaluating the impact of these emissions on health and climate change.

\subsection{Biological treatment}

Biological treatment processes are understood as the controlled conversion of waste by living organisms. Biotechnological and biochemical conversion processes also fall under this category. Biochemical processes are substantially slower than a thermochemical conversion but require significantly less external energy input (Basu 2013). As all living organisms require water for survival, biological treatment always takes place in a moist environment. Biochemical conversion processes are thus mainly applied to wastes with high moisture levels. The black soldier fly treatment method was selected as an example for waste conversion by insect larvae for protein production, since other insects (e.g. house flies, blow flies) are mainly applied for manure or slaughterhouse waste management.

\subsubsection{Composting}

Introduction Composting involves the controlled aerobic decomposition of organic matter that results in a relatively stable organic end product called humus. Composting is unquestionably an ancient practice, documented from Greeks, Romans and also early civilizations in South America, China, Japan or India (Hershey 1992). Early scientific publications about composting as a management option in agriculture date back to publications of Sir Howard around 1933. Based in India, Sir Howard was inspired by the use of composting in Chinese agriculture (Diaz and de Bertoldi 2007), so he developed and documented the principles of modern composting which he called the Indore Process (Howard 1935).

Input material Many different types of organic solid wastes are suitable for composting as long as key parameters are fulfilled (see Table 1 for process parameter requirements). Suitable substrates include yard waste (branches, leaves, grass), food waste, agricultural waste, manure, and even septage and human feces (Epstein 1997). Mixed municipal waste may also be composted, however, this is not recommended as the resulting compost quality will be poor (Haug 1993). Depending on the moisture content of the feedstock used in composting and the climate, the addition of water may be necessary at the beginning or during the process to ensure sufficient moisture for microbial activity (Cooperband 2002; Polprasert 2007).

Conversion process Composting of organic matter is driven by a diverse population of microorganisms and invertebrates, where population dynamics vary greatly both temporally and spatially (Insam and de Bertoldi 2007). Microorganisms break down organic matter and produce carbon dioxide, water and heat. Controlling the process implies that the predominant parameters such as organic material composition (carbonnitrogen ratio), particle size, free air space, aeration, temperature, moisture, or $\mathrm{pH}$ are managed, steered and adjusted to achieve fast degradation and good compost quality. When conditions are not optimal, the process may be slowed or may not happen at all. Under optimal composting conditions, the degradation by composting proceeds through three phases: (1) the mesophilic phase, which lasts for a couple of days; (2) the thermophilic, which can last from a few weeks to several months, and finally, (3) a cooling and maturation phase which can last several months (Epstein 1997). During the thermophilic phase the temperature can rise up to $55-70{ }^{\circ} \mathrm{C}$ due to the metabolism of the microorganisms, which contributes to hygienization of the material. The end of the composting process is reached when the inner temperature of the pile is similar to ambient temperature and the oxygen concentration in the air cavities within the pile remains $>10-15 \%$ for several days (Cooperband 2002).

Composting of organic solid waste can be conducted at different scales and with different use of technology and mechanization. Small-scale home 
Table 1 Differences between the composting and vermicomposting process (adapted from Ali et al. 2015; Lim et al. 2016)

\begin{tabular}{lll}
\hline Parameters & Composting & Vermicomposting \\
\hline Type of process & Three stages & One (mesophilic) stage $\left(10-35{ }^{\circ} \mathrm{C}\right)$ \\
& (1) Mesophilic stage & \\
& (2) Thermophilic phase (up to $\left.70^{\circ} \mathrm{C}\right)$ & \\
& (3) Cooling and maturation phase $\left(>15^{\circ} \mathrm{C}\right)$ & No hard, oily, salty, acidic and alkaline \\
Organic waste & Sorted organic waste, combination of waste with & compounds \\
characteristics & similar decomposition rate & Earthworms and microorganisms \\
Organisms involved in & Microorganisms and macroinvertebrates & \\
biodegradation & & $27-35$ worms $/ \mathrm{kg}$ feed \\
Stocking density & - & $1.25 \mathrm{~kg}$ feed $/ \mathrm{kg}$ worm and day \\
Feed rate & - & $25-30$ \\
Initial C/N ratio & $20-50$ & $5-8$ \\
pH & $5.5-7.5$ & $70-90 \%$ \\
Moisture content & Coarse organic waste: $70-75 \%$ & \\
Product characteristics & Fine organic waste: $55-65 \%$ & Texture is finer and heavy metals accumulate \\
& & in earthworm bodies
\end{tabular}

composting is most frequently conducted in bins or open heaps relying on a passive aeration process. Medium- and large-scale composting facilities more frequently rely on mechanization with regular turning or active aeration and the use of open windrows, bins or in-vessel composting reactors (Couth and Trois 2012).

Products and uses The main output product from composting is compost, a stable dark-brown, soil-like material with a crumbly texture, dark color and earthy smell. Besides compost, other output products emitted during the composting process are leachate, water vapor and carbon dioxide (Polprasert 2007).

Under ideal operating conditions compost can be produced within 3 months (Rothenberger et al. 2006). The quality of the input material and the key biological and physical operating parameters have a major influence on the quality of the final compost (Rothenberger et al. 2006). Impurities in the composted waste can be removed by sieving. Sieving can also serve to produce a range of products suitable to various end uses (soil conditioning, mulching). Compost contains important plant nutrients such as nitrogen, potassium, and phosphorus, though usually not as much as animal manure or chemical fertilizers (Polprasert 2007). It also contains a range of beneficial minerals and is rich in humus and micro-organisms beneficial to plant growth (Brinton and Evans 2001). Compost can be used to amend soils but research also reports the use for landfill cover, land remediation or land restoration schemes. For example, application of composts at acidic heavy metal contaminated sites has ameliorated soil pollution with minimal risk (Farrell and Jones 2009).

Critical review of challenges and trends in low-and middle-income settings In urban waste management, composting can be considered a well-established, mature and proven treatment technology. Composting is well known by waste managers in high- as well as middle- and low-income settings as a simple and robust technology. Nevertheless, urban waste composting is not so widespread as one would expect. If implemented in a municipal system, such initiatives seldom endure over time (Zurbrügg et al. 2004). Reasons may comprise a lack of segregated "pure" organic waste, in other words a low quality feedstock which then yields poor quality compost. Also inadequate attention to, or knowledge of, the biological process requirements may result in a nuisance potential, such as odors and vermin. This can lead to poor acceptance by the resident population or lack of acceptance by the potential compost users. Furthermore, poor supporting policies and governmental measures as well as limited marketing experiences often hinder the economics of composting (Zurbrügg et al. 2012). Without an obvious revenue stream and with the increased cost of operating and maintaining 
the facility there is little incentive, especially in financial resource scarce settings, to keep such a facility running. Given the simplicity and robustness to process a wide range of biowaste types, the global degradation of soils and the global trend towards nutrient recycling and ensuring food security, it seems imperative that composting be given more attention in waste management. Pure waste streams through segregated collection, a prerequisite for high quality compost, need higher priority by waste managers and marketing efforts need support by policies to favor and incentive the use of compost and strengthen its competitiveness with regard to other organic solid amendments and fertilizers.

When analyzing the research conducted on composting and compost over the past few years, one can distinguish three main directions of research. The first focus, mainly related to low- and middleincome settings, pertains to case study descriptions of specific locations implementing composting schemes as waste management strategies (Zurbrügg et al. 2012). This typically includes application of life cycle analysis methods as well as economic assessments (Karagiannidis et al. 2010; Lim et al. 2016; Pandyaswargo and Premakumara 2014; Sánchez et al. 2015) and the analysis of climate change mitigation measures (Dedinec et al. 2015). Besides the typical case study descriptions, such research is usually not only about composting, but rather tackles the comparison and selection of waste management options, of which composting is one (Van Fan et al. 2016). A second line of research is on the use and benefits of compost, be this in terms of compost quality related to the feedstock (Mahmud et al. 2015; Pérez et al. 2016) and the respective benefits and impact on agricultural crops (Santos et al. 2016; Scotti et al. 2016), or the function of compost as substance for the remediation of contaminated soils (Taiwo et al. 2016). A third line in composting research is the quite regular and frequent research on the complex microbial processes, bacterial and fungal communities and their dynamics during the composting process (Kinet et al. 2015; Xi et al. 2015). The application of such rather basic and labbased research for waste management could be seen in finding ways to reduce the duration of the composting process or improve compost quality. In waste management practice there is some debate on the value of adding a mixture of enhanced microorganisms to the composting processing to reduce odor emission, speed up the process and improve the output quality. This practice is promoted strongly by the vendors of these mixtures but their claims are not substantiated by independent research studies. Finally, in light of the recent trend towards energy generation from waste a novel line of research involves experiments with paddy plant microbial fuel cells in soil mixed with compost. Cells with compost showed higher values of voltage and power density with time indicating the influence of compost on bio-electricity generation (Moqsud et al. 2015).

\subsubsection{Vermicomposting}

Introduction Vermicomposting is defined as an aerobic process of organic waste degradation and stabilization by interaction of microorganisms and earthworms under controlled conditions. Microbial communities help degrade organic matter and a high density of earthworms then feed on the waste and generate earthworm castings, also called vermicompost. Such vermicompost has shown to have higher levels of nutrients than compost (Ndegwa et al. 2000). The role of the earthworm in degradation of organic matter in soil was already described by Darwin (Darwin 1881), but regular publication of research papers on the use of vermicomposting as a waste treatment options started only early 1980 (Aalok et al. 2008).

Input material Earthworms are able to process household waste, organic municipal waste, sewage sludge and organic waste residues from different (paper, wood and food) industries (Edwards 1998; Garg et al. 2006). There are some food wastes that earthworms do not tolerate such as dairy products, meat and fish waste, grease and oils, salty and vinegary foods. Smaller feedstock particles will increase surface area of the material and hence increase the speed of degradation and vermicomposting.

Conversion process Vermicomposting depends on the interaction between microorganisms and earthworms. Microorganisms in the waste prepare the waste for the earthworms through a first step of aerobic degradation, i.e. vermicomposting is thus preceded by a pre-composting phase. This facilitates the feeding of the worms on the substrate. Furthermore, microorganisms are also contained in the gut and intestine of 
the worms. Here they decompose the organic material into finer particles and also provide the earthworm with nourishment. The earthworms in turn feed on the waste and also promote microbial activity by producing microbial active fecal material that is beneficial for quicker organic waste degradation and improves the nutritional quality of the vermicompost product (Singh et al. 2011). Attention needs to be paid to provide the feed in shallow layers into bins or beds. The amounts should be based on the feeding rate of the worms. Otherwise, the microorganisms degrading the feed could increase the temperature in the waste layer or anaerobic conditions could occur; both situations are most unfavorable for the worms.

Appropriate earthworm species for vermicomposting are those that have high adaptability to different waste types and conditions, rapid feeding and digestion, and fast growth and reproductive rate. Epigeic earthworms live right underneath the soil surface (they avoid direct sunlight), are litter feeders and are most suited for vermicomposting operations. Among these, Eisenia fetida is the most frequently used species besides Lumbricus rubellus, Eisenia andrei, Perionyx excavatus and Eudrilus eugeniae which is popular in tropical and subtropical countries (Kumar 2005). According to Reinecke et al. (1992) the complete life cycle of E. fetida encompasses around 70 days. Maturation is attained after ca. 50 days, start of cocoon production after 55 days (i.e. 4-5 days after mating), and incubation period is about 23 days. In average, there are three hatchlings per cocoon. It is important to leave the cocoons in the waste material to ensure continuation of the life cycle. Table 1 shows the optimal ranges of parameters for best worm growth and reproduction, combined with the characteristics and requirements of conventional composting. In contrast to composting, vermicomposting is not an exothermic process, which means that it does not lead to a temperature rise in the vermicompost. Most earthworm species require moderate/mesophilic temperatures in the range of $10-35^{\circ} \mathrm{C}$ (Sim and Wu 2010). In this range the worms feel most comfortable and feed most rapidly. Important factors influencing the vermicomposting process are: stocking density, temperature, feeding rate, moisture, $\mathrm{C} / \mathrm{N}$ ratio and $\mathrm{pH}$.

For optimal engineered vermicomposting many different systems have been developed. They all have in common that waste is fed in shallow layers into bins or beds with a shaded environment (Board 2004).
Regarding stocking density, higher density slows the reproductive urge, as competition for food and space increases. A lower population density will enhance growth as enough food is available for each worm, however, it will delay reproduction as the worms do not find each other to reproduce. Moisture content in the waste bins of below $60 \%$ delay the sexual development, thus negatively influences the reproduction rate of the worms while high moisture content (above 90\%) will hinder breathing of the worms.

Products and uses As feed passes through the earthworm gut the waste material is mineralized and plant nutrients are made available. The grinding effect of the gut leads to the formation of a granules, a typical feature of vermicompost. Nitrogen content of vermicompost is typically $1-2 \%$ higher than that of compost and the nutrients are reported to be more easily available to the plants (Adhikary 2012). Furthermore, enzymes and microorganisms from the gut show very beneficial properties for soil and plants, also suppressing diseases. Leachate from the worm bins can also be used as a liquid fertilizer, which is typically used in small-scale systems. Another product from vermicomposting are the earthworms themselves which are rich in protein $(65 \%)$ with all essential amino acids and they can be used for animal feed (Lalander et al. 2015). They are considered a good pro-biotic feed or used as additives for fish or poultry feed (Adhikary 2012). Pulverized and ingested earthworms have also been studied with regard to their medicinal properties and were found to be effective in treating thrombotic diseases (Christy et al. 2015) and beneficial on the wound healing process (Goodarzi et al. 2016).

Critical review of challenges and trends in low-and middle-income settings Vermicomposting has gained strong interest since the early 1990s and has meanwhile established itself as a recognized organic waste treatment option especially for low- and middleincome settings (Gupta and Garg 2011; Singh et al. 2011). The growing interest derives from the potential of adding more value to waste then only compost. Vermicomposting systems are considered less energy consuming, more cost effective and economically feasible when compared to conventional treatment technologies. Nevertheless, vermicomposting is not a widespread approach used in urban waste management in low- and middle-income settings. Many of the implemented facilities report vermicomposting but 
when examined in more detail actually revert to the process of composting with worms present in the late maturation stage (which does not qualify as vermicomposting). One expected barrier to vermicomposting might be seen in the requirement of much space. However, this can be easily overcome by stacking the feeding boxes in a vertical axis. Another barrier is the required stage of pretreatment by composting before feeding to the worms. If a composting pile is already required, then often the second step of vermicomposting is considered more effort than benefit. This links again to the barriers already stated with composting: a lack of segregated "pure" organic waste, in other words a low quality feedstock, inadequate attention to, or knowledge of, the biological process requirements, poor supporting policies and governmental measures and finally limited marketing experiences. All this hinder the economic feasibility of vermicomposting. The revenue stream of vermicompost is not attractive enough to sustain operation. In those cases where the worms are marketed there is an increased chance of success. It is often more effective to feed the worms other feedstock than waste. Compared to composting, vermicomposting needs more skills and understanding of the worm lifecycle and the optimal processing conditions. Nevertheless, if a pure segregated biowaste stream can be ensured, the relative simplicity and the prospect of obtaining a nutrient product as well as a protein product should theoretically favor this technology when compared to composting. False expectations of waste managers regarding potential revenues and their limited marketing efforts hinder successful implementation of vermicomposting in urban waste management. Lack of favoring policies constitute additional barriers.

With regard to innovations required from science, a wide variety of research has been published on the factors influencing the vermicomposting rate, worm growth and reproduction rate (Reinecke and Viljoen 1990). Recent research has further studied the potential of using vermicomposting for different waste types, such as food industry waste (Garg et al. 2012), and also for treatment of industrial and polluted waste. Vermicomposting has shown to reduce toxic metal content and break down of chemicals to non-toxic forms (Jain et al. 2004). Used in sludge management, Shahmansouri et al. (2005) show that heavy metals in organic matter are taken up by the skin and intestine of earthworms during ingestion resulting in lower concentrations in the sludge. There is, however, very limited research on aspects of feasibility and sustainability of vermicomposting for urban waste management, especially highlighting possible measures to promote and foster this technology.

\subsubsection{Black soldier fly treatment}

Introduction Black soldier fly (BSF) treatment is an emerging technology in organic waste treatment. It involves the transformation of biowastes into insect protein and insect oil. Originally native to the Americas, transport of goods has contributed to a broad distribution of the black soldier fly, Hermetia illucens L. (Diptera: Stratiomyidae). Today, it can be found in the tropics and sub-tropics all over the world (Rozkosny 1982). Its appetite for decaying organic matter has been discovered already in the early twentieth century by Dunn (1916) who describes masses of BSF larvae found feeding on a dead body. Another publication documented BSF larvae breeding in outhouses in Louisiana (Bradley 1930). Around mid-twentieth century, Furman et al. (1959) scientifically tested if the presence of BSF larvae can suppress the breeding of the house fly, Musca domestica, in poultry farms. This statement could not only be confirmed but the authors also discovered a massive reduction of the manure where BSF larvae were present in large numbers. This seminal paper stands at the beginning of a line of scientific studies on the controlled rearing and feeding of BSF for waste treatment.

Input material Suitable waste sources for larvacomposting are manifold and there is no general rule for the suitability of a waste source for BSF treatment. For waste management BSF larvae can be fed with food and market waste (Diener et al. 2011; Leong et al. 2015; Nguyen et al. 2015; Parra Paz et al. 2015), animal manure (Li et al. 2011b; Myers et al. 2008; Sheppard et al. 1994; Yu et al. 2011), human excreta (Banks et al. 2014; Lalander et al. 2013) and fish waste (St-Hilaire et al. 2007). The importance of a certain moisture level in the feedstock was demonstrated by Furman et al. (1959) where moistening chicken manure resulted in significant higher waste reduction. Although BSF larvae can survive in liquid environments, large number of larvae seem to develop only 
under moist or semi-solid conditions (Newton et al. 1995). Highly cellulosic waste such as wood and dry leaves are not suitable for larva-composting and might at most be added as a structure forming agent. In an industrial BSF treatment facility, incoming waste has to be shredded to reduce particle size and the water content must have a value between 65 and $80 \%$. This requires either a dewatering of wet materials such as fruit/vegetable waste or faecal sludge, or adding water to dry waste sources such as chicken manure. Ideally, wet and dry materials are mixed and combined to generate a suitable larva feed.

Conversion process The growth rate of BSF larvae, and therefore also the waste reduction and bioconversion rate, depends on several factors such as temperature and moisture content of the feedstock. Temperatures between 25 and $32{ }^{\circ} \mathrm{C}$ are most suitable for all of the BSF live stages (Tomberlin et al. 2009; Tomberlin and Sheppard 2002). The BSF develops through 6 larval instars with the last larval stage $(15-20 \mathrm{~mm})$, the so-called pre-pupa, crawling out of the moist feed source in search for a dry pupation site. Under controlled conditions (Gainesville house fly diet, $28{ }^{\circ} \mathrm{C}, 75 \% \mathrm{RH}$ ) the total development from egg to adult lasts 20-35 days (Zhou et al. 2013). The larvae can reduce the feedstock weight by $50-80 \%$ and convert up to $20 \%$ (on a total solids basis) into larval biomass within $\sim 14$ days (Diener et al. 2011; Lalander et al. 2014; Zhou et al. 2013). Space requirement for BSF treatment depends on operational parameters such as larval density and feeding rate. Defining these parameters requires deciding on a trade-off between high waste reduction (high larvae density and low feeding rate) and high biomass production (low larvae density and high feeding rate) (Parra Paz et al. 2015). Reported feeding rates range from $1.9 \mathrm{~kg} / \mathrm{m}^{2}$ and day (Diener et al. 2009) to $9.8 \mathrm{~kg} / \mathrm{m}^{2}$ and day (Parra Paz et al. 2015).

Different treatment unit designs have been proposed (Diener et al. 2011; Newton et al. 2005). Larger treatment facilities with a waste managerial focus require a productive nursery which produces sufficient young larvae to stock the treatment units and a regular waste flow to achieve economic feasibility. As an emerging technology with high potential for economic success, designs and operating procedures of existing large treatment facilities, however, are not shared. On the other hand, small-scale backyard applications can be well designed systems, but they rely on colonization by the natural fly population (Čičková et al. 2015) and are thus not suitable for a controlled waste management operation.

Products and uses The main products resulting from the BSF technology are the larvae and the residue. Protein content and amino-acid profile of the defatted insect meal is similar to fishmeal and may thus replace fishmeal in animal feed. The grown larvae are suited as a (partial) replacement of fish meal in animal feed and experiments have shown good results when fed to fish, chicken or pigs (Makkar et al. 2014; Stamer 2015). Other possible products to be explored are the production of biodiesel from larvae or the use of the chitin and the oil (Li et al. 2011a). The residue, on the other hand, still contains valuable nutrients and might be used as a soil amendment. However, due to the short processing time, the residue needs to undergo a maturation phase in order to prevent oxygen depletion in the soil which inhibits seed germination or suppresses root and plant growth (Brinton and Evans 2001).

When waste-derived products are recycled into the food chain, identification and management of risks related to pathogens and toxic substances (e.g. heavy metals, pesticides or pharmaceuticals) are critical. Although BSF activity accelerates the reduction of Salmonella spp., further processing of both the residue and the larvae is required as other pathogens such as Enterococcus spp., bacteriophages and helminth eggs are not reduced (Lalander et al. 2013). Furthermore, heavy metals present in the feedstock may accumulate in larvae and prepupae requiring precautionary measures, ideally by avoiding the use of contaminated organic waste as feedstock (Diener et al. 2015). Interestingly, BSF treatment accelerates degradation of pharmaceuticals and pesticides. A study by Lalander et al. (2016) found a shorter half-life in the residue of all five substances investigated and could not detect any bioaccumulation in the larvae.

Critical review of challenges and trends in low-and middle-income settings The conversion of biowaste into insect protein is a proven process. Published research so far mostly focused on the biological mechanisms such as waste conversion ratio, mating behaviour or survival rates of different life stages, typically studied at lab- or bench-scale. However, the 
success of the BSF-treatment approach stands or falls with scaling to an industrial setting. Living animals behave differently when managed in big masses, and scaling-up also requires integration of other skills and disciplines, such as logistics of raw material and products, automation, climate control, product refining, hygiene control, market development or legal issues. As currently most $R \& D$ activities are private sector driven and take place behind closed doors, it is rather difficult to identify the current state-of-technology development.

Overall, a high potential is attributed to the BSF treatment technology for low- and middle-income settings. This is partly due to the climatic conditions in most of these regions which are suitable for application of the BSF-technology. Establishing a BSF colony in a rough-and-ready manner requires limited skills and efforts. Unfortunately, the importance of a controlled, efficient rearing regime to produce a defined number of young larvae is often underestimated. Yet the production of sufficient young larvae is considered key to the BSF-technology and needs to be synchronized with a reliable waste supply, both in quality and quantity. The emphasized focus on the fly colony rearing is particularly important when operating a waste management business. In comparison to ensuring a productive fly colony, the treatment step itself (i.e. larvae feed on organic waste for a defined amount of time and are then harvested) is rather simple. Therefore, a two-tier model that includes the segregation of these two steps seems promising and may facilitate the uptake of the BSF waste treatment technology. Such a model could consist of a centralized BSF facility, specialized in rearing stocking larvae and refining the harvested products. This facility serves several decentralized, robust biowaste treatment units. In other words, small entrepreneurs or waste generators obtain young larvae from a centralized BSF facility and convert their organic waste into insect protein. The fattened larvae are then either directly sold to chicken and fish farmers or vended back to the centralized BSF facility for post-processing. The separation and centralization of the most delicate and sophisticated task within the BSFconversion chain, the production of small larvae, can alleviate the growth of a loose network of organic waste processors applying the BSF technology, thus reducing transport costs and emissions of the waste treatment.
Current legal barriers hinder the development of BSF-technology for waste treatment in several countries. The EU regulatory framework has restrictions when it comes to (1) feeding waste to insects and (2) feeding insects to farmed animals. With respect to feeding waste to insects, Annex III of Regulation (EC) No 767/2009 prohibits the use of faeces and separated digestive tract content for insect production. Similarly, regulation (EC) No 1069/2009 considers insects as 'farmed animals' and thus does not allow manure, catering waste or former foodstuff that may contain meat and fish as feed. With regard to feeding insects to farmed animals, the so-called processed animal protein (PAP) is allowed for feeding aquaculture species but not in pig and poultry farming. The European Commission is aware of the need for action and changes are on the way. Before taking decision, however, regulatory bodies ask for data on topics such as biosafety, the fate of hazardous contaminants (e.g. heavy metals, hormones, micro-pollutants) or allergens (EFSA Scientific Committee 2015). Universities and research programs are about to fill the knowledge gap to help accelerate the modification of the regulatory framework. Certain research groups are close to disclosing results on the interactions of larvae with bacterial symbionts and its effect on life history traits, bioconversion ratio and waste reduction (e.g. Lee et al. 2014; Zheng et al. 2013). Besides the classic research questions on the fly's biology and the use of the larvae as animal feed (e.g. Diener et al. 2015; Lalander et al. 2013, 2014, 2016), a closer collaboration between private companies and academia should be pursued as this is considered beneficial for a breakthrough of the BSF treatment technology.

\subsubsection{Anaerobic digestion}

Introduction Anaerobic digestion (AD), also referred to as biomethanization or biomethanation, is a robust, well-established engineered process to biochemically decompose both liquid and solid organic matter by various bacterial activities in an oxygen-free environment. The AD process occurs naturally in many anoxic environments, such as watercourses, soils, animal intestines, and landfills (Vögeli et al. 2014). The utilization of AD of biowaste originates thousands of years back when biogas was used in Assyrian bath houses for heating water (Suryawanshi et al. 2010). Historically, AD has mainly been 
associated with the treatment of sewage sludge from aerobic wastewater treatment and animal manure (Esposito et al. 2012). Over the years, the main fields of $\mathrm{AD}$ application shifted from municipal sewage sludge to liquid (mainly industrial) wastewater, then to the municipal organic fraction of solid waste and agricultural residues (Jimenez et al. 2015). While the first industrial scale digesters date back to the first half of the twentieth century, interest in $\mathrm{AD}$ of solid biowaste has rapidly increased since the energy crises of the 1970s (Cecchi and Cavinato 2015).

Input material A wide range of different biomasses can be used as substrates for biogas production. AD feedstock includes sewage sludge, animal manure, food industry waste (incl. slaughterhouse waste), energy crops and harvesting residues (incl. algae), and the organic fraction of municipal solid waste (Romero-Güiza et al. 2016). As AD typically occurs in an aqueous environment, feedstock with high moisture contents (even containing more than $60 \%$ water) can be processed without pre-treatment (Appels et al. 2011). Generally, strong lignified organic substances (e.g. wood) are not suitable for $\mathrm{AD}$ as such substances cannot be degraded by anaerobic microorganisms (Mata-Alvarez 2003). However, research on pretreatment of lignocellulosic waste before $\mathrm{AD}$ is ongoing (Sawatdeenarunat et al. 2015). Extensive studies on AD feedstock include the use of food waste (Zhang et al. 2014), and fruit and vegetable waste (Bouallagui et al. 2005; Gunaseelan 2004). Co-digestion is increasingly being applied for simultaneous treatment of several solid and liquid organic wastes as a homogeneous mixture results in increasing process stability and performance (Esposito et al. 2012).

Conversion process The anaerobic biodegradation of complex organic matter to $\mathrm{CH}_{4}$ and $\mathrm{CO}_{2}$ consists of a series of microbial processes: hydrolysis, acidogenesis, acetogenesis, and methanogenesis. Fundamentals and kinetics of the AD process can be found in Mata-Alvarez (2003). Much is known about the basic metabolism in different types of AD processes, but knowledge on the microbes responsible for these processes is yet limited. A few percent of bacteria and archaea involved in AD have so far been isolated, but little is still known about the dynamics and interactions between these microorganisms (Weiland 2010). The key operational parameters of $\mathrm{AD}$ (e.g. temperature, $\mathrm{pH}$, moisture, substrate, $\mathrm{C} / \mathrm{N}$ ratio, loading rate, retention time, inoculation, stirring) and their influence on process stability and biogas yield and quality are described in Khalid et al. (2011) and Jain et al. (2015). One challenge in the conversion process of AD is to avoid acidification and inhibition of the methanogenic bacteria. Large amounts and high fraction of easy biodegradable organic matter in the feedstock for instance can result in a decreasing $\mathrm{pH}$ in the reactor and a larger production of volatile fatty acids, which stresses and inhibits the activity of methanogenic bacteria (Bouallagui et al. 2009). Typically this effect can be avoided by anaerobic co-digestion, which implies the addition of a buffering co-substrate (Mata-Alvarez et al. 2014). More on AD process inhibition due to ammonia, sulfide, light metal ions, heavy metals and other compounds is discussed in Chen et al. (2008), Zhao et al. (2010) and Yenigün and Demirel (2013). A review on the issue of instrumentation and process control can be found in Jimenez et al. (2015), on mathematical models for both simulation and control purposes in Lauwers et al. (2013), and on recent advances in the utilization of inorganic and biological additives to improve digester performance in Romero-Güiza et al. (2016).

The AD processes can be classified according to the reactor temperature (mesophilic, thermophilic), solids content (low- and high-solids concentration), feeding mode (batch, continuous fed), or the number of process steps (single- and multi-stage) (Hartmann and Ahring 2006; Kothari et al. 2014; Mao et al. 2015; Vögeli et al. 2014). Solid-state AD, or dry digestion [TS $>15 \%$ (Ge et al. 2014)], has lately been in the center of research focus. The benefits of dry over wet $\mathrm{AD}$ include smaller reactor capacity requirements, lower energy inputs needed for heating and stirring, more effective performance at higher organic loading rates and higher volumetric biogas productivity, greater tolerance of feedstock impurities such as glass, plastics and grit and producing a compost-like digestate that is easier to handle than the effluent of wet AD (Brown and Li 2013; Brown et al. 2012; Kothari et al. 2014; Li et al. 2011c; Yang et al. 2015a). An overview of the different digester types is presented in Vandevivere et al. (2003) and Rajendran et al. (2012). The main types of AD systems in lowand middle-income settings are fixed-dome digester, floating-dome digester and tubular digester (Vögeli et al. 2014). 
Products and uses The main products of $\mathrm{AD}$ are biogas and digestate. The biogas is formed through the conversion of the organic carbon of the feedstock into its most reduced form (methane, $\mathrm{CH}_{4}$ ) and its most oxidized state (carbon dioxide, $\mathrm{CO}_{2}$ ). Apart from $\mathrm{CH}_{4}$ (55-60\%) and $\mathrm{CO}_{2}(35-40 \%)$, biogas also contains several other gaseous "impurities" such as hydrogen sulphide, nitrogen, oxygen and hydrogen (Cecchi et al. 2003). Methane is the biogas component mainly responsible for its typical lower heating value (LHV) of $21-24 \mathrm{MJ} / \mathrm{m}^{3}$ or around $6 \mathrm{kWh} / \mathrm{m}^{3}$ biogas (Bond and Templeton 2011). Biogas with a $\mathrm{CH}_{4}$ content higher than $45 \%$ is flammable (Deublein and Steinhasuer 2009). Biogas yield of the individual substrates varies considerably, dependent on the feedstock origin, organic matter content and substrate composition. Fats provide the highest biogas yield, but require a long retention time due to their poor availability for the microorganisms. Carbohydrates and proteins show much faster conversion rates but lower gas yields (Weiland 2010). The average methane yield of solid organic waste is between 0.36 and $0.53 \mathrm{~m}^{3} / \mathrm{kg} \mathrm{VS}$ (Bouallagui et al. 2005; Khalid et al. 2011). The biochemical methane potential (BMP) of 54 fruits and vegetable wastes samples was determined by Gunaseelan (2004) and range from 0.18 to $0.732 \mathrm{~L} / \mathrm{g}$ VS for fruit waste, and $0.19-0.4 \mathrm{~L} / \mathrm{g}$ VS for vegetable waste.

Direct burning of biogas in stoves is the easiest way of taking advantage of biogas energy. Alternatively, biogas can be used in lamps or converted to electricity in gas generators. If biogas is valorized energetically in a combined heat and power installation for the simultaneous generation of heat and electricity, an electrical efficiency of $33 \%$ and a thermal efficiency of 45\% can be achieved (Appels et al. 2011). Refining the biogas from an $\mathrm{AD}$ system is recommended when used in a gas-driven engine to produce electricity, and it is absolutely necessary for more novel applications like vehicle fuel and fuel cells. If properly upgraded, which includes dewatering, desulphurization, and removal of $\mathrm{CO}_{2}$, the biogas can also be introduced in the natural gas grid (Appels et al. 2011). The main bottleneck of biogas utilization is that it cannot be stored over long periods at reasonable costs (Mata-Alvarez 2003). The critical temperature of $\mathrm{CH}_{4}$ is around $-82.5{ }^{\circ} \mathrm{C}$, i.e. even with a very high pressure it is not possible to liquefy methane at higher temperature. If the final methanogenic steps of the $\mathrm{AD}$ process are fully inhibited, the resulting products of the process are volatile fatty acids (and carbon dioxide and hydrogen). As the organic acid stream can be concentrated or (bio-) converted to high-value end products, this research has lately received significant attention (Kleerebezem et al. 2015).

The produced slurry (digestate) is rich in nitrogen and, depending on the nature of the feedstock, and adequate crop-specific dilution, can be utilized in agriculture as a nutrient fertilizer and/or organic amendment (Groot and Bogdanski 2013; Möller and Müller 2012). The AD process is only partly able to inactivate weed seeds, bacteria (e.g. Salmonella, Escherichia coli, Listeria), viruses, fungi, and parasites, which is of great importance if the digestate is to be used as fertilizer. The decay rate of pathogens is dependent on temperature, treatment time, $\mathrm{pH}$, and volatile fatty acids concentration, with temperature being the most important factor concerning pathogens reduction during AD. The best hygienization effect is obtained at thermophilic temperatures above $50{ }^{\circ} \mathrm{C}$ and long retention times, or with post-treatment of digestate, e.g. aerobic composting (Weiland 2010).

Critical review of challenges and trends in low-and middle-income settings The AD theory and technology is considered mature and well developed (Mao et al. 2015). Current global AD research comprises the identification of microbial community dynamics, extension of existing $\mathrm{AD}$ models by inclusion of microbial community data, further development and optimization of pre-treatment methods to enhance the anaerobic degradability, and upgrading and purification of the obtained biogas incl. its transformation into more value-added components (Appels et al. 2011; Krishania et al. 2013). The overall benefits of anaerobic digestion are manifold and fit well into the broader sustainability debate as it transforms waste into a renewable energy carrier, while at the same time also conserving plant nutrients. To unlock the full potential of AD products and by-products, the scientific, regulatory and socioeconomic barriers need to be tackled, which requires good interactions between scientists, regulators and end users (Riding et al. 2015).

In low- and middle-income settings, specifically with tropical climates, mesophilic anaerobic digestion has a high potential for biowaste treatment (Suryawanshi et al. 2010). While agricultural AD systems using manure as feedstock are widely implemented, urban 
AD systems with biowaste as feedstock still exist only in limited numbers (Vögeli et al. 2014). It is well acknowledged that many $\mathrm{AD}$ projects in low- and middle-income settings face severe operational problems or have failed (Bond and Templeton 2011). Inappropriate technology selection, poor design and construction of digesters, inadequate operation, lack of ownership, responsibility and maintenance by operators, lack of project monitoring and follow-up by the promoters, lack of markets for biogas and digestate, and weak business models are some of the failure reasons (Bond and Templeton 2011; Parawira 2009). Thus prior to construction proper feasibility assessments are needed including the selection of $\mathrm{AD}$ systems that are technically, financially and environmentally appropriate for the local context (Lohri et al. 2013; Nzila et al. 2012). Once operation has started, special emphasis should be placed on operational support networks to ensure maintenance and repair of existing facilities (Bond and Templeton 2011). Promising research efforts have also gone into the development of an medium-size plug-flow digester appropriate for low- and middle income countries (Edelmann and Engeli 2015).

One of the bottlenecks of $\mathrm{AD}$ and respective gas use is the low energy density of biogas. This requires either continuous gas use at the site of production or transformation into a more easily transportable fuel. A line of research tackles the issues of upgrading, compression and bottling of biogas. The Indian Institute of Technology has successfully developed an automated biogas upgrading and bottling system to obtain biomethane of high purity $\left(90-92 \% \mathrm{CH}_{4}\right)$ with minimal gas losses. While the biogas purification is achieved by water scrubbing at ambient temperature $\left(25^{\circ} \mathrm{C}\right)$ using automated controls, the purified biogas is bottled by means of a high pressure compressor at 200 bar and filled in biogas operated car and threewheeler using CNG (compressed natural gas) dispensing systems (Vijay et al. 2015). A different concept involves the autogenerative high pressure digestion (AHPD), where methanogenic biomass builds up pressure inside the reactor. Since $\mathrm{CO}_{2}$ has a higher solubility than $\mathrm{CH}_{4}$, it will at higher pressures proportionally more be dissolved in the liquid phase. AHPD biogas is thus characterized by a high $\mathrm{CH}_{4}$ content, reaching equilibrium values between 90 and 95\% at a pressure of 3-90 bar (Lindeboom et al. 2012).

\subsubsection{Fermentation}

Introduction Fermentation is the key process step in the production of bio-ethanol (ethyl alcohol, $\mathrm{CH}_{3}$ $\mathrm{CH}_{2} \mathrm{OH}$ or EtOH), the leading biofuel on the global market (Mussatto et al. 2010). Bio-ethanol/gasoline blends are promoted as an environmental-friendly, clean-burning fuel that reduces vehicle exhaust emissions (Balat and Balat 2009). Currently, about 820 million cars and light trucks are running with bioethanol (Sarris and Papanikolaou 2016). Bio-ethanol can be produced from several sugar-, starch-, and lignocellulose-based biomass sources by means of different conversion technologies. Currently, it is predominately produced from corn-derived (starchbased) feedstocks and from sugarcane-derived (saccharose-based) feedstocks. The USA (corn) and Brazil (sugarcane) are the two major ethanol producing countries, contributing 56.7 and $26.7 \%$ of the world production (Gupta and Verma 2015). However, bioethanol production from such edible (1st generation) feedstock has raised substantial concerns in regard to competition to food and feed. Non-edible lignocellulosic (2nd generation) feedstock derived from several waste streams is suggested as a sustainable alternative substrate (Vohra et al. 2014).

The first prototypes of internal combustion engines built in the nineteenth century were able to use ethanol as fuel (Mussatto et al. 2010). Henry Ford, whose first cars were capable of running exclusively on ethanol, even termed ethanol the "fuel of the future" (Vohra et al. 2014). As the production of ethanol became more expensive than petroleum-based fuel, its potential was largely ignored until the oil crisis of the 1970s (Balat and Balat 2009). Extensive research and novel commercial approaches for bio-ethanol production from low-grade lignocellulosic biomass have started only a few decades ago (Hahn-Hägerdal et al. 2006). Major attention is currently given to the development of efficient processes to use agricultural crop residues, hardwood, softwood, cellulose wastes, herbaceous biomass, and municipal solid waste (Zinoviev et al. 2010).

Input material Carbohydrate sources for bio-ethanol production can be divided into three major groups: (1) simple sugars (sucrose-containing) feedstocks: e.g. sugarcane, sugar beet, sweet sorghum, molasses and fruits, (2) starchy materials: grains, e.g. corn, wheat, 
barley, rice; root crops, e.g. potato, cassava, and (3) lignocellulosic biomass: e.g. woody materials, straw, agricultural waste and crop residues (Balat and Balat 2009; Mussatto et al. 2010). The first two groups are classified as 1st generation, edible feedstock, whereas the third group (lignocellulose) is described as 2nd generation, non-edible feedstock. Currently, about $40 \%$ of the global bio-ethanol production derive from sugar crops and nearly $60 \%$ for starch crops (Vohra et al. 2014). For lignocellulosic feedstock, the involved technologies are more complex and the costs of bio-ethanol production higher compared to sugarcane, beet or corn feedstock. However, most lignocellulosic materials are by-products of agricultural activities and industrial residues, thus they are seen as main feedstock for ethanol production in the near future (Mussatto et al. 2010). Due to the complex nature of the lignocellulosic feedstock, numerous pretreatment strategies have been developed to increase cellulose digestibility, such as physical treatment, chemical treatment (alkaline or acid), biological treatment, physicochemical treatment and thermochemical treatment (Alvira et al. 2010). Enzymatic hydrolysis is the most common pre-treatment method in ethanol production from food waste (Pham et al. 2015). Recently, even source-separated urban solid biowaste including kitchen waste, food waste, garden waste and fruit waste are being considered as suitable substrates for ethanol production (Gupta and Verma 2015; Liguori et al. 2013).

Conversion process Bio-ethanol production is usually performed in three steps, with an additional pretreatment step if lignocellulosic feedstock is used: (o) pre-treatment (delignification) to render cellulose and hemicellulose more accessible to the subsequent steps, (1) acid or enzymatic hydrolysis (saccharification) to break down polysaccharides to simple sugars, (2) fermentation of the sugars (hexoses and pentoses) to ethanol using microorganisms, mainly yeast, (3) separation and concentration of ethanol produced by distillation-rectification-dehydration (Vohra et al. 2014). The conversion can be performed as a batch process, fed-batch or continuous process, however, the fed-batch process is most widely used (Fodor and Klemeš 2012). The anaerobic fermentation reaction occurs at temperatures of $25-30{ }^{\circ} \mathrm{C}$ and lasts between 6 and $72 \mathrm{~h}$ depending on the composition of the hydrolysate, cell density, physiological activity and yeast species. The broth typically contains $8-14 \%$ ethanol on a volume basis. Above this concentration, inhibition of yeast activity may occur. The distillation step yields an azeotrope made up of $95.5 \%$ alcohol and $4.5 \%$ water, which is then dehydrated to obtain an 'anhydrous' ethanol containing up to $99.6 \%$ alcohol and $0.4 \%$ water (Vohra et al. 2014). The thermochemical/gasification and fermentation process is another relatively new technological conversion route (Balat and Balat 2009).

Products and uses The hypothetical ethanol yields from sugar and starch are superior compared to the yield from lignocelluloses agro-residues (Gupta and Verma 2015). An average energy content of $8.3-11.6 \mathrm{MJ} / \mathrm{kg}$ TS is estimated for ethanol produced from food waste based on 26.9 MJ/kg energy content of ethanol (Pham et al. 2015). In average one liter of ethanol contains $66 \%$ of the energy provided by one liter of petrol (Nigam and Singh 2011). Bio-ethanol can be used in blends from 5\% (E5) to $100 \%$ (E100) with gasoline. The most popular blends are E85 (85\% bioethanol, $15 \%$ gasoline), E20 (20\% bioethanol, $80 \%$ gasoline) and E10 (10\% bioethanol, 90\% gasoline; also called gasohol in the US). The fuel mixtures up to E10 can be used in the internal combustion engines of modern automobiles and light-duty vehicles without modifications on the engine or fuel system. As the ethanol percentage in the blend increases some modifications are necessary, e.g. in the fuel injection system and in the evaporation system (Sarris and Papanikolaou 2016). Ethanol, which has a higher octane level and lower sulphur content compared to gasoline, improves the fuel combustion and thus the vehicle's performance, and shows reduced emissions of carbon monoxide, unburned hydrocarbons and sulphur oxide, a carcinogen and major component of acid rain (Nigam and Singh 2011). Ethanol can also be used in the transesterification process of vegetable oils for biodiesel production (Sarris and Papanikolaou 2016). By-products of the bioethanol production are thin stillage (the centrifuged, liquid, non-volatile components of the fermentation slurry) and condensed distillers solubles (thin stillage after evaporation). The latter can be dried to produce dried distillers grains with solubles, which can either be sold as animal feed or used for the production of lactic acid (Moon et al. 2014).

Critical review of challenges and trends in low-and middle-income settings While technologies to produce ethanol from sugar or starch are well established, 
technologies using 2nd generation biowastes are still under development all over the world (Mussatto et al. 2010). In India, for instance, many research groups have set up pilot plants to study the production of ethanol, but mature technologies for lignocellulosic bioethanol production are still lacking and processing costs are high (Sukumaran et al. 2010). Cost minimization of ethanol production is the prime objective of most research programs in general (Kumar et al. 2009 b). Yet reaching financial feasibility with the current political and institutional set-up is particularly difficult in low- and middle-income countries. Supportive policy measures could help to enhance the competitiveness of bioethanol production.

Current biowaste fermentation research with regard to low- and middle-income settings primarily centers around assessment studies on the suitability of various waste types and bio-ethanol potentials of different countries, e.g. Pakistan: (Bhutto et al. 2015), Colombia: (Quintero et al. 2013), India: (Sukumaran et al. 2010), China: (Fang et al. 2010). In the African context, existing bioethanol plants are mostly concentrated in the Southern tip of the continent such as South Africa, Malawi, Swaziland, Mauritius, and Zimbabwe. Other commercial ethanol producing countries are Ethiopia and Kenya (Amigun et al. 2008). According to Sukumaran et al. (2010) one of the major difficulties faced by bio-ethanol technology developers as well as future entrepreneurs is the choice of feedstock. India, for instance, generates a huge amount of diverse agroand forest wastes, but due to problems in collection and logistics only crop residues are considered a feasible feedstock. Yet also the availability of these crop residues is limited for bioethanol production as a major fraction is needed as feed and fuel in rural areas (Sukumaran et al. 2010).

On the way to cost-effective and competitive bioethanol production from lignocellulosic feedstock several challenges remain, such as developing more efficient pre-treatment technologies and integrating the optimal components into ethanol production systems (Chen and Fu 2016; Liguori et al. 2013). These challenges can be attributed to four aspects, which are (1) feedstock: obstacles are cost, supply and handling, (2) conversion technology: hindrances are biomass processing, proper and cost effective pretreatment technology, (3) hydrolysis process: challenge is to achieve an efficient process for depolymerization of cellulose and hemicellulose to produce fermentable monomers with high concentration, and (4) fermentation configuration: challenges involved are xylose and glucose co-fermentation, and the use of recombinant microbial strains (Mussatto et al. 2010; Sarkar et al. 2012). Analyzed from an African perspective, Bensah et al. (2015) suggest that for commercial production of cellulosic ethanol research and development should highlight favorable pre-treatment methods such as extrusion, steaming/ boiling, and chemical methods employing lime, $\mathrm{KOH}$ and crude glycerol (from biodiesel production), as well as the development of crude enzyme complexes from local materials. With the rationale of achieving significant reduction of the operating process costs an important innovation recently developed in biotechnological processes refers to the accomplishment of the bioprocess under completely non-aseptic conditions (Sarris and Papanikolaou 2016).

\subsection{Physico-chemical treatment}

Physico-chemical treatment summarizes conversion processes that are induced by chemical reactions or apply physical, mechanical force. The chemical process of transesterification for biodiesel production, and the physical densification process for the production of pellets and briquettes are included here. Transesterification for biodiesel production is only covered briefly in this review, given the liquid nature of the feedstock and thus limited applicability for urban solid wastes. Densification is applied to raw biowaste, as pre-treatment step for biomass pellet/ briquette use in pyrolysis, gasification and combustion systems, and also in the post-processing step for char, the product of slow pyrolysis. The resulting charbriquettes are suitable for use as cooking fuel (Kaliyan and Morey 2010).

\subsubsection{Transesterification}

Introduction To obtain biodiesel, vegetable oils or animal fats are subjected to a chemical reaction termed transesterification, also called alcoholysis (Knothe et al. 2010). It entails a catalyzed reaction of oil or fat in the presence of alcohol to form fatty acid methyl esters (biodiesel) and glycerol (Bhuiya et al. 2016a, b). 
The purpose of the transesterification process is to lower the viscosity of the oil or fat to enhance its suitability for diesel engines.

Input material In terms of urban biowaste, waste cooking oil, animal fats from slaughter houses, and grease from grease traps, typically collected in the septic tanks of restaurants, are potential feedstocks for biodiesel production (Canakci 2007; Park et al. 2010; Wang et al. 2008).

Conversion process To produce biodiesel, moisturefree vegetable oil is first pre-heated, then mixed with alcohol and a catalyst in a closed reactor to start transesterification. After a few hours under mechanical stirring, the mixture is allowed to settle at room temperature. The settled glycerol is then separated from the top crude biodiesel layer. Discussion on the variables affecting the transesterification, reaction kinetics and mechanisms and issues on analytical monitoring of the reaction can be found in Meher et al. (2006) and Verma and Sharma (2016). While smaller biodiesel production plants often use batch reactors, most larger plants ( $>4$ million liters/year) use continuous flow processes involving continuous stirred-tank reactors or plug flow reactors (Gerpen 2005).

Products and uses Biodiesel is a yellowish liquid with an energy density of 38-45 MJ/kg (HHV), which is approximately $90 \%$ of that of petroleum-based diesel (Guo et al. 2015). It can be used in neat form or mixed with petroleum-based diesel. Glycerol, the byproduct of transesterification has become an issue for biodiesel plants (Almeida et al. 2012; Leoneti et al. 2012). Several methods for valorizing glycerol have been studied, e.g. using it as feed ingredient for animal (Yang et al. 2012), converting it microbially to valuable chemicals using various bacteria, yeast, fungi, and microalgae ( $\mathrm{Li}$ et al. 2013), using it as substrate or co-substrate in anaerobic digestion (Hutňan et al. 2013; Larsen et al. 2013), for ethanol production (Liu et al. 2012), or microbial fuel cells to generate electricity (Reiche and Kirkwood 2012).

Critical review of challenges and trends in low-and middle-income settings The scaling-up of biodiesel production from lab to industrial level remains difficult, mainly due to heat and mass transfer inefficiencies with current catalysts and operational set-ups (Baskar and Aiswarya 2016). Up-scaling also includes a shift from batch operations to continuous operated systems, entailing the major obstacle of requiring higher initial investment (Amigun et al. 2008). Biodiesel is currently more expensive to produce than petroleum-based diesel, which is one of the primary reasons preventing its more widespread use (Yaakob et al. 2013). Available literature shows that the costs of vegetable oils as feedstock of biodiesel represents 70-95\% of the total production cost (Bhuiya et al. 2016a). Waste cooking oil is considered a more promising feedstock as it is $2-3$ times cheaper than virgin vegetable oils in most countries (Bhuiya et al. 2016a). However, waste cooking oil also has some drawbacks, such as the high free fatty acid and high water content. To remove these impurities, drying and chemical pre-treatment is required, which considerably increases the biodiesel production cost (Yaakob et al. 2013).

In the low- and middle-income context, a major impediment to large-scale biodiesel production is feedstock availability. In Bali, for instance, a climate change mitigation project has been implemented which involves the conversion of used cooking oil into biodiesel to substitute fossil fuels. The main challenge was to obtain the amount of oil required to operate the transesterification process on a cost effective basis (Reckerzügl 2013). Recycled oil is the feedstock used for most biodiesel plants operating in Southern Africa, however, the existing market for waste oil and grease for use in soap and lubricant manufacturing makes the inconsistent cost and availability of this feedstock untenable for large-scale biodiesel production (Babajide et al. 2015). Due to this, most research on biodiesel implementation in low- and middle-income regions has focused primarily on the cultivation of feedstock oil crops. However, this stands in competition with land use for food crops cultivation and is therefore a questionable approach.

\subsubsection{Densification}

Introduction Densification involves the compaction of biomass by applying mechanical force or sometimes binding agents to create inter-particle cohesion, resulting in homogenous briquettes or pellets with consistent shapes and sizes, and bulk densities ranging from 450 to $700 \mathrm{~kg} / \mathrm{m}^{3}$ (Kaliyan and Morey 2010; Karkania et al. 2012). Densification helps overcome the challenges of dealing with lignocellulosic biomass residues, which are characterized by low bulk density, low heating value per unit volume, high dust level, and 
a wide range of physical shapes. Increasing bulk density facilitates easier handling, reduces storage and transportation costs, and the improved consistent physical properties improve fuel quality and make the densified biomass suitable for many residential and industrial applications (Tumuluru et al. 2011).

Densification typically follows the century-old mature technology of coal briquetting (Demirbas and Sahin-Demirbas 2004). In India, the briquetting industry started in the early 1980s with the introduction of low density and high density technologies. While the former technology requires pyrolysis of the biomass followed by briquetting using a binder, high density briquetting technology compacts the biomass and holds the structure together without a binder. Europe and the US have pursued and perfected the reciprocating ram and piston press to achieve this, while Japan has independently invented and developed the screw press technology in 1945 (Grover and Mishra 1996).

Input material Biowaste used for densification can be divided in two types of lignocellulosic residues: crop wastes and agro-industrial residues. Crop wastes include the residues which remain in the field after harvesting, for instance, paddy straw, bean straw, soya straw, maize straw and wheat straw. Agro-industrial residues on the other hand are generated during the processing of crops or logwood, and include rice husk, coffee husk and soybean husk, bagasse, sawdust and other wood processing products (Felfli et al. 2011). Other lignocellulosic wastes (e.g. groundnut shells, mustard stalks, cotton stalks, coconut fibers, palm fruit fibers) have also been researched as suitable feedstocks, as well as urban solid biowastes such as leaves, grass, tree trimmings and waste paper (Carone et al. 2011; Demirbas and Sahin-Demirbas 2004; Manickam et al. 2006; Yank et al. 2016). For waste to be densified, moisture content should be as low as possible, generally in the range of $10-15 \%$ (Chen et al. 2009; Felfli et al. 2011). Pre-treatment steps can include grinding, drying/pre-heating, torrefaction, and slow or wet pyrolysis (Liu et al. 2014; Tumuluru et al. 2011).

Conversion process A typical biomass densification process comprises drying, grinding, pelletizing or briquetting, cooling, screening, bagging, storage and delivery (Karkania et al. 2012). Common biomass densification systems have been adapted from other processing industries like feed, food, and pharmaceuticals (Tumuluru et al. 2011). Conventional processes for biomass densification can be classified into three types according to their working principle: extrusion, pelletizing, and roll briquetting. In an extruder, the raw material is conveyed and compressed by a screw or a piston through a die to form small cylindrical shapes (Li and Liu 2000). A pelletizer (or pellet mill) consists of a perforated hard steel die with one or two rollers with cylindrical shaped press channels. By rotating the die and/or rollers, the feedstock is forced through the channels to form densified pellets. Heat is generated from the high friction between the biomass and the press channel walls (Stelte et al. 2011b). In a briquetting roller press, the feedstock falls in between two rollers rotating in opposite direction and is compacted into pillow-shaped briquettes ( $\mathrm{Li}$ and Liu 2000). Briquetting machines can handle larger-sized particles and higher moisture contents without the addition of binders compared to pelletizers (Tumuluru et al. 2011). Most producers preheat the biomass to form stable and dense pellets or briquettes. This also significantly increases the throughput of the pelletizing machine and reduces the energy requirement per $\mathrm{kg}$ of the biomass pellets formed (Li and Liu 2000). The density and mechanical strength of the resulting biomass is affected by many factors including the type of densification equipment, the applied compression force and temperature, the particle size, moisture content and chemical composition of biomass feedstock, and the use and type of binding materials (Manickam et al. 2006; Rhén et al. 2005; Stelte et al. 2011a). Lignin in biomass can serve as a natural binder when the pelletizing temperature is higher than the lignin's phase transition temperature $\left(140{ }^{\circ} \mathrm{C}\right)$. Protein content also plays a major role as a binding agent between different particles during compaction (Chen et al. 2009; Liu et al. 2014). Stelte et al. (2011b) and Kaliyan and Morey (2010) have studied the binding mechanisms in briquettes and pellets. Studies have reported briquette production at modest pressures of 5-7 MPa (Chin and Siddiqui 2000; Yank et al. 2016), and pellet production using medium pressure of 46-114 MPa (Rhén et al. 2005), and high pressure of 170-180 MPa (Carone et al. 2011). In addition to these mechanized densification technologies for higher capacity operations, several low-tech, nonautomated small-scale briquetting technologies, such 
as hand presses or molds, exist (Ferguson 2012; GVEP 2010; Njenga et al. 2009).

Products and uses A pellet has uniform product characteristics in terms of size (length: $<35 \mathrm{~mm}$, diameter: $<10 \mathrm{~mm}$ ), shape (cylindrical), and unit densities $\left(1000-1400 \mathrm{~kg} / \mathrm{m}^{3}\right)$. Briquettes have other properties, larger sizes (typically $40 \times 40$-mm cylinders) or a particular size range (length: $75-300 \mathrm{~mm}$, diameter: $50-90 \mathrm{~mm}$ ), and unit densities in the range of $800-1000 \mathrm{~kg} / \mathrm{m}^{3}$ (Nunes et al. 2014; Stelte et al. 2011a; Tumuluru et al. 2011). Physical quality attributes describing densified biomass include moisture content, unit and bulk density, durability index, percent fines, and heating value. The standards for densified biomass application as a solid fuel in the USA are given by the Pellet Fuels Institute and in Europe by the European Committee for Standardization (Karkania et al. 2012; Tumuluru et al. 2011).

Briquettes and pellets can theoretically both be used for domestic heating, cooking and as industrial fuel, thereby replacing wood-based fuels and fossil fuels. Roy and Corscadden (2012) investigated the potential of burning hay and switch grass briquettes in domestic stoves and compared their performance and emissions to commercially available wood briquettes. The average HHV of grassy briquettes (17.0 MJ/kg) and overall combustion efficiency (74.6\%) were found to be comparable to that of woody briquettes (HHV: $17.9 \mathrm{MJ} / \mathrm{kg}$; combustion efficiency: 74.2\%). Grassy briquettes showed lower $\mathrm{CO}$ emissions, higher $\mathrm{NO}_{\mathrm{x}}$ emissions and similar $\mathrm{SO}_{2}$ and particular matter emissions in comparison to woody briquettes. Overall, Roy and Corscadden (2012) concluded that hay and grass briquettes can successfully be used in domestic wood stoves with similar or better performance and emissions compared to a range of biomass briquettes available in the market.

Critical review of challenges and trends in low-and middle-income settings Densification of biomass has been in practice for a long time and is considered a robust and mature technology. However, some research gaps still need to be addressed to fully understand the interaction of feedstock, process variables, and pre-treatment methods on the quality of the densified biomass (Tumuluru et al. 2011). Densification is particularly suitable for lignocellulosic biowaste, thus often practiced in the rural, agricultural context, where it stands in competition with the use for animal fodder and soil amendment. For mixed biomass pellets, the availability of a sales market, and not of the biomass resource, is considered to be the most critical factor (Karkania et al. 2012). Overall, current research mainly focuses on feedstock suitability and end-use of the densified products. For efficient and safe combustion of pellets without harmful emissions, households need to use appropriate equipment and ensure adequate operation. Considerable efforts have gone into promotion of improved cooking stoves (UNF 2016) to enhance indoor air quality (Bruce et al. 2015; WHO 2014). On household level, top-lit updraft (TLUD) semi-gasifier stoves, which can be fed with densified biomass, are a promising alternative to traditional stoves (Roth 2014). They are increasingly being researched as they have shown to be the lowest-emitting type of solid biomass cookstoves (Jetter et al. 2012; Tryner et al. 2014). These efforts might further increase the potential of the urban biowaste densification technology. On industrial level, combustion of pellets and briquettes are also feasible, however, legal and institutional frameworks and standards are required to guarantee efficient and safe combustion.

One of the advantages of the densification technology is its flexibility to be operated at a wide range of scales, from manual, low-cost production up to sophisticated, high-throughput systems. Although locally produced briquettes are an attractive energy carrier for individual consumers in different parts of the world, especially in low- and middle-income settings (Stolarski et al. 2013), briquetting technology has yet to get a strong foothold in these countries because of the technical constraints involved and the lack of knowledge to adapt the technology to suit local conditions (Alade and Betiku 2014). In China, for instance, the main drawback of the biomass densification (screw-, piston- and roller-press) technologies is the high energy consumption along with severe wear and short working life of the main components. This increases the biomass fuel cost and contributes to the difficulty in increasing the popularity of the densification technology (Cui et al. 2014). However, research and development of biomass briquetting technology was one of the key projects within China's Eleventh Five-Year Plan (2006-2010). The objectives of this project were (1) to investigate the effect of preprocessing on densified biomass properties, (2) to 
explore the binding mechanism of biomass densification, (3) to develop briquetting technology which can process a wide range of biomass material, (4) to develop briquetting device with high productivity and low energy consumption, (5) to establish demonstration projects of densified biofuel (3000 tons/year) using agro-forest residues as raw materials (Chen et al. 2009). The biomass briquetting industries and their perspectives are also being studied in other countries such as Nigeria (Alade and Betiku 2014), Kenya (GVEP 2010), Uganda (Ferguson 2012; Okello et al. 2013) and Brazil (Felfli et al. 2011), indicating a growing interest in this technology and the corresponding sector.

\subsection{Thermochemical treatment}

Thermochemical conversion processes apply heat to induce chemical reactions as a means of extracting and creating energy carriers as products. These processes include combustion, pyrolysis, liquefaction and gasification. Each of these differs in terms of temperature, heating rate, and the oxygen level present during the process. Direct combustion of raw waste is not covered here as it has been described in Sect. 3.1.3 as part of the biowaste treatment category 'Direct use'. The energy stored in biomass can be directly released as heat via combustion, or can be transformed into solid (e.g. charcoal), liquid (e.g. bio-oils), or gaseous (e.g. syngas) fuels via pyrolysis, liquefaction, or gasification with various utilization purposes (Zhang et al. 2010b). Thermochemical conversion processes proceed faster than biochemical processes, but require substantial energy input.

\subsubsection{Pyrolysis}

Introduction Pyrolysis entails the decomposition of biomass by heat in the absence of oxygen $(\lambda=0)$, resulting in the production of solid, liquid and gaseous products. In principle, there are two main types of dry pyrolysis techniques, named according to their heating rate: slow pyrolysis, where the main output is a solid product called char, and fast pyrolysis with bio-oil as the main product. Other sub-types of pyrolysis also exist such as intermediate, flash, ultra and vacuum pyrolysis, which differ in their residence time, heating rate, temperature and major products produced (Mohan et al. 2006; Vamvuka 2011). Slow pyrolysis involves heating biomass for hours to days and has traditionally been used in earth pit/mound kilns for the conversion of wood into charcoal. Fast pyrolysis is characterized by high heating rates and rapid condensation of the vapors in a continuous flow system with the main goal to produce bio-oil (Tripathi et al. 2016) (see Table 2). Torrefaction is a mild form (lower temperature) of pyrolysis (Ciolkosz and Wallace 2011; Eseyin et al. 2015; van der Stelt et al. 2011). Studies on pyrolysis for treating a mixed fraction of municipal solid waste requires a technically more sophisticated system which are discussed in Chen et al. (2015). A growing body of literature is available covering wet pyrolysis (or hydrothermal carbonization, HTC) where the main products is char (Funke and Ziegler 2010; Kambo and Dutta 2015; Libra et al. 2011).

The pyrolysis technology dates back thousands of years when it was used for charcoal production (Jahirul et al. 2012). In the 'Bronze Age' 5000 years ago, humans started using charcoal in metallurgy to obtain the temperatures necessary to smelt ores for copper and iron (Guo et al. 2015). Pyrolysis has also been used to produce tar for sealing boats and for embalming purposes in ancient Egypt (Jahirul et al. 2012). The modern petrochemical industry owes a great deal to the invention of the fast pyrolysis process for kerosene production in the mid-1840s (Basu 2013). Today, charcoal is still one of the primary cooking

Table 2 Typical feedstock requirements, operating conditions and product yields (dry basis) of slow and fast pyrolysis (adapted from Duku et al. 2011; Tripathi et al. 2016; Vamvuka 2011)

\begin{tabular}{|c|c|c|c|c|c|c|c|}
\hline & \multirow{2}{*}{$\begin{array}{l}\text { Feedstock } \\
\text { Particle size }\end{array}$} & \multicolumn{3}{|c|}{ Operating conditions } & \multicolumn{3}{|c|}{ Product yield (wood pyrolysis) } \\
\hline & & $\begin{array}{l}\text { Residence } \\
\text { time }\end{array}$ & Heating rate & $\begin{array}{l}\text { Temp. } \\
\left({ }^{\circ} \mathrm{C}\right)\end{array}$ & $\begin{array}{l}\text { Solid } \\
(\%)\end{array}$ & Liquid & Gas $(\%)$ \\
\hline Slow pyrolysis & $\begin{array}{l}\text { Medium } \\
\quad(\mathrm{cm} \text { to } \operatorname{logs})\end{array}$ & $\begin{array}{l}\text { Minutes } \\
\text { to days }\end{array}$ & Low $(0.1-1 \mathrm{~K} / \mathrm{s})$ & $300-500$ & 35 & $30 \%$ bio-oil (70\% water) & 35 \\
\hline Fast pyrolysis & Small $(<1 \mathrm{~mm})$ & Seconds & High $(10-200 \mathrm{~K} / \mathrm{s})$ & $400-650$ & 12 & $75 \%$ bio-oil ( $25 \%$ water) & 13 \\
\hline
\end{tabular}


fuels in many low- and middle-income settings, with 80-90\% of urban households in sub-Saharan Africa depending on it (Lohri et al. 2016). Apart from cooking, charcoal is used for heating, air and water purification, in industrial processes requiring heat, and as soil amendment (Guo et al. 2015). Pyrolysis with a focus on high oil yield is a relatively new 'rediscovery' since it was recognized in the 1980s that fast pyrolysis is a good alternative to the expensive hydrocracking technology (Vamvuka 2011). Over the last two decades, fundamental research has been conducted on fast pyrolysis using carbonaceous feedstock and the use of its liquid product as fuels and chemicals (Mohan et al. 2006).

Input material Common feedstock characteristic requirements for both slow and fast pyrolysis processes are: dry, unmixed, homogeneous, uncontaminated substrate, preferably with high carbon and low ash content, available at no or low costs. Other feedstock that might not meet these requirements can also be pyrolyzed if a pre-treatment step is added. For instance drying of feedstock to a moisture content of $10-15 \%$ is usually required unless the substrate is a naturally dry material such as straw (Bridgwater 1999; Isahak et al. 2012). High moisture contents result in large amounts of energy losses as every kilogram of water in biomass requires $2.26 \mathrm{MJ}$ for vaporization (Basu 2010). In addition, the biomass feedstock frequently requires some form of pre-treatment to evenly destruct the lignocellulosic structure and enhance pyrolysis efficiency (Kan et al. 2016). The feedstock particle size has a major influence on the heating rate and yields (Isahak et al. 2012). In theory, virtually any form of biomass can be considered for pyrolysis. In the urban solid waste context, lignocellulosic waste from carpentries and saw mills, park and garden waste (trimmings/ pruning), paper and cardboard waste are suitable for pyrolysis. Wood remains the substance most extensively studied given its uniformity that allows comparability among tests. For fast pyrolysis, nearly 100 types of biomass have been tested, ranging from agricultural wastes to energy crops, forestry wastes and other solid wastes, including sewage sludge and leather wastes (Mohan et al. 2006; Yaman 2004). To select suitable waste types as feedstock for slow pyrolysis, simple assessment tools have been developed with criteria such as feedstock, market, technology selection and production cost selection (Biomass Technology Group 2013), or availability/ accessibility criteria and physico-chemical properties (Lohri et al. 2016).

Conversion process The exact decomposition mechanism and reaction scheme for the conversion of most biomass types into gaseous, liquid, and solid fractions are not fully understood due to the complexity of the process, the many intermediate products that are produced, and the variation in composition of biomass feedstock (Babu 2008; Burhenne et al. 2013). A large number of reactions take place in parallel and series, including dehydration, depolymerization, isomerization, aromatization, decarboxylation, and charring (Kan et al. 2016). From a thermal standpoint, the pyrolysis process can be divided into four stages, which partly overlap (Basu 2013).

1 Drying (ca. $100{ }^{\circ} \mathrm{C}$ ): The biomass is heated at low temperature and releases moisture and loosely bound water through evaporation.

2 Initial stage (ca. $100-300{ }^{\circ} \mathrm{C}$ ): Exothermic dehydration of the biomass takes place during the torrefaction stage with the release of water and low-molecular-weight gases like $\mathrm{CO}$ and $\mathrm{CO}_{2}$.

3 Intermediate stage $\left(>200^{\circ} \mathrm{C}\right)$ : Primary pyrolysis takes place in the temperature range of 200-600 ${ }^{\circ} \mathrm{C}$. Most of the vapor or precursor to bio-oil is produced at this stage. Large molecules of biomass particles decompose into (primary) char, condensable gases (vapors and precursors of the liquid yield), and non-condensable gases.

4 Final stage (ca. $300-900{ }^{\circ} \mathrm{C}$ ): The final stage of pyrolysis above $300{ }^{\circ} \mathrm{C}$ involves secondary cracking of volatiles into char and non-condensable gases. If they reside in the biomass long enough, relatively large-molecular-weight condensable gases can crack, yielding additional (secondary) char and gases. Fast pyrolysis involves the quick removal and rapid quenching of the condensable gases at the end of the process to terminate the secondary conversion process and results in higher bio-oil yield.

The typical operating conditions of slow and fast pyrolysis were shown in Table 2. Many researchers have studied the influence of operating conditions on product yields and it is generally accepted that the process parameters which most influence product 
distribution are temperature, heating rate, residence time and reactor pressure. Particle size, shape and physical properties (ash content, density, moisture content, etc.), and the chemical composition of the biomass, which is constituted by three main polymers (i.e. cellulose, hemicelluloses and lignin), also play an important role (Lohri et al. 2016). Discussion of the pyrolysis conversion steps of the aforementioned polymers can be found in Collard and Blin (2014), information about tar reduction in Han and Kim (2008). For slow pyrolysis, the effect of process parameters on production of char are discussed in Tripathi et al. (2016), the effect of processing parameters during fast pyrolysis on liquid oil yield in Akhtar and Amin (2012), whereas discussion of the kinetics of pyrolysis is found in Babu (2008), and of reactor types in Meyer et al. (2011), Isahak et al. (2012) and Jahirul et al. (2012).

Products and uses The relative amounts of the main products of pyrolysis, char (the black, solid residue), bio-oil (the brown vapor condensate), and syngas (the non-condensable vapor), depend on several factors including the heating rate, peak temperature and residence time (Basu 2013; Guo et al. 2015) as shown in Table 2.

Char Char has received increasing attention due to its suitability for several applications (Nanda et al. 2016; Qian et al. 2015; Xie et al. 2015), which include the use as a solid fuel (Lohri et al. 2016), soil amendment (bio-char) (Ennis et al. 2012; Lehmann et al. 2011; Tang et al. 2013; Xu et al. 2012), or precursor for making catalysts and contaminant adsorbents (Inyang and Dickenson 2015; Manyà 2012; Mohan et al. 2014; Tan et al. 2015). As discussed above, the feedstock type and pyrolysis operating conditions influences the physical, chemical, and mechanical properties of chars which in turn have an effect on the potential to utilize char for the various applications (Kan et al. 2016; Qian et al. 2015). Waste-derived char needs further processing (densification) into charcoal-briquettes and can then be used for household cooking as alternative to woodbased charcoal (Mwampamba et al. 2013). Higher heating value of char is reported to be between 20 and $36 \mathrm{MJ} / \mathrm{kg}$ (Kan et al. 2016; Lohri et al. 2015; Vamvuka 2011). Char can contain $15-45 \%$ (by mass) of volatile matter, which facilitates the ignition of the char, but at the same time emits more visible smoke. In comparison a good-quality commercial charcoal can have a net volatile matter content (moisture free) of about 30\% (Lohri et al. 2016; Vamvuka 2011).

Bio-oil The liquid pyrolysis product is known as biooil, pyrolysis oil, bio-crude oil, wood oil, wood distillates, pyroligneous acid, liquid wood and liquid smoke (Mohan et al. 2006). It is typically of dark redbrown to almost black color, has a distinctive acid, smoky smell, and can irritate the eyes (Venderbosch and Prins 2010). Bio-oils are a complex mixture of water and organic chemicals with more than 300 identified compounds. Due to the high moisture content and acid content, crude pyrolysis bio-oil is instable, corrosive, viscous, low in energy density, and difficult to ignite (Guo et al. 2015). Because of the presence of large amounts of oxygenated components, the oil has a polar nature and does not mix readily with hydrocarbons. The high water content, typically 15-35 wt \% which cannot be removed by conventional methods like distillation, is a serious drawback in terms of the heating values: the higher heating value (HHV) is between 15 and $20 \mathrm{MJ} / \mathrm{kg}$ (Basu 2013; Kan et al. 2016; Venderbosch and Prins 2010). Bio-oils have been extensively tested as combustion fuels for electricity and heat production in boilers, furnaces, and combustors, diesel engines, and gas turbines, or they alternatively can be upgraded to produce bulk chemicals (Isahak et al. 2012; Kan et al. 2016). Due to the undesired properties (Xiu and Shahbazi 2012), it is essential to chemically upgrade bio-oil, i.e. reduce volatility, increase thermal stability, reduce viscosity through oxygen removal and molecular weight reduction to make it useful as transportation fuel (Jacobson et al. 2013). Reduction and control of the oxygen functionalities should be the ultimate goal instead of the reduction in oxygen content itself (Venderbosch and Prins 2010). Upgrading of bio-oil has extensively been researched (Gollakota et al. 2016; Jacobson et al. 2013; Xiu and Shahbazi 2012; Zhang et al. 2013; Zhang et al. 2007). More challenges related to bio-oil are discussed in Bridgwater (2013).

Gas The pyrolysis gas contains carbon dioxide, carbon monoxide, methane, hydrogen, ethane, ethylene, minor amounts of higher gaseous organics and water vapor (Vamvuka 2011). The typical LHVs of the pyrolytic gases range between 10 and $20 \mathrm{MJ} / \mathrm{Nm}^{3}$ (Basu 2013; Kan et al. 2016). The pyrolysis gas has multiple potential applications, such as direct use for 
production of heat or electricity, either directly or cofired with coal, production of individual gas components, including $\mathrm{CH}_{4}, \mathrm{H}_{2}$ or other volatiles, or in production of liquid bio-fuels through synthesis. In some applications, the hot pyrolytic gas can be used to preheat the inert sweeping gas or can be returned to the pyrolysis reactor as a carrier gas (Kan et al. 2016).

Critical review of challenges and trends in low-and middle-income settings Due to the lower process complexity (hence lower investment costs) and the high demand for cooking fuel such as charcoal and char-briquettes, slow pyrolysis and the production of char has received more attention in the low- and middle-income settings context compared to fast pyrolysis. Low-tech slow pyrolysis systems were mainly designed for carbonization of wood logs, thus need to be adapted for biowaste as alternative feedstock. It is further recommended to measure and critically evaluate the emissions, which are released during the carbonization process, including critical pollutants and products of incomplete combustion (PICs) such as carbon monoxide (CO), polycyclic aromatic hydrocarbons (PAHs) and particulate matter (Lohri et al. 2015). Apart from these environmental and public health risks, further challenges include socio-economic barriers, negative perceptions and attitudes towards (bio)char, and a lack of finance, empirical data and supportive policy framework. These constraints have been reported in the context of Ghana (Duku et al. 2011), sub-Saharan Africa (Gwenzi et al. 2015) and in general (Manyà 2012). Similarly, Murugan and Gu (2015) highlight the R\&D pyrolysis activities in India over the last three decades and conclude that enhancing the quality of pyrolysis products for better marketability, use and safety, and minimizing process energy input and losses are the points that require major further attention on the path towards commercialization. An efficient, environmental friendly and thus much-noticed low-cost kiln-retort system (called Adam-retort) was developed for carbonization of biomass waste (Adam 2009). It has been further optimized and implemented in various lowand middle income countries (Adam 2013; Adam 2014). However, it is generally acknowledged that continuous feeding in contrast to batch operation is not only recommended for facilitation of emission treatment, but also for enhanced energy efficiency (Lohri et al. 2016). A promising continuous operating semi- automated biomass pyrolysis system has been developed by the Center of Appropriate Technology and Social Ecology (CATSE) of Ökozentrum Langenbruck and is also being constructed and tested in Vietnam. This system, initially designed for wet coffee pulp, but also successfully tested using other feedstocks with water content of up to $55 \%$, can treat approximately $50 \mathrm{~kg} / \mathrm{h}$ biowaste. The system is characterized by a high energy efficiency, partly due to a lambda sensor controlled FLOX ${ }^{\circledR}$ burner, and very low emissions (Schmid et al. 2015).

In terms of fast pyrolysis, several fundamental research challenges still need to be overcome to facilitate commercialization (Bridgwater 2013; Jahirul et al. 2012; Mettler et al. 2012; Venderbosch and Prins 2010). These challenges, which partly also apply for slow pyrolysis, comprise (1) improving the operational reliability of demonstration scale pyrolysis reactors and processes, (2) achieving feedstock flexibility (accepting all kinds of biomass residues, instead of only wood), (3) increasing the heat transfer to the pyrolysis reactor and transfer from the char combustor, and (4) improving the process heat integration and its control. R\&D should be directed to improving the quality (and stability) of the resulting oil depending on the end-application envisaged. The poor quality and undesirable properties of bio-oil imply the need of high cost upgrading efforts and hinder the use of bio-oil as a substitute for petroleumbased fuel (Jacobson et al. 2013). Thus novel integrated refinery processes are required to systematically upgrade bio-oils into transportation fuels that have desirable qualities, while producing other valueadded co-products to make the process economically feasible (Xiu and Shahbazi 2012).

\subsubsection{Liquefaction}

Introduction Hydrothermal liquefaction (HTL), also known as direct liquefaction, implies processing of biomass in a hot, highly pressurized water environment for sufficient time to break down the solid biopolymeric structure into mainly liquid components called bio-oil or bio-crude (Elliott 2011; Elliott et al. 2015; Peterson et al. 2008). Water is an important reactant and catalyst, and thus wet biomass can be directly converted without an energy consuming drying step (Arturi et al. 2016; Toor et al. 2011; Xue 
et al. 2016). The thermochemical processes of HTL and fast pyrolysis are sometimes confused with each other as both can convert feedstock organic compounds into liquid products. Demirbaş (2000) and Doassans-Carrère et al. (2014) compare these two technologies in terms of operating conditions, products yields and characteristics.

Direct biomass liquefaction applied to coal has been an active research topic since the first Arab oil embargo in the 1970s (Elliott 2011). Low oil prices influences the research characterized by rather shortterm projects, a lack of cooperation and exchange of knowledge, and problems finding capital for commercial size plants (Toor et al. 2011).

Input material The nature of the process allows processing of feedstock with high moisture content. Thus any wet biomass, including complex mixtures of lignocellulose, protein and fats, can be converted into bio-oil through HTL (Arturi et al. 2016). Therefore, many types of urban biowaste such as kitchen, market and garden wastes are theoretically suitable for HTL. Publications report liquefaction of wood, forest and agricultural residues, urban biowastes, sewage sludge, manure, and algae (Ramirez et al. 2015). Lignocellulosic and algal biomass are the most commonly used feedstock types, with cellulose exhibiting higher bio-oil conversion than lignin (Xue et al. 2016). HTL of 18 types of Indonesian agricultural and forest residues was reported in Minowa et al. (1998), producing bio-oil with a heating value comparable to high rank coal and revealing a positive energy balance.

Conversion process Hydrothermal liquefaction is a conversion process occurring in a liquid phase at temperatures of $280-370{ }^{\circ} \mathrm{C}$ and pressures between 7 and $30 \mathrm{MPa}$ (Peterson et al. 2008). The high temperature is needed to initiate pyrolytic mechanisms in the bio-polymers, and the pressure has to be high enough to maintain a liquid water processing phase (Elliott 2011). HTL exploits the properties of superheated fluids to reduce mass transfer resistances, whereas the high pressure enables higher penetration of the solvent into the biomass structure to facilitate fragmentation of biomass molecules (Ramirez et al. 2015). Biomass is broken down into fragments of light molecules and these unstable and active light fragments are subsequently re-polymerized into heavier oily compounds. Hydrogen and organic solvents are often added into the reaction system (Demirbaş 2000) to prevent undesired side reactions of intermediate products and heavy solid char formation during re-polymerization. A significant amount of research and development on catalytic methods for HTL has been undertaken (Elliott et al. 2015). Catalysts (e.g. alkaline hydroxides and carbonates) lower the amount of solid residue and improve the yield of bio-oils (Srirangan et al. 2012). Akhtar and Amin (2011) and Xue et al. (2016) discuss the influence of operating parameters such as biomass type, biomass $/ \mathrm{H}_{2} \mathrm{O}$ ratio, particle size, reaction temperature, heating rate, solvent density, pressure, residence time, catalysts and reducing gas/hydrogen donors on bio-oil yield and quality.

Products and uses HTL products are typically a two-phase mixture of bio-oil (bio-crude) and process water with suspended char particles, and small amounts of synthesis gas (Arturi et al. 2016). Almost all of these gaseous-, aqueous-, and solid-phase byproducts can be utilized in the field of advanced carbon materials, chemicals, or as fuel for the transportation industry (Xue et al. 2016). HTL biooil is semi-liquid, dark-colored and has a smoke-like smell (Ramirez et al. 2015). To lower the bio-oil's viscosity, organic solvents (e.g. propanol, butanol, acetone, methyl ethyl ketone and ethyl acetate) need to be added to the reaction system. All these solvents, except ethyl acetate, may be produced from wood during liquefaction, suggesting that the solvent can be recovered for reuse (Demirbaş 2000). In addition to carbon, hydrogen and oxygen content, the HTL-generated bio-oil contains both nitrogen and sulfur, depending on the composition of the biomass substrate. The energy density in the bio-oil ranges between 30 and $37 \mathrm{MJ} / \mathrm{kg}$ and can be directly used as a heavy fuel oil (Toor et al. 2011). Bio-oil, however, still contains $10-20 \%$ of oxygen (Peterson et al. 2008), making it more polar than crude oil. This causes a number of disadvantages, such as a relatively high water content, corrosive properties, and thermal instability etc. The oil product can be upgraded through catalytic hydro-processing, primarily to remove oxygen (Elliott 2011; Toor et al. 2011) but this will increase production costs. A review of the available upgrading technologies and how they can be used to convert HTL bio-crude into a transportation fuel that meets current fuel property standards can be found in Ramirez et al. (2015). 
Critical review of challenges and trends in low-and middle-income settings Technological advances in hydrothermal liquefaction of biomass are still in their infancy (Srirangan et al. 2012). The low level of technology maturity is underlined by the fact that HTL has only been demonstrated at lab- or bench-scale for short time periods (Lee et al. 2016; Toor et al. 2011). Numerous research gaps still exist in terms of the technology development, the influence of the input material, and the upgrading of the bio-oil. Several authors present a number of critical issues hindering commercialization (e.g. reactor corrosion, precipitation of inorganic salts, coking and deactivation of heterogeneous catalysts), which all need to be resolved before hydrothermal technologies can be piloted and ultimately scaled up (Peterson et al. 2008; Tran 2016). Challenges regarding feedstock and upgrading of bio-oil include questions about decomposition of lignin in the HTL process, as well as the challenge of high oxygen and nitrogen levels in the bio-oil (Xue et al. 2016). Although technologies for the upgrading of the bio-crude exist, applications of these techniques are limited by economic considerations (Lee et al. 2016). Moreover, the overall economic feasibility of HTL is uncertain due to the high cost associated with the complex reactor and feeding system (Srirangan et al. 2012). Different technological approaches are mentioned in literature to solve the remaining challenges, but none of them have proven their technical and financial feasibility on scale (Behrendt et al. 2008; Tran 2016).

One major bottlenecks for commercialization of hydrothermal technologies in general and specifically HTL application in low- and middle-income settings is the high pressure needed for processing. This demands special reactor and separator designs and thus requires substantial capital investments for full-scale plants (Peterson et al. 2008). Such high pressures furthermore present a significant safety issue. From a technical, financial, and safety perspective, HTL is currently considered an unsuitable biowaste treatment technology for low- and middle-income settings.

\subsubsection{Gasification}

Introduction Gasification is a thermal treatment that converts carbonaceous material into a gas (producer gas, synthesis gas or syngas), which can be used as fuel or for the production of value-added chemicals. The main difference between the two closely related thermochemical processes of gasification and combustion is that gasification packs energy into chemical bonds in the gas by adding hydrogen $\left(\mathrm{H}_{2}\right)$ and stripping away carbon $(\mathrm{C})$ from the feedstock, whereas combustion oxidizes the $\mathrm{H}_{2}$ and $\mathrm{C}$ of the feedstock into water and carbon dioxide, thus breaking those bonds to release the energy (Basu 2010).

The basic principles of biomass gasification have been known since the late eighteenth century. By 1850 an established industry had emerged using 'heat gasifiers' to make gas mainly from coal and biomass fuels, to supply the town gas lights. By the 1920s, producer gas systems for operating stationary engines as well as trucks, tractors, and automobiles were demonstrated in Europe and elsewhere, but they failed to gain widespread acceptance because of their inconvenience and unreliability (Strassen 1995). Due to an acute shortage in liquid fuels a revival of smallscale gasification was seen during World War II (Kirkels and Verbong 2011). More recently, the disruption of oil supply and high oil prices in the 1970s have played a major role in the renewed interest for biomass gasification. Waste gasification has been applied in Japan since 1997, where the shortage of landfill space and the policy to avoid incineration and dioxin emissions have been the main drivers.

Input material Similar to other thermochemical conversion processes that do not take place in a liquid medium, gasification also requires dry biomass with moisture contents between 10 and $20 \%$ as feedstock. Biomass with higher moisture content must be dried before gasification (Ahmad et al. 2016). Other pretreatment steps comprise homogenizing the biomass feedstock in size and composition (Kumar et al. 2009a; Molino et al. 2016). The most prevailing feedstock considered for biomass gasification is wood. But also peat, black liquor (a by-product of the paper industry) and rice husk, particularly in Asia, have been gasified (Kirkels and Verbong 2011). Contrary to biomass gasification that comprises conversion of pure, source separated organic material (e.g. trimmings, pruning, leaves of urban park and garden waste), gasification has also been applied to mixed municipal solid waste (Arena 2012; Couto et al. 2015).

Conversion process The gasification process consists of a complex thermal and chemical process that 
converts organic matter into a gaseous product under oxygen-deficient conditions and temperatures between 750 and $1000{ }^{\circ} \mathrm{C}$ (Fodor and Klemeš 2012). Only limited air, oxygen or steam is supplied to the reaction as an oxidizing agent $(\lambda=0.2-0.5)$. The influence of operating parameters (e.g. residence time, reaction temperature, pressure, type and amount of oxidizing agents and catalysts) on gasification product yield and quality is described in Kumar et al. (2009a), Ruiz et al. (2013) and Ahmad et al. (2016). Broadly speaking, typical biomass gasification involves the following, overlapping stages (Balat 2009; Basu 2010; Puig-Arnavat et al. 2010; Ruiz et al. 2013):

1 Drying Occurs at temperatures between 100 and $200{ }^{\circ} \mathrm{C}$ and reduces the moisture content to below $5 \%$ (endothermic).

2 Devolatilization (pyrolysis) Occurs in the temperature range of $150-400{ }^{\circ} \mathrm{C}$. This endothermic stage involves the thermal breakdown of larger hydrocarbon biomass molecules into smaller (condensable and non-condensable) gas molecules and results in the formation of char. One important product of this stage is tar, formed through condensation of vapor produced in the temperature range between 250 and $300{ }^{\circ} \mathrm{C}$.

3 Oxidation This is a reaction between solid carbonized biomass and oxygen, generating $\mathrm{CO}_{2}$ and oxidization of hydrogen present in the biomass to generate water. With this exothermic oxidation of carbon and hydrogen a large amount of heat is released. When oxygen is present in only sub-stoichiometric quantities, partial oxidation of carbon may occur, generating $\mathrm{CO}$.

4 Reduction Occurs in a temperature range of 800 and $1000{ }^{\circ} \mathrm{C}$. In the absence (or sub-stoichiometric presence) of oxygen, several endothermic reduction reactions take place in this stage.

The designs of gasification reactors can be classified by the gasification agent, heat source, gasifier pressure, or by reactor design used. Gasification agent can involve air blown into the systems, supply of oxygen, or the supply of steam. Heat source variations are: heat provided by partial combustion of biomass, (autothermal), or heat supplied by an external source via a heat exchanger or an indirect process (allothermal or indirect). Gasifiers can further be operated at atmospheric or under pressure. Finally, different reactor designs can also be distinguished such as fixed-bed, fluidized-bed, entrained-flow, or stage gasification (Puig-Arnavat et al. 2010). Details on technical reactor components are described in Balat (2009).

Products and uses The resulting hot fuel gases (syngas) from gasification contain large amounts of incomplete oxidized products. These have a heating value which can be utilized in a separate process, even at different times or locations (Arena 2012). The syngas mixture consists of carbon monoxide (CO), hydrogen $\left(\mathrm{H}_{2}\right)$, methane $\left(\mathrm{CH}_{4}\right)$ and carbon dioxide $\left(\mathrm{CO}_{2}\right)$ as well as light hydrocarbons, such as ethane and propane, and also heavier hydrocarbons, such as tars. Hydrogen sulphide $\left(\mathrm{H}_{2} \mathrm{~S}\right)$ and hydrogen chloride $(\mathrm{HCl})$, or inert gases, such as nitrogen $\left(\mathrm{N}_{2}\right)$, can also be present in the syngas (Molino et al. 2016). Amount of syngas produced from gasification range from 1 to $3 \mathrm{Nm}^{3} / \mathrm{kg}$ on a dry basis, with an average LHV spanning between 4 and $15 \mathrm{MJ} / \mathrm{Nm}^{3}$. These results are affected by the gasification technology and the operating conditions. Air as gasification medium results in values between 4 and $7 \mathrm{MJ} / \mathrm{Nm}^{3}$ whereas steam will result in ranges between 10 and $18 \mathrm{MJ} / \mathrm{Nm}^{3}$ and oxygen between 12 and $28 \mathrm{MJ} / \mathrm{Nm}^{3}$. (Basu 2010; Molino et al. 2016). Syngas can be used in a conventional burner, connected to a boiler and a steam turbine. In a more efficient energy conversion device, such as gas reciprocating engines or gas turbines, heat or electricity can be generated (Arena 2012; Balat 2009). Syngas is also a key intermediate substance in the chemical industry and used in many highly selective syntheses of chemicals and fuels, such as Fischer-Tropsch liquids, methanol and ammonia or as a source of pure hydrogen and carbon monoxide (Ahmad et al. 2016). Syngas from gasification requires conditioning, which involves cooling and disposal of particulate matter and tar (Abdoulmoumine et al. 2015; Heidenreich and Foscolo 2015).

Critical review of challenges and trends in low-and middle-income settings Biomass gasification is a complex technology which is considered immature, inflexible, less competitive than other technologies, and with a high risk of failure (Ruiz et al. 2013). There is a wide range of gasification designs and technological set-ups, many of which are still in the research stage (Molino et al. 2016). The main overall research challenges comprise finding solutions to deal with heterogeneous feedstocks, developing the knowledge 
to maximize syngas yield, optimizing gas quality and gas purity, increasing the overall process efficiency, and decreasing system and production costs to improve its economic viability (Heidenreich and Foscolo 2015). The feedstock requirements are similar to other dry thermochemical treatment processes in terms of low moisture and ash content, but gasification requires an even higher degree of homogeneity and particle size reduction. Modeling and simulation of biomass gasification are required to predict the effect of process parameters (Ahmad et al. 2016; Baruah and Baruah 2014). Since the late 1990s a significant amount of research efforts have focused on gas cleaning (Kirkels and Verbong 2011). Considering the fact that only a few pilot or industrial plants for the production of liquid or gaseous biofuels from syngas are functioning at present, Molino et al. (2016) stated that a new approach, capable to valorize all gasification products (chemicals, fuels and heat), is required to enable the diffusion of biomass gasification into the international market.

In the low- and middle-income context, the low technology maturity, high complexity and financial requirements reduce the application potential of biowaste gasification. However, the promise of rural electrification and local development have been driving gasification projects in India and China, where hundreds to thousands small fixed bed gasifier systems have been installed (Kirkels and Verbong 2011). Yet applications remain troublesome, with reported predominant problems of tar generation, operation, maintenance and economic feasibility (Buragohain et al. 2010; Kirkels and Verbong 2011). Microgasification for cooking is a relatively new and promising development as it allows biowaste (e.g. in the form of pellets) to be efficiently and safely burned for cooking purposes at household level (Roth 2014).

\subsection{Comparative overview of biowaste treatment technologies}

Table 3 (treatment technologies with agricultural and animal feed products) and Table 4 (treatment technologies with bio-energy products) provide a comparative overview of the presented biowaste treatment technologies in terms of feedstock suitability, main operational parameters and output products. In the thermochemical treatment category 'controlled combustion', which occurs in a controlled manner (i.e. high temperatures with sufficient oxygen supply to ensure complete combustion of the organic matter), is also listed for the sake of completeness although it can substantially differ from the 'direct combustion' (or open burning) of biowaste as covered in this review.

\section{State-of-research overview}

\subsection{Quantification of scientific articles published on Scopus 2005-2015}

A search of articles on treatment technologies for biowaste published from 2005 to 2015 (search level 2) reveals that the highest number of scientific publications relate to the topics of anaerobic digestion, composting and pyrolysis. Least publications were found covering liquefaction, direct combustion and black soldier fly conversion (Fig. 3a).

Filtering these results with regard to low- and middle-income settings (Fig. 3b) reveals that composting and anaerobic digestion are also the technologies on which most articles were published. The categories 'direct use' which comprise land application and animal feed are also well represented in the frequency of publications and show that these topics are relevant for low- and middle-income settings, likely due to the simplicity and low costs involved, and thus stimulate interest of researchers. The same applies for slow pyrolysis, whereas fast pyrolysis as more complex treatment process involves higher costs, and a different set of technical capacities. The highest fraction of technology-specific articles on lowand middle-income settings (search level 3) compared to biowaste treatment articles (search level 2) is found for 'direct combustion' (35\%: 39 out of 111) followed by 'direct land application' (16\%: 206 out of 1257), indicating their relevance in these settings. The technologies with the lowest absolute number of publications in the economically developing context are fermentation, black soldier fly and liquefaction. The high investment and operating costs of fermentation and liquefaction could be a reason for their limited publication output in low- and middle-income settings. Such innovative approaches are typically conducted in and for high-income settings where more 


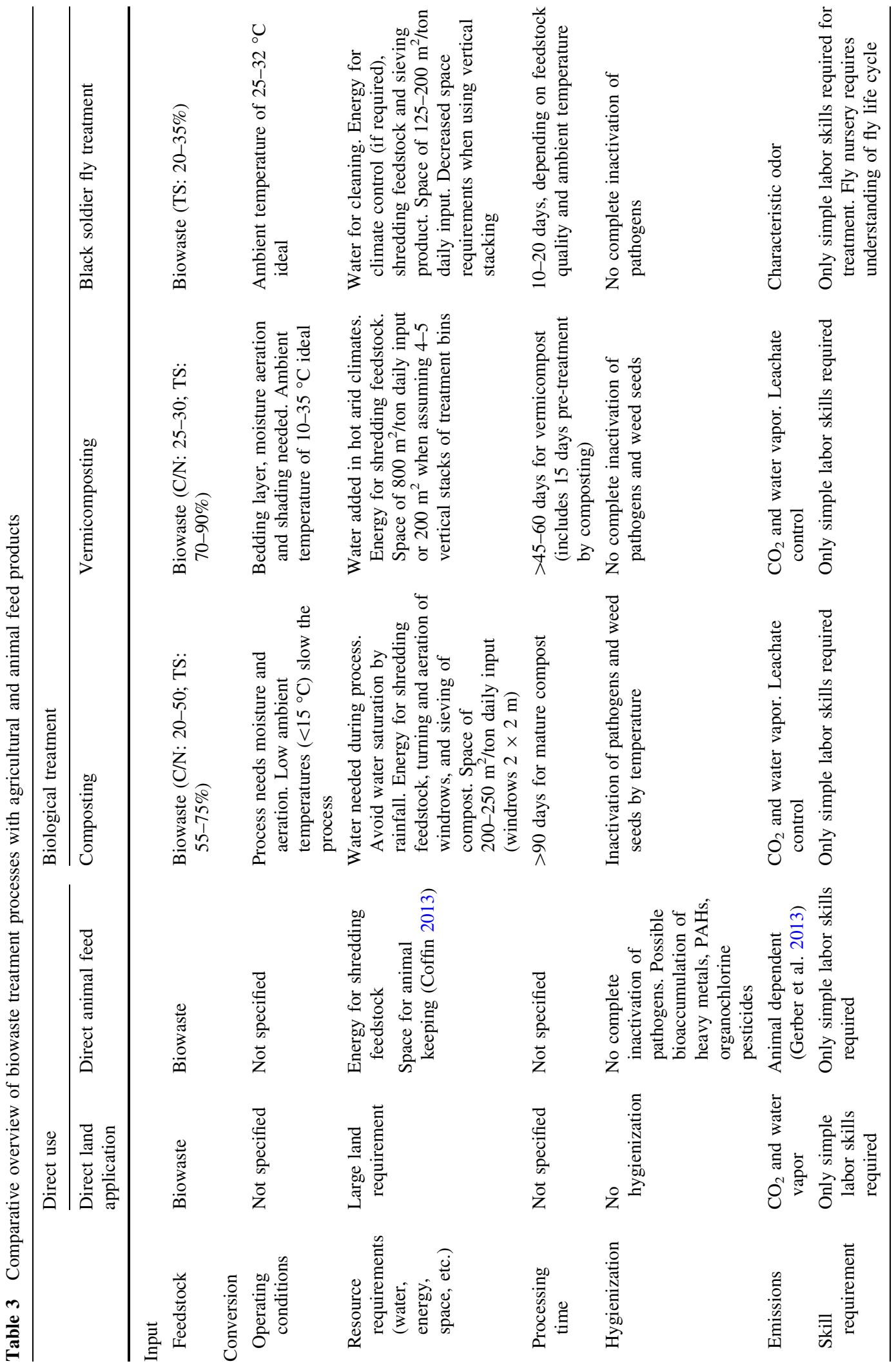




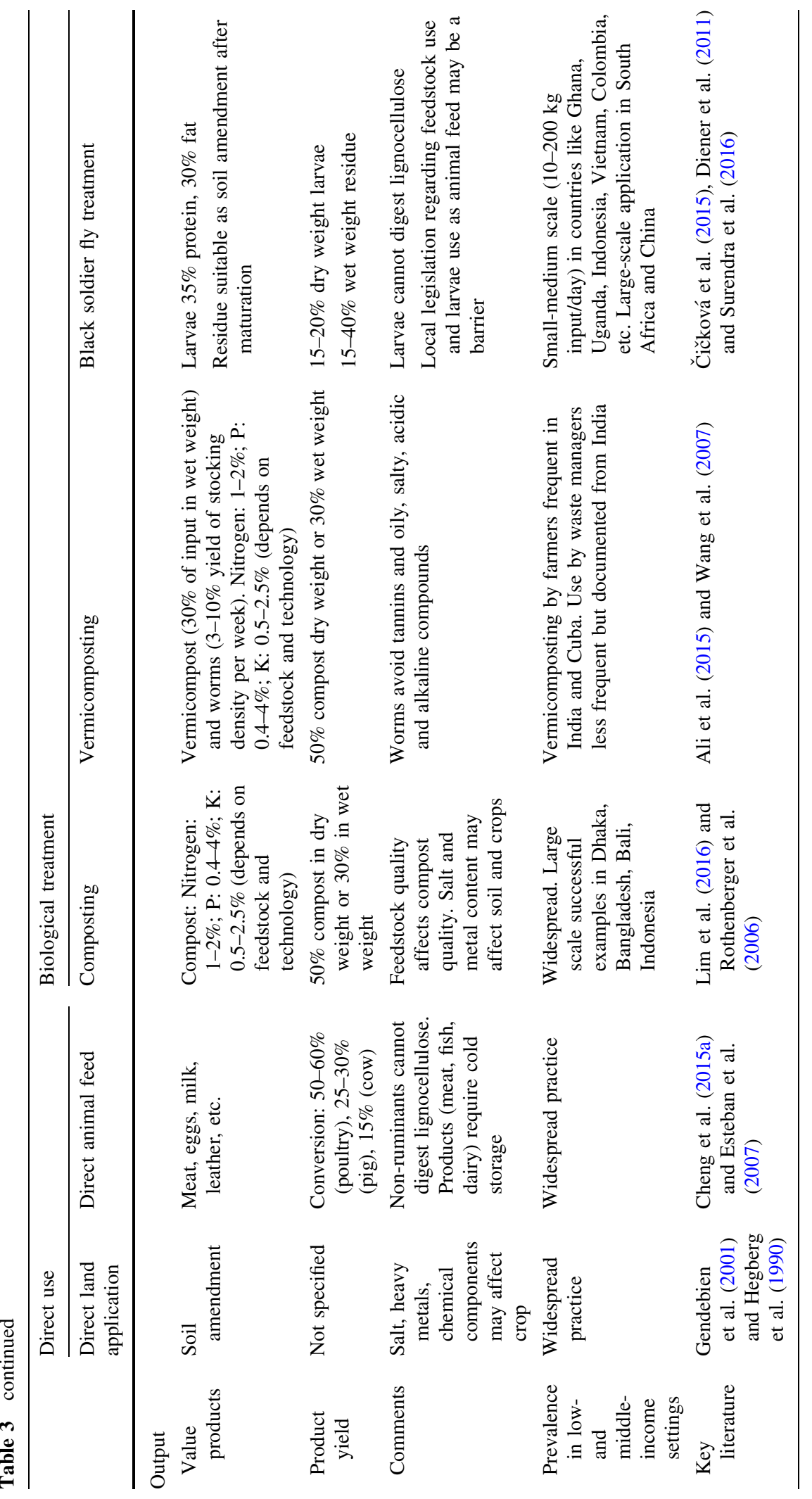




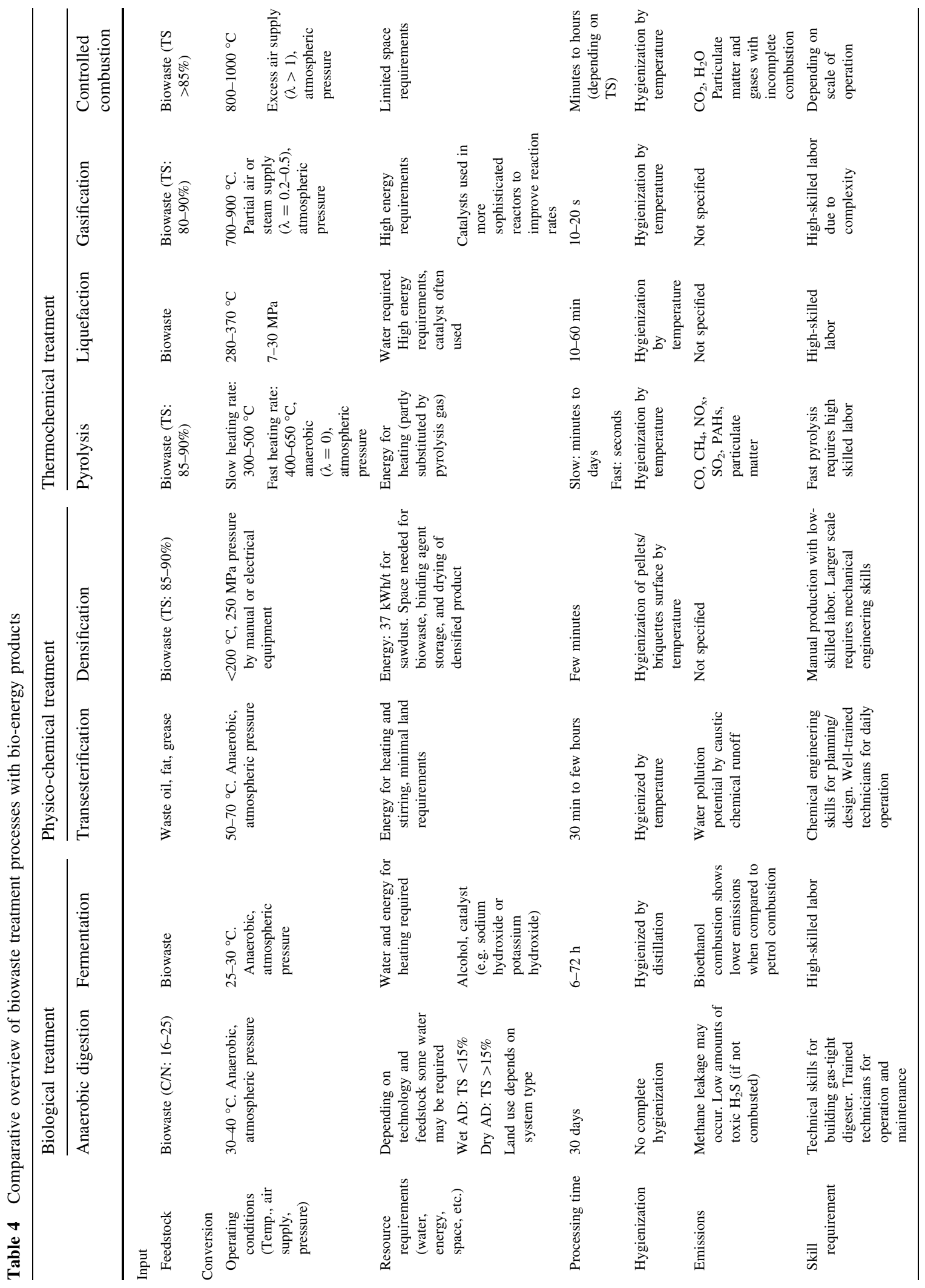




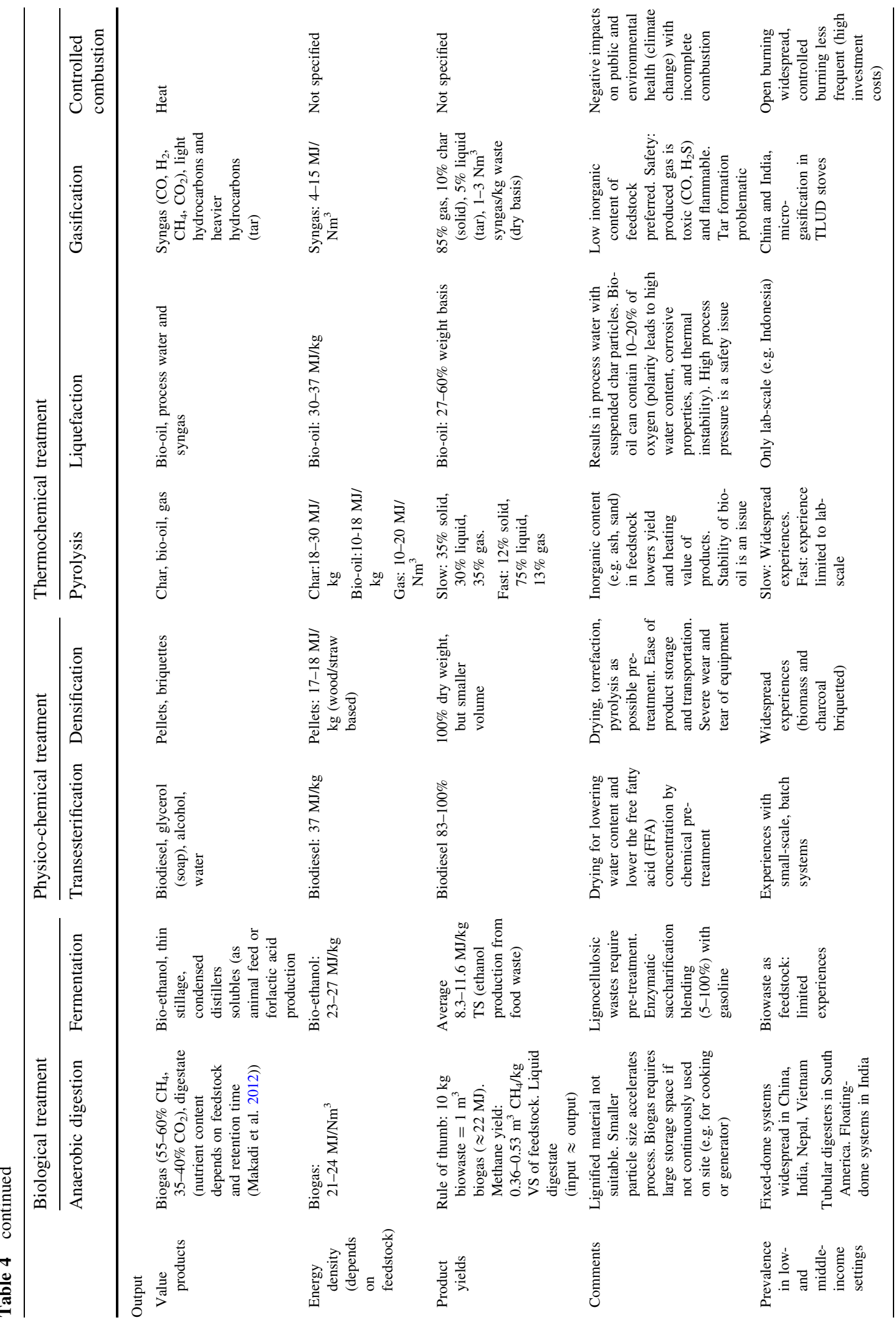


research funds are available. Black soldier fly conversion is also still a rather new biowaste treatment technology, which is likely one of the reasons for the low numbers of publications. However, with $13 \% \mathrm{BSF}$ conversion ranks 3rd regarding the fraction of publications that covers low- and middle-income settings out of all articles on BSF biowaste treatment.

Examination of the publications on biowaste treatment technologies in low- and middle-income settings over time (in 5-year groups) reveals that densification is the only technology of which substantially more articles were published 2006-2010 (72\%) compared to publications in 2011-2015 (28\%). In contrast, fermentation, direct combustion, anaerobic digestion and transesterification show an increase of publications from 2006-2010 (33-36\%) to 2011-2015 (64-67\%). The most striking increase of published articles relates to pyrolysis (22-78\%) and BSF (0-100\%), although for the latter the small absolute number of articles (3) must be considered.

\subsection{Type of research in scientific articles}

Of the total 3653 articles on biowaste treatment technologies published between 2005 and 2015 (search level 2) and categorized according to their research type, an average of $53 \%$ fall into the category of research on process engineering, while $22 \%$ are on technology implementation, and $25 \%$ deal with sustainability aspects. Figure 4 shows the distribution of research type for each treatment technology. The highest fraction with a focus on process engineering show in the publications on BSF conversion. Pyrolysis, fermentation, liquefaction and vermicomposting follow with more than $66 \%$ of articles of process engineering type, while anaerobic digestion still shows a fraction of $53 \%$ of process engineering type. These results can be explained by the technology readiness level, where for an immature technology stage it can be expected that research will largely focus on research results from laboratory/bench scale studies with an increased focus on generating a basic understanding and fundamentals of the process as well as lab-scale studies which target opportunities of optimizing the process steps. With an increasing technology level readiness one would then expect more publications on pilot/demonstration scale or case studies discussing the field application. However, even for technologies that are already mature and in a 
(A) Scientific publications on treatment technologies for solid waste

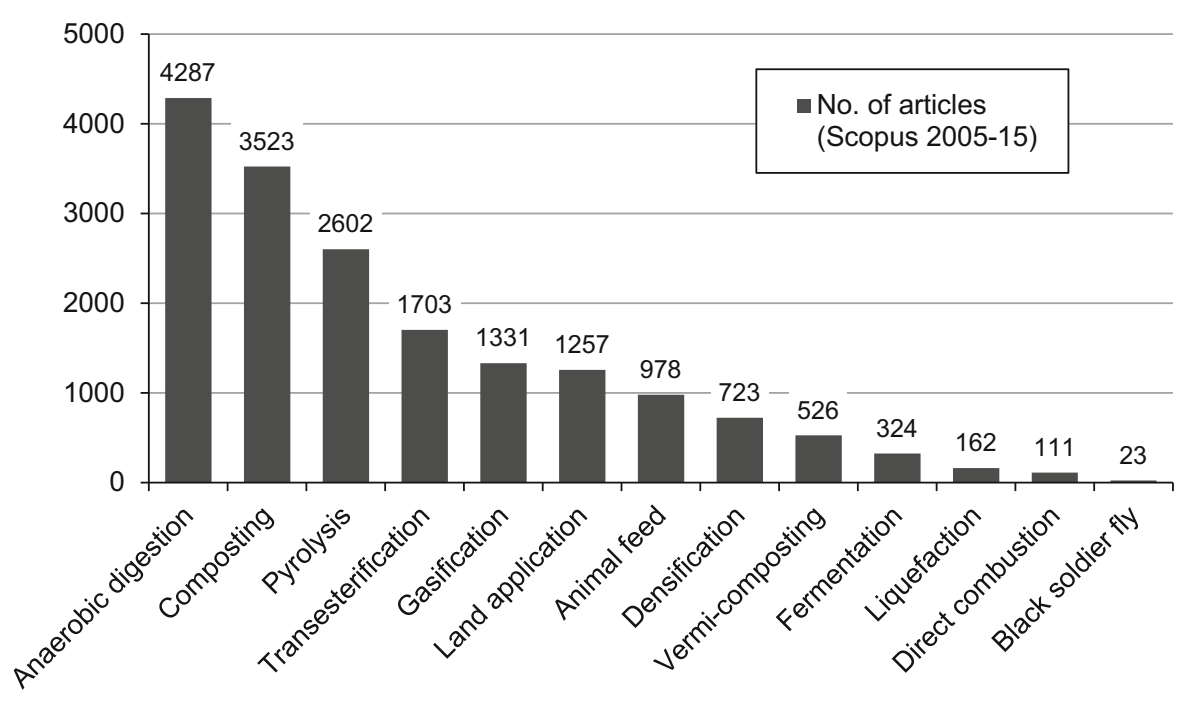

(B) Scientific publications on treatment technologies for solid waste in low- and middle-income settings

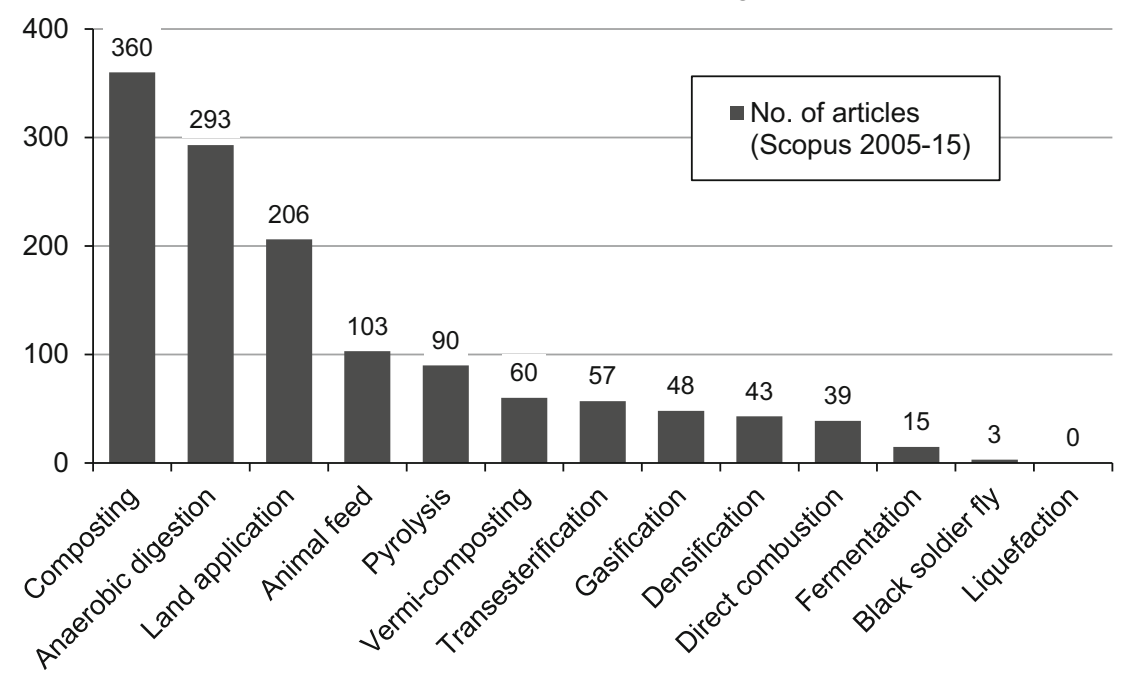

Fig. 3 Total number of articles in Scopus (2005-2015) regarding solid waste treatment technologies (a), and when adding terms related to a low-and middle-income setting (b)

commercialized phase at larger or even industrial scale, the results show that the main bulk of research publications can still be categorized as process engineering type.

An example of this may be reflected in the results regarding vermicomposting, which although being a relatively old and well-understood process, still shows a strong frequency towards research on better understanding the digestive functions and genetic variations among worms and their performance for waste management. Similarly, also the technology of anaerobic digestion, although widely applied in waste management, shows a high fraction of research on process engineering such as studies on interaction and/ or transition of different microbial communities during the process. Such research has probably also gained increased momentum given new detection and methods of analysis. Technologies such as densification and direct combustion, both technologies of low-complexity seems less conducive for process engineering 
Sustainability aspects Implementation $\quad$ Process Engineering

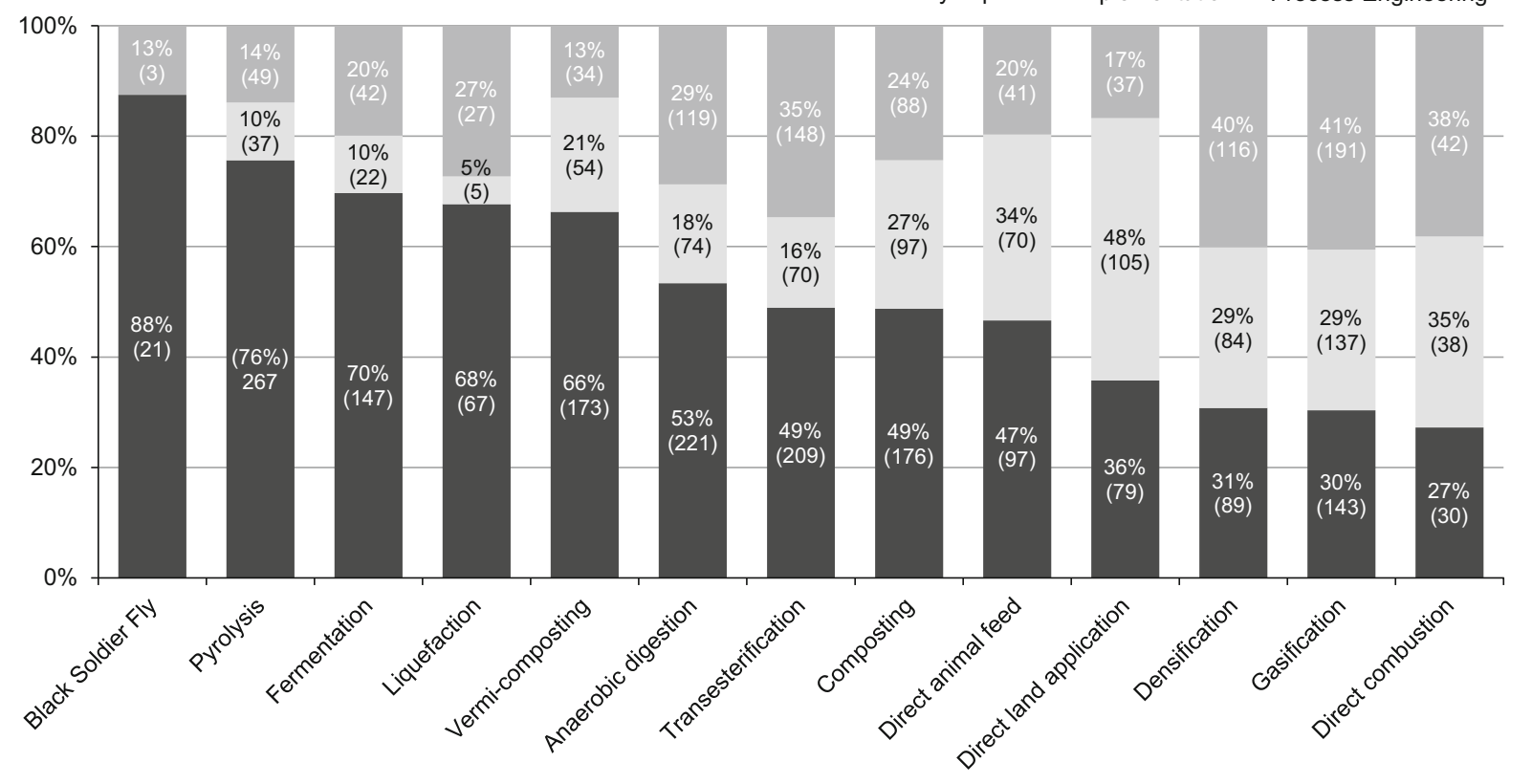

Fig. 4 Type of research of scientific articles on solid waste treatment technologies retrieved from Scopus (2005-2015). The figures in brackets indicate the absolute number of articles

research. Here a relatively high fraction $(38-40 \%)$ of publication covers the aspect of sustainability, which includes assessments and application of methods such as Life Cycle Analysis (LCA), economic analyses and studies regarding the emissions and impacts of the technology with regard to environmental pollution or human health. Publications on gasification, despite being a technology of higher complexity and lower maturity level, also predominantly cover sustainability issues. This can be interpreted as a substantial interest in bringing gasification to scale (e.g. due to the attractiveness of the products), while at the same time acknowledging the need to further assess the impacts (costs and benefits) of this technology. The topic of direct land application shows a high fraction of published articles on implementation issues. This can be explained by the fact that lab or bench scale process engineering research makes limited sense and most experiments and analysis have to be conducted on-field at a specific case study location. One overall argument that explains the comparatively low numbers of articles with type "implementation" is that this remains a blind spot for the research community where significant $\mathrm{R} \& \mathrm{D}$ is rather conducted by the private sector or involved enterprises. This information, given the competitive nature of the business then does not make its way into scientific journals.

\section{Conclusions and outlook}

A wide range of treatment technologies for solid biowaste already exist and have been extensively researched over the last decades. All these treatment technologies can convert organic waste into a variety of output products with more or less market value and ecological benefits. This review distinguishes four categories of technologies: (1) direct use, (2) biological treatment, (3) physico-chemical treatment, and (4) thermochemical treatment (Fig. 2) and highlights the expected biowaste derived products and their possible end-use. Each technology can handle a specific type of waste feedstock whereby some technologies are more restrictive in their requirements than others. Each technology can be described by relevant process steps and parameters to generate products with different properties.

Regarding feedstock requirements, a waste manager's perspective might consider those technologies that can treat the widest range of urban biowaste 
feedstock type and quality (i.e. one technology treats most waste), although investment and operational cost cannot be neglected. Another more entrepreneurial viewpoint, however, would be to focus on the value of products generated without necessarily prioritizing the overall contribution to waste management. A focus on the value and market demand of waste-derived products will tend to select a specific high quality waste feedstock. Accessing such specific waste types of high quality thus directs the attention to specific waste sourcing, in other words, a collaboration with waste generators (segregation at source) and a specific separate collection system. A comprehensive assessment of the available waste streams (quantities, characteristics, purity, etc.) in combination with a good overview of the different biowaste treatment technologies, the products they generate and how these fit into the local market demand, is thus key information for informed decision-making with regard to the most appropriate technology for the local context. The 'waste as a resource' paradigm has increasingly been adopted in the scientific arena, which for instance resulted in the incorporation of market-demand assessments for biowaste-derived end-products. Yet, also considering the by-products and their further use is necessary to foster a bioconversion approach with overall economic benefits. Combining different treatment technologies to an integrated system that makes best use of the products and sub-products is an interesting route to pursue. Yet, it adds complexity to the system understanding and also requires an extended set of interdisciplinary knowledge. This can be shown on the example of BSF waste treatment where waste is converted into protein for fish feed on one hand, biodiesel production from BSF larvae fat as fuel source, anaerobic digestion and production of biogas from the BSF residue, and use of this biogas to pre-treat waste (e.g. shredding) or postprocessing of the larvae (e.g. drying and pelletizing larvae meal). Such a more holistic biowaste valorization approach could be exemplary for the shift from linear to circular design thinking with diverse and farreaching benefits.

Technology readiness for a low- and middleincome setting is another important element. A systematic search on Scopus directed towards research on biowaste technologies that targets lowand middle-income settings shows substantial differences in the amount and type of research published over the last decade. This can be explained with the maturity of the technology and its readiness for implementation in practice. For new, complex or less mature technologies (e.g. BSF, pyrolysis, fermentation, liquefaction) analysis of the research type published, shows more focus on process engineering and lab-scale or bench-scale experiments. On the other hand, research on proven approaches (composting, anaerobic digestion) shows more research at scale, looking at case studies, economics or sustainability. Finally, research on "unscientific practices" (e.g. direct land application, densification, direct combustion) focuses more on the issues of environmental impacts. For all technologies, research from case studies and field research at scale seem disproportionately underrepresented, even when considering mature technologies which are already considered state-of-the-art, and would seem affordable even in low- and middle-income settings. One may argue that this underrepresentation reflects the main tasks of researchers-to conduct fundamental research to enhance basic process understanding whereas less research value is seen in practical implementation challenges. But this may also be the result of the waste sector traditionally being embedded in the discipline of engineering science thus directing research towards process engineering research questions. In view of improving waste management in low- and middle-income settings, more unbiased, well-structured and reproducible evidence from case studies at scale would clearly be desirable to foster sharing and transfer of knowledge to practitioners and also enhance the exchange and communication between academia, policy and practice. Research results on aspects of sustainability (incl. feasibility studies) are also important on the way to technology application and dissemination. As the broader context of technology application also involves consideration of waste sourcing, the value of research on municipal solid waste segregation at source should not be underestimated. It is considered key for effective recycling and to ensure high quality of the endproducts (Wilson 2015). What has been stated for the case of China by Zhang et al. (2010a) also applies to other low- and middle-income settings: The solid waste recycling sector not only needs further technology development, but also improved operating standards, product standards, and enhanced market development. 
Acknowledgements The authors wish to thank the Swiss Agency for Development and Cooperation (SDC) for their financial support. Alix Reichenecker is acknowledged for her preliminary work regarding trend analysis in solid waste management publications and Barbara Jeanne Ward for her comments on biowaste-to-energy technologies.

Open Access This article is distributed under the terms of the Creative Commons Attribution 4.0 International License (http:// creativecommons.org/licenses/by/4.0/), which permits unrestricted use, distribution, and reproduction in any medium, provided you give appropriate credit to the original author(s) and the source, provide a link to the Creative Commons license, and indicate if changes were made.

\section{References}

Aalok A, Tripathi AK, Soni P (2008) Vermicomposting: a better option for organic solid waste management. J Hum Ecol 24(1):59-64

Abdoulmoumine N, Adhikari S, Kulkarni A, Chattanathan S (2015) A review on biomass gasification syngas cleanup. Appl Energy 155:294-307

Adam JC (2009) Improved and more environmentally friendly charcoal production system using a low-cost retort-kiln (Eco-charcoal). Renew Energy 34(8):1923-1925

Adam JC (2013) Design, construction and emissions of a carbonization system including a hybrid retort to char Biomass [Dissertation]. University of Technology in Zvolen, Zvolen

Adam JC (2014) Die Verwendung von "low-cost" Retorten Technologien für die Verkohlung von Holz und anderer Biomasse am Beispiel von Bambus. In: Presentations of Biochar Workshop 2014, University of Applied Science, Bingen am Rhein, September 2014

Adhikary S (2012) Vermicompost, the story of organic gold: a review. Agric Sci 3(7):905-917

Ahmad R, Jilani G, Arshad M, Zahir ZA, Khalid A (2007) Bioconversion of organic wastes for their recycling in agriculture: an overview of perspectives and prospects. Ann Microbiol 57(4):471-479

Ahmad AA, Zawawi NA, Kasim FH, Inayat A, Khasri A (2016) Assessing the gasification performance of biomass: a review on biomass gasification process conditions, optimization and economic evaluation. Renew Sustain Energy Rev 53:1333-1347

Akhtar J, Amin NAS (2011) A review on process conditions for optimum bio-oil yield in hydrothermal liquefaction of biomass. Renew Sustain Energy Rev 15(3):1615-1624

Akhtar J, Amin NAS (2012) A review on operating parameters for optimum liquid oil yield in biomass pyrolysis. Renew Sustain Energy Rev 16(7):5101-5109

Alade OS, Betiku E (2014) Potential utilization of grass as solidfuel (briquette) in Nigeria. Energy Sources Part A Recovery Util Environ Effects 36(23):2519-2526

Ali U, Sajid N, Khalid A, Riaz L, Rabbani MM, Syed JH, Malik RN (2015) A review on vermicomposting of organic wastes. Environ Prog Sustain Energy 34(4):1050-1062
Almeida JRM, Fávaro LCL, Quirino BF (2012) Biodiesel biorefinery: opportunities and challenges for microbial production of fuels and chemicals from glycerol waste. Biotechnol Biofuels 5:48. doi:10.1186/1754-6834-5-48

Alouéimine S, Matejka G, Zurbrügg C, Sidi Mohamed M (2006) Caractérisation des ordures ménagères à NouakchottPartie Il: Résultats en saison sèche et en saison humide. Revue francophone d'écologie industrielle (44)

Alvarenga P, Palma P, Gonçalves AP, Fernandes RM, CunhaQueda AC, Duarte E, Vallini G (2007) Evaluation of chemical and ecotoxicological characteristics of biodegradable organic residues for application to agricultural land. Environ Int 33(4):505-513

Alvira P, Tomás-Pejó E, Ballesteros M, Negro MJ (2010) Pretreatment technologies for an efficient bioethanol production process based on enzymatic hydrolysis: a review. Bioresour Technol 101(13):4851-4861

Amigun B, Sigamoney R, von Blottnitz H (2008) Commercialisation of biofuel industry in Africa: a review. Renew Sustain Energy Rev 12(3):690-711

Angulo J, Mahecha L, Yepes SA, Yepes AM, Bustamante G, Jaramillo H, Valencia E, Villamil T, Gallo J (2012) Quantitative and nutritional characterization of fruit and vegetable waste from marketplace: a potential use as bovine feedstuff? J Environ Manag 95(Supplement):S203S209

Appels L, Lauwers J, Degrève J, Helsen L, Lievens B, Willems K, Van Impe J, Dewil R (2011) Anaerobic digestion in global bio-energy production: potential and research challenges. Renew Sustain Energy Rev 15(9):4295-4301

Arena U (2012) Process and technological aspects of municipal solid waste gasification. A review. Waste Manag 32(4):625-639

Arturi KR, Toft KR, Nielsen RP, Rosendahl LA, Søgaard EG (2016) Characterization of liquid products from hydrothermal liquefaction (HTL) of biomass via solidphase microextraction (SPME). Biomass Bioenergy 88:116-125

Astrup T, Møller J, Fruergaard T (2009) Incineration and cocombustion of waste: accounting of greenhouse gases and global warming contributions. Waste Manag Res 27(8):789-799

Babajide O, Petrik L, Ameer F (2015) Technologies for biodiesel production in Sub-Saharan African countries. Biofuels Status Perspect 39-57

Babel S, Vilaysouk X (2016) Greenhouse gas emissions from municipal solid waste management in Vientiane, Lao PDR. Waste Manag Res 34(1):30-37

Babu BV (2008) Biomass pyrolysis: a state-of-the-art review. Biofuels Bioprod Biorefin 2(5):393-414

Balat M (2009) Gasification of biomass to produce gaseous products. Energy Sources Part A Recovery Util Environ Eff 31(6):516-526

Balat M, Balat H (2009) Recent trends in global production and utilization of bio-ethanol fuel. Appl Energy 86(11): 2273-2282

Banks IJ, Gibson WT, Cameron MM (2014) Growth rates of black soldier fly larvae fed on fresh human faeces and their implication for improving sanitation. Trop Med Int Health 19(1):14-22 
Baruah D, Baruah DC (2014) Modeling of biomass gasification: a review. Renew Sustain Energy Rev 39:806-815

Baskar G, Aiswarya R (2016) Trends in catalytic production of biodiesel from various feedstocks. Renew Sustain Energy Rev 57:496-504

Basu P (ed) (2010) Chapter 5-gasification theory and modeling of gasifiers. In: Biomass gasification and pyrolysis. Academic Press, Boston, pp 117-165

Basu P (2013) Biomass gasification, pyrolysis and torrefaction. Academic Press, Boston

Behrendt F, Neubauer Y, Oevermann M, Wilmes B, Zobel N (2008) Direct liquefaction of biomass. Chem Eng Technol 31(5):667-677

Bensah EC, Kemausuor F, Miezah K, Kádár Z, Mensah M (2015) African perspective on cellulosic ethanol production. Renew Sustain Energy Rev 49:1-11

Bhuiya MMK, Rasul MG, Khan MMK, Ashwath N, Azad AK (2016a) Prospects of 2nd generation biodiesel as a sustainable fuel-part: 1 selection of feedstocks, oil extraction techniques and conversion technologies. Renew Sustain Energy Rev 55:1109-1128

Bhuiya MMK, Rasul MG, Khan MMK, Ashwath N, Azad AK, Hazrat MA (2016b) Prospects of 2nd generation biodiesel as a sustainable fuel-part 2: properties, performance and emission characteristics. Renew Sustain Energy Rev 55:1129-1146

Bhutto AW, Harijan K, Qureshi K, Bazmi AA, Bahadori A (2015) Perspectives for the production of ethanol from lignocellulosic feedstock - a case study. J Clean Prod 95:184-193

Biomass Technology Group (2013) Alternative Charcoal Tool (ACT). http://www.btgworld.com/en/references/publications/ alternative-charcoal-tool. Last accessed 2 Feb 2017

Board N (2004) The complete technology book on vermiculture and vermicompost. National Institute of Industrial Research, New Delhi

Bogner J, Pipatti R, Hashimoto S, Diaz C, Mareckova K, Diaz L, Kjeldsen P, Monni S, Faaij A, Qingxian G et al (2008) Mitigation of global greenhouse gas emissions from waste: conclusions and strategies from the Intergovernmental Panel on Climate Change (IPCC) Fourth Assessment Report. Working Group III (Mitigation). Waste Manag Res 26(1):11-32

Bond T, Templeton MR (2011) History and future of domestic biogas plants in the developing world. Energy Sustain Dev 15(4):347-354

Bond TC, Doherty SJ, Fahey DW, Forster PM, Berntsen T, DeAngelo BJ, Flanner MG, Ghan S, Kärcher B, Koch D et al (2013) Bounding the role of black carbon in the climate system: a scientific assessment. J Geophys Res Atmos 118(11):5380-5552

Bouallagui H, Touhami Y, Ben Cheikh R, Hamdi M (2005) Bioreactor performance in anaerobic digestion of fruit and vegetable wastes. Process Biochem 40(3-4):989995

Bouallagui H, Lahdheb H, Ben Romdan E, Rachdi B, Hamdi M (2009) Improvement of fruit and vegetable waste anaerobic digestion performance and stability with co-substrates addition. J Environ Manag 90(5):1844-1849

Bradley GH (1930) Hermetia illucens L. A pest in sanitary privies in Louisiana. J Econ Entomol 23:1012-1013
Bridgwater AV (1999) Principles and practice of biomass fast pyrolysis processes for liquids. J Appl Pyrol 51(1):3-22

Bridgwater A (2013) 7-fast pyrolysis of biomass for the production of liquids A2-Rosendahl, Lasse. Biomass Combustion Science, Technology and Engineering, Woodhead Publishing, pp 130-171

Brinton WF, Evans E (2001) How compost maturity affects container grown plants. Biocycle 42(1):56-60

Brown D, Li Y (2013) Solid state anaerobic co-digestion of yard waste and food waste for biogas production. Bioresour Technol 127:275-280

Brown D, Shi J, Li Y (2012) Comparison of solid-state to liquid anaerobic digestion of lignocellulosic feedstocks for biogas production. Bioresour Technol 124:379-386

Bruce N, Pope D, Rehfuess E, Balakrishnan K, Adair-Rohani H, Dora C (2015) WHO indoor air quality guidelines on household fuel combustion: strategy implications of new evidence on interventions and exposure-risk functions. Atmos Environ 106:451-457

Buragohain B, Mahanta P, Moholkar VS (2010) Biomass gasification for decentralized power generation: the Indian perspective. Renew Sustain Energy Rev 14(1):73-92

Burhenne L, Messmer J, Aicher T, Laborie M-P (2013) The effect of the biomass components lignin, cellulose and hemicellulose on TGA and fixed bed pyrolysis. J Anal Appl Pyrol 101:177-184

Canakci M (2007) The potential of restaurant waste lipids as biodiesel feedstocks. Bioresour Technol 98(1):183-190

Carone MT, Pantaleo A, Pellerano A (2011) Influence of process parameters and biomass characteristics on the durability of pellets from the pruning residues of Olea europaea L. Biomass Bioenergy 35(1):402-410

Cecchi F, Cavinato C (2015) Anaerobic digestion of bio-waste: a mini-review focusing on territorial and environmental aspects. Waste Manag Res 33(5):429-438

Cecchi F, Traverso P, Pavan P, Bolzonella D, Innocenti L (2003) Characteristics of the OFMSW and behavious of the anaerobic digestion process. In: Mata-Alvarez J (ed) Biomethanization of the organic fraction of municipal solid wastes. IWA Publishing, Cornwall, pp 141-178

Chen H, Fu X (2016) Industrial technologies for bioethanol production from lignocellulosic biomass. Renew Sustain Energy Rev 57:468-478

Chen Y, Cheng JJ, Creamer KS (2008) Inhibition of anaerobic digestion process: a review. Bioresour Technol 99(10):4044-4064

Chen L, Xing L, Han L (2009) Renewable energy from agroresidues in China: solid biofuels and biomass briquetting technology. Renew Sustain Energy Rev 13(9):2689-2695

Chen D, Yin L, Wang H, He P (2015) Reprint of: pyrolysis technologies for municipal solid waste: a review. Waste Manag 37:116-136

Cheng JYK, Lo IMC (2016) Investigation of the available technologies and their feasibility for the conversion of food waste into fish feed in Hong Kong. Environ Sci Pollut Res 23(8):7169-7177

Cheng Z, Mo W-Y, Man Y-B, Nie X-P, Li K-B, Wong M-H (2014) Replacing fish meal by food waste in feed pellets to culture lower trophic level fish containing acceptable levels of organochlorine pesticides: health risk assessments. Environ Int 73:22-27 
Cheng Z, Mo WY, Lam CL, Choi WM, Wong MH (2015a) Replacing fish meal by food waste to produce lower trophic level fish containing acceptable levels of polycyclic aromatic hydrocarbons: health risk assessments. Sci Total Environ 523:253-261

Cheng Z, Mo WY, Man YB, Lam CL, Choi WM, Nie XP, Liu YH, Wong MH (2015b) Environmental mercury concentrations in cultured low-trophic-level fish using food wastebased diets. Environ Sci Pollut Res Int 22(1):495-507

Cheng Z, Lam C-L, Mo W-Y, Nie X-P, Choi W-M, Man Y-B, Wong M-H (2016a) Food wastes as fish feeds for polyculture of low-trophic-level fish: bioaccumulation and health risk assessments of heavy metals in the cultured fish. Environ Sci Pollut Res 23(8):7195-7203

Cheng Z, Mo W-Y, Nie X-P, Li K-B, Choi W-M, Man Y-B, Wong M-H (2016b) The use of food waste-based diets and Napier grass to culture grass carp: growth performance and contaminants contained in cultured fish. Environ Sci Pollut Res 23(8):7204-7210

Chin OC, Siddiqui KM (2000) Characteristics of some biomass briquettes prepared under modest die pressures. Biomass Bioenergy 18(3):223-228

Christy G, Tjandrawinata RR, Rachmawati H (2015) Tabletting process of pellets containing bioactive fraction DLBS1033F isolated from Lumbricus rubellus: challenge and strategy. Biol Pharm Bull 38(12):1843-1849

Čičková H, Newton GL, Lacy RC, Kozánek M (2015) The use of fly larvae for organic waste treatment. Waste Manag 35:68-80

Ciolkosz D, Wallace R (2011) A review of torrefaction for bioenergy feedstock production. Biofuels Bioprod Biorefin 5(3):317-329

Coffin D (2013) Space planning for small, multipurpose livestock barns. Bulletin 1021, University of Maine, Orono

Collard F-X, Blin J (2014) A review on pyrolysis of biomass constituents: mechanisms and composition of the products obtained from the conversion of cellulose, hemicelluloses and lignin. Renew Sustain Energy Rev 38:594-608

Cooperband L (2002) The art and science of composting - a resource for farmers and compost producers. Center for Integrated Agricultural Systems, University of Wisconsin, Madison

Couth R, Trois C (2012) Cost effective waste management through composting in Africa. Waste Manag 32(12):2518-2525

Couto N, Silva V, Monteiro E, Teixeira S, Chacartegui R, Bouziane K, Brito PSD, Rouboa A (2015) Numerical and experimental analysis of municipal solid wastes gasification process. Appl Therm Eng 78:185-195

Cui HM, Wu P, Ma YH, ChuanZhong X (2014) Review and prospective challences on biomass densification technologies and processes. Int Agric Eng J 23(1):30-38

Darwin C (1881) The formation of vegetable mould through the action of worms, with observations on their habitats. Murray, London

Dedinec A, Markovska N, Ristovski I, Velevski G, Gjorgjievska VT, Grncarovska TO, Zdraveva P (2015) Economic and environmental evaluation of climate change mitigation measures in the waste sector of developing countries. J Clean Prod 88:234-241
Demirbaş A (2000) Mechanisms of liquefaction and pyrolysis reactions of biomass. Energy Convers Manag 41(6):633-646

Demirbas A, Sahin-Demirbas A (2004) Briquetting properties of biomass waste materials. Energy Sources 26(1):83-91

Deublein D, Steinhasuer A (2009) Biogas from waste and renewable resources. Wiley-VCH Verlag, Weinheim

Di Lonardo MC, Lombardi F, Gavasci R (2012) Characterization of MBT plants input and outputs: a review. Rev Environ Sci Bio/Technol 11(4):353-363

Diaz LF, de Bertoldi M (2007) Chapter 2 History of composting. In: Diaz LF, De Bertoldi M, Stentiford E (eds) Waste management series. Elsevier, Amsterdam, pp 7-24

Diener S, Zurbrügg C, Tockner K (2009) Conversion of organic material by black soldier fly larvae-establishing optimal feeding rates. Waste Manag Res 27:603-610

Diener S, Studt Solano NM, Roa Gutiérrez F, Zurbrugg C, Tockner K (2011) Biological treatment of municipal organic waste using black soldier fly larvae. Waste Biomass Valoriz 2(4):357-363

Diener S, Zurbrügg C, Tockner K (2015) Bioaccumulation of heavy metals in the black soldier fly, Hermetia illucens and effects on its life cycle. J Insects Food Feed 1(4):261-270

Doassans-Carrère N, Ferrasse J-H, Boutin O, Mauviel G, Lédé J (2014) Comparative study of biomass fast pyrolysis and direct liquefaction for bio-oils production: products yield and characterizations. Energy Fuels 28(8):5103-5111

Duku MH, Gu S, Hagan EB (2011) Biochar production potential in Ghana-a review. Renew Sustain Energy Rev 15(8):3539-3551

Dulac N (2001) The organic waste flow in integrated sustainable waste management. Integrated Sustainable Waste Management: a set of five tools for decision-makers. WASTE, Gouda

Dunn LH (1916) Hermetia illucens breeding in a human cadaver (Dipt.). Entomol News 17(2):59-61

Edelmann W, Engeli H (2015) The arbi plug-flow digester in Tanzania-a medium size biogas plant for developing countries. Final Report, Repic, NET. St. Ursen, p 73

Edwards CA (ed) (1998) The use of earthworms in the breakdown and management of organic wastes. In: Earthworm ecology. CRC Press, Boco Roton, pp 327-354

EFSA Scientific Committee (2015) Risk profile related to production and consumption of insects as food and feed. EFSA J 13(10):4257

Elliott DC (2011) Hydrothermal processing. In: Brown RC (ed) Thermochemical processing of biomass: conversion into fuels, chemicals and power. Wiley, Chichester. doi:10. 1002/9781119990840.ch7

Elliott DC, Biller P, Ross AB, Schmidt AJ, Jones SB (2015) Hydrothermal liquefaction of biomass: developments from batch to continuous process. Bioresour Technol 178:147-156

Ennis CJ, Evans AG, Islam M, Ralebitso-Senior TK, Senior E (2012) Biochar: carbon sequestration, land remediation, and impacts on soil microbiology. Crit Rev Environ Sci Technol 42(22):2311-2364

EPA (2004) Landspreading of organic waste-guidance on groundwater vulnerability assessment of land. Environmental Protection Agency, Johnstown Castle Estate, p 57 
Epstein E (1997) The science of composting. CRC Press, Boca Raton

Eseyin AE, Steele PH, Pittman CU Jr (2015) Current trends in the production and applications of torrefied wood/biomass-a review. BioResources 10(4):8812-8858

Esposito G, Frunzo L, Giordano A, Liotta F, Panico A, Pirozzi F (2012) Anaerobic co-digestion of organic wastes. Rev Environ Sci Biotechnol 11(4):325-341

Esteban MB, García AJ, Ramos P, Márquez MC (2007) Evaluation of fruit-vegetable and fish wastes as alternative feedstuffs in pig diets. Waste Manag 27(2):193-200

Estrellan CR, Iino F (2010) Toxic emissions from open burning. Chemosphere 80(3):193-207

EU (1994) Food safety: from the farm to the fork. Food: European Commission. p Decision 94/381 327 June 1994 (feed ban)

Fang X, Shen Y, Zhao J, Bao X, Qu Y (2010) Status and prospect of lignocellulosic bioethanol production in China. Bioresour Technol 101(13):4814-4819

FAO (2003) World agriculture: towards 2015/2030. An FAO perspective. Earthscan Publications Ltd, London

FAO (2011) World Livestock 2011-Livestock in food security. Food and Agriculture Organization of the United Nations, Rome

FAO (2016) Food Outlook-biannual report on global food markets. Food and Agriculture Organization of the United Nations, Rome

Farrell M, Jones DL (2009) Critical evaluation of municipal solid waste composting and potential compost markets. Bioresour Technol 100(19):4301-4310

Felfli FF, Mesa PJM, Rocha JD, Filippetto D, Luengo CA, Pippo WA (2011) Biomass briquetting and its perspectives in Brazil. Biomass Bioenergy 35(1):236-242

Ferguson H (2012) Briquette businesses in Uganda. GVEP International, London

Fodor Z, Klemeš JJ (2012) Waste as alternative fuel-minimising emissions and effluents by advanced design. Process Saf Environ Prot 90(3):263-284

Forbid GT, Ghogomu JN, Busch G, Frey R (2011) Open waste burning in Cameroonian cities: an environmental impact analysis. Environmentalist 31(3):254-262

Friedrich E, Trois C (2011) Quantification of greenhouse gas emissions from waste management processes for municipalities - a comparative review focusing on Africa. Waste Manag 31(7):1585-1596

Froetschel MA, Ross CL, Stewart RL Jr, Azain MJ, Michot P, Rekaya R (2014) Nutritional value of ensiled grocery food waste for cattle. J Anim Sci 92(11):5124-5133

Funke A, Ziegler F (2010) Hydrothermal carbonization of biomass: a summary and discussion of chemical mechanisms for process engineering. Biofuels Bioprod Biorefin 4(2):160-177

Furman DP, Young RD, Catts EP (1959) Hermetia illucens (Linnaeus) as a factor in the natural control of Musca domestica Linnaeus. J Econ Entomol 52(5):917-921

Garg P, Gupta A, Satya S (2006) Vermicomposting of different types of waste using Eisenia foetida: a comparative study. Bioresour Technol 97(3):391-395

Garg VK, Suthar S, Yadav A (2012) Management of food industry waste employing vermicomposting technology. Bioresour Technol 126:437-443
Ge X, Matsumoto T, Keith L, Li Y (2014) Biogas energy production from tropical biomass wastes by anaerobic digestion. Bioresour Technol 169:38-44

Gendebien A, Ferguson R, Brink J, Horth H, Sullivan M, Davis R, Brunet H, Dalimier F, Landrea B, Krack D, Perot J, Orsi C (2001) Survey of wastes spread on land. European Communities, Luxembourg

Gerber PJ, Steinfeld H, Henderson B, Mottet A, Opio C, Dijkman J, Falcucci A, Tempio G (2013) Tackling climate change through livestock-a global assessment of emissions and mitigation opportunities. Food and Agriculture Organization of the United Nations (FAO), Rome

Gerpen JV (2005) Biodiesel processing and production. Fuel Process Technol 86(10):1097-1107

Ghisellini P, Cialani C, Ulgiati S (2016) A review on circular economy: the expected transition to a balanced interplay of environmental and economic systems. J Clean Prod $114: 11-32$

Gilbert J (2015) Circular economy: carbon, nutrients and soil. Task Force Report 4. ISWA task force on resource management. International Solid Waste Association (ISWA), Vienna

Gollakota ARK, Reddy M, Subramanyam MD, Kishore N (2016) A review on the upgradation techniques of pyrolysis oil. Renew Sustain Energy Rev 58:1543-1568

Goodarzi G, Qujeq D, Elmi MM, Feizi F, Fathai S (2016) The effect of the glycolipoprotein extract (G-90) from earthworm Eisenia foetida on the wound healing process in alloxan-induced diabetic rats. Cell Biochem Funct 34(4):242-249

Groot L, Bogdanski A (2013) Bioslurry = Brown Gold? A review of scientific literature on the co-product of biogas production. FAO, Food and Agriculture Organization of the United Nations, Rome

Grover PD, Mishra SK (1996) Biomass briquetting: technology and practices. Food and Agriculture Organization (FAO) of the United Nations, Bangkok, p 48

Guerrero LA, Maas G, Hogland W (2013) Solid waste management challenges for cities in developing countries. Waste Manag 33(1):220-232

Gunaseelan VN (2004) Biochemical methane potential of fruits and vegetable solid waste feedstocks. Biomass Bioenergy 26(4):389-399

Guo M, Song W, Buhain J (2015) Bioenergy and biofuels: history, status, and perspective. Renew Sustain Energy Rev 42:712-725

Gupta R, Garg VK (2011) Potential and possibilities of vermicomposting in sustainable solid waste management: a review. Int J Environ Waste Manage 7(3-4):210-234

Gupta A, Verma JP (2015) Sustainable bio-ethanol production from agro-residues: a review. Renew Sustain Energy Rev 41:550-567

GVEP (2010) Kenya briquette industry study. GVEP International, London

Gwenzi W, Chaukura N, Mukome FND, Machado S, Nyamasoka B (2015) Biochar production and applications in subSaharan Africa: opportunities, constraints, risks and uncertainties. J Environ Manag 150:250-261

Hahn-Hägerdal B, Galbe M, Gorwa-Grauslund MF, Lidén G, Zacchi G (2006) Bio-ethanol-the fuel of tomorrow from the residues of today. Trends Biotechnol 24(12):549-556 
Han J, Kim H (2008) The reduction and control technology of tar during biomass gasification/pyrolysis: an overview. Renew Sustain Energy Rev 12(2):397-416

Hartmann H, Ahring BK (2006) Strategies for the anaerobic digestion of the organic fraction of municipal solid waste: an overview. Water Sci Technol 53(8):7-22

Hashisho J, El-Fadel M (2014) Determinants of optimal aerobic bioreactor landfilling for the treatment of the organic fraction of municipal waste. Crit Rev Environ Sci Technol 44(16):1865-1891

Haug RT (1993) The practical handbook of compost engineering. Lewis Rublishers, Washington

Hegberg BA, Brenniman GR, Hallenberck WH, Wadden RA (1990) Landspreading yard waste. BioCycle 31(12): $60-62$

Heidenreich S, Foscolo PU (2015) New concepts in biomass gasification. Prog Energy Combust Sci 46:72-95

Hershey DR (1992) Sir Albert Howard and the Indore process. HortTechnology 2(2):267-269

Hoornweg D, Bhada-Tata P (2012) What a waste-a global review of solid waste management. Urban Development \& Local Government Unit, World Bank, Washington

Howard A (1935) The manufacture of humus by the Indore process. J R Soc Arts 84(25):26-59

Hutňan M, Kolesárová N, Bodík I (2013) Anaerobic digestion of crude glycerol as sole substrate in mixed reactor. Environ Technol (UK) 34(13-14):2179-2187

Insam H, de Bertoldi M (2007) Chapter 3 Microbiology of the composting process. In: Diaz LF, De Bertoldi M, Stentiford E (eds) Waste management series. Elsevier, Amsterdam, pp 25-48

Inyang M, Dickenson E (2015) The potential role of biochar in the removal of organic and microbial contaminants from potable and reuse water: a review. Chemosphere 134:232-240

Isahak WNRW, Hisham MWM, Yarmo MA, T-y Yun Hin (2012) A review on bio-oil production from biomass by using pyrolysis method. Renew Sustain Energy Rev 16(8):5910-5923

Jacobson K, Maheria KC, Kumar Dalai A (2013) Bio-oil valorization: a review. Renew Sustain Energy Rev 23:91-106

Jahirul M, Rasul M, Chowdhury A, Ashwath N (2012) Biofuels production through biomass pyrolysis - a technological review. Energies 5(12):4952

Jain K, Singh J, Chauhan LKS, Murthy RC, Gupta SK (2004) Modulation of flyash-induced genotoxicity in Vicia faba by vermicomposting. Ecotoxicol Environ Saf 59(1):89-94

Jain S, Jain S, Wolf IT, Lee J, Tong YW (2015) A comprehensive review on operating parameters and different pretreatment methodologies for anaerobic digestion of municipal solid waste. Renew Sustain Energy Rev 52:142-154

Jetter J, Zhao Y, Smith KR, Khan B, Yelverton T, DeCarlo P, Hays MD (2012) Pollutant emissions and energy efficiency under controlled conditions for household biomass cookstoves and implications for metrics useful in setting international test standards. Environ Sci Technol 46(19):10827-10834

Jimenez J, Latrille E, Harmand J, Robles A, Ferrer J, Gaida D, Wolf C, Mairet F, Bernard O, Alcaraz-Gonzalez V et al (2015) Instrumentation and control of anaerobic digestion processes: a review and some research challenges. Rev Environ Sci Bio/Technol 14(4):615-648

Kaliyan N, Morey RV (2010) Natural binders and solid bridge type binding mechanisms in briquettes and pellets made from corn stover and switchgrass. Bioresour Technol 101(3):1082-1090

Kambo HS, Dutta A (2015) A comparative review of biochar and hydrochar in terms of production, physico-chemical properties and applications. Renew Sustain Energy Rev 45:359-378

Kan T, Strezov V, Evans TJ (2016) Lignocellulosic biomass pyrolysis: a review of product properties and effects of pyrolysis parameters. Renew Sustain Energy Rev 57:1126-1140

Karagiannidis A, Theodoseli M, Malamakis A, Bilitewski B, Reichenbach J, Nguyen T, Galang A, Parayno P (2010) Decentralized aerobic composting of urban solid wastes: some lessons learned from ASIAN-EU cooperative research. Glob Nest J 12(4):343-351

Karak T, Bhagat RM, Bhattacharyya P (2012) Municipal solid waste generation, composition, and management: the world scenario. Crit Rev Environ Sci Technol 42(15):1509-1630

Karkania V, Fanara E, Zabaniotou A (2012) Review of sustainable biomass pellets production-a study for agricultural residues pellets' market in Greece. Renew Sustain Energy Rev 16(3):1426-1436

Khalid A, Arshad M, Anjum M, Mahmood T, Dawson L (2011) The anaerobic digestion of solid organic waste. Waste Manag 31(8):1737-1744

Kinet R, Destain J, Hiligsmann S, Thonart P, Delhalle L, Taminiau B, Daube G, Delvigne F (2015) Thermophilic and cellulolytic consortium isolated from composting plants improves anaerobic digestion of cellulosic biomass: toward a microbial resource management approach. Bioresour Technol 189:138-144

Kirkels AF, Verbong GPJ (2011) Biomass gasification: still promising? A 30-year global overview. Renew Sustain Energy Rev 15(1):471-481

Kleerebezem R, Joosse B, Rozendal R, Van Loosdrecht MCM (2015) Anaerobic digestion without biogas? Rev Environ Sci Bio/Technol 14(4):787-801

Knothe G, Krahl J, Van Gerpen J (2010) The biodiesel handbook. AOCS Press, Urbana

Kothari R, Pandey AK, Kumar S, Tyagi VV, Tyagi SK (2014) Different aspects of dry anaerobic digestion for bio-energy: an overview. Renew Sustain Energy Rev 39:174-195

Krishania M, Kumar V, Vijay VK, Malik A (2013) Analysis of different techniques used for improvement of biomethanation process: a review. Fuel 106:1-9

Kumar A (2005) Verms \& vermitechnology. APH Publishing, New Delhi

Kumar A, Jones D, Hanna M (2009a) Thermochemical biomass gasification: a review of the current status of the technology. Energies 2(3):556

Kumar S, Singh SP, Mishra IM, Adhikari DK (2009b) Recent advances in production of bioethanol from lignocellulosic biomass. Chem Eng Technol 32(4):517-526

Kwak WS, Kang JS (2006) Effect of feeding food waste-broiler litter and bakery by-product mixture to pigs. Bioresour Technol 97(2):243-249 
Lalander C, Diener S, Magri ME, Zurbrugg C, Lindstrom A, Vinneras B (2013) Faecal sludge management with the larvae of the black soldier fly (Hermetia illucens) — from a hygiene aspect. Sci Total Environ 458-460C:312-318

Lalander $\mathrm{CH}$, Fidjeland J, Diener S, Eriksson S, Vinnerås B (2014) High waste-to-biomass conversion and efficient Salmonella spp. reduction using black soldier fly for waste recycling. Agron Sustain Dev 35(1):261-271

Lalander CH, Komakech AJ, Vinnerås B (2015) Vermicomposting as manure management strategy for urban smallholder animal farms - Kampala case study. Waste Manag 39:96-103

Lalander C, Senecal J, Gros Calvo M, Ahrens L, Josefsson S, Wiberg K, Vinnerås B (2016) Fate of pharmaceuticals and pesticides in fly larvae composting. Sci Total Environ 565:279-286

Lardinois I, van De Klundert A (1993) Organic waste—options for small-scale resource recovery. TOOL, Amsterdam and WASTE Consultants, Gouda

Larsen AC, Gomes BM, Gomes SD, Zenatti DC, Torres DGB (2013) Anaerobic co-digestion of crude glycerin and starch industry effluent. Engenharia Agricola 33(2):341-352

Lauwers J, Appels L, Thompson IP, Degrève J, Van Impe JF, Dewil R (2013) Mathematical modelling of anaerobic digestion of biomass and waste: power and limitations. Prog Energy Combust Sci 39(4):383-402

Lee CM, Lee YS, Seo SH, Yoon SH, Kim SJ, Hahn BS, Sim JS, Koo BS (2014) Screening and characterization of a novel cellulase gene from the gut microflora of Hermetia illucens using metagenomic library. J Microbiol Biotechnol 24(9):1196-1206

Lee A, Lewis D, Kalaitzidis T, Ashman P (2016) Technical issues in the large-scale hydrothermal liquefaction of microalgal biomass to biocrude. Curr Opin Biotechnol 38:85-89

Lehmann J, Rillig MC, Thies J, Masiello CA, Hockaday WC, Crowley D (2011) Biochar effects on soil biota-a review. Soil Biol Biochem 43(9):1812-1836

Leoneti AB, Aragão-Leoneti V, de Oliveira SVWB (2012) Glycerol as a by-product of biodiesel production in Brazil: alternatives for the use of unrefined glycerol. Renew Energy 45:138-145

Leong SY, Kutty SRM, Tan CK, Tey LH (2015) Comparative study on the effect of organic waste on lauric acid produced by Hermetia illucens larvae via bioconversion. J Eng Sci Technol 10: Spec. Issue on Advances in Civil and Environmental Engineering ACEE 2015, pp 52-63

Li Y, Liu H (2000) High-pressure densification of wood residues to form an upgraded fuel. Biomass Bioenergy 19(3):177-186

Li Q, Zheng L, Cai H, Garza E, Yu Z, Zhou S (2011a) From organic waste to biodiesel: black soldier fly, Hermetia illucens, makes it feasible. Fuel 90:1545-1548

Li Q, Zheng L, Qiu N, Cai H, Tomberlin JK, Yu Z (2011b) Bioconversion of dairy manure by black soldier fly (Diptera: Stratiomyidae) for biodiesel and sugar production. Waste Manag 31(6):1316-1320

Li Y, Park SY, Zhu J (2011c) Solid-state anaerobic digestion for methane production from organic waste. Renew Sustain Energy Rev 15(1):821-826
Li C, Lesnik K, Liu H (2013) Microbial conversion of waste glycerol from biodiesel production into value-added products. Energies 6(9):4739

Libra JA, Ro KS, Kammann C, Funke A, Berge ND, Neubauer Y, Titirici MM, Fühner C, Bens O, Kern J et al (2011) Hydrothermal carbonization of biomass residuals: a comparative review of the chemistry, processes and applications of wet and dry pyrolysis. Biofuels 2(1):71-106

Liguori R, Amore A, Faraco V (2013) Waste valorization by biotechnological conversion into added value products. Appl Microbiol Biotechnol 97(14):6129-6147

Lim SL, Lee LH, Wu TY (2016) Sustainability of using composting and vermicomposting technologies for organic solid waste biotransformation: recent overview, greenhouse gases emissions and economic analysis. J Clean Prod 111(Part A):262-278

Lindeboom REF, Weijma J, van Lier JB (2012) High-calorific biogas production by selective $\mathrm{CO}_{2}$ retention at autogenerated biogas pressures up to 20 bar. Environ Sci Technol 46(3):1895-1902

Liu X, Jensen PR, Workman M (2012) Bioconversion of crude glycerol feedstocks into ethanol by Pachysolen tannophilus. Bioresour Technol 104:579-586

Liu Z, Quek A, Balasubramanian R (2014) Preparation and characterization of fuel pellets from woody biomass, agroresidues and their corresponding hydrochars. Appl Energy 113:1315-1322

Lohri CR, Rodić L, Zurbrügg C (2013) Feasibility assessment tool for urban anaerobic digestion in developing countries. J Environ Manage 126:122-131

Lohri CR, Camenzind EJ, Zurbrügg C (2014) Financial sustainability in municipal solid waste management-costs and revenues in Bahir Dar, Ethiopia. Waste Manag 34(2):542-552

Lohri CR, Faraji A, Ephata E, Rajabu HM, Zurbrügg C (2015) Urban biowaste for solid fuel production: waste suitability assessment and experimental carbonization in Dar es Salaam, Tanzania. Waste Manag Res 33(2):175-182

Lohri CR, Rajabu HM, Sweeney DJ, Zurbrügg C (2016) Char fuel production in developing countries - a review of urban biowaste carbonization. Renew Sustain Energy Rev 59:1514-1530

Mahmud A, Mehmood S, Hussain J, Ahmad S (2015) Composting of poultry dead birds and litter. World's Poult Sci J 71(04):621-629

Makádi M, Tomócsik A, Orosz V (2012) Chapter 14: digestate: a new nutrient source-review. In: Kumar S (ed) Biogas. InTech, Rijeka. doi:10.5772/31355

Makkar HPS, Tran G, Heuzé V, Ankers P (2014) State-of-theart on use of insects as animal feed. Anim Feed Sci Technol 197:1-33

Manickam IN, Ravindran D, Subramanian P (2006) Biomass densification methods and mechanism. Cogener Distrib Gener J 21(4):33-45

Manyà JJ (2012) Pyrolysis for biochar purposes: a review to establish current knowledge gaps and research needs. Environ Sci Technol 46(15):7939-7954

Mao C, Feng Y, Wang X, Ren G (2015) Review on research achievements of biogas from anaerobic digestion. Renew Sustain Energy Rev 45:540-555 
Márquez MA, Diánez F, Camacho F (2011) The use of vegetable subproducts from greenhouses (VSG) for animal feed in the Poniente region of Almería. Renew Agric Food Syst 26(1):4-12

Marshall RE, Farahbakhsh K (2013) Systems approaches to integrated solid waste management in developing countries. Waste Manag 33(4):988-1003

Mata-Alvarez JE (2003) Biomethanization of the organic fraction of municipal solid wastes. IWA Publishing, Cornwall

Mata-Alvarez J, Dosta J, Romero-Güiza MS, Fonoll X, Peces M, Astals S (2014) A critical review on anaerobic co-digestion achievements between 2010 and 2013. Renew Sustain Energy Rev 36:412-427

Meher LC, Vidya Sagar D, Naik SN (2006) Technical aspects of biodiesel production by transesterification-a review. Renew Sustain Energy Rev 10(3):248-268

Mettler MS, Vlachos DG, Dauenhauer PJ (2012) Top ten fundamental challenges of biomass pyrolysis for biofuels. Energy Environ Sci 5(7):7797-7809

Meyer S, Glaser B, Quicker P (2011) Technical, economical, and climate-related aspects of biochar production technologies: a literature review. Environ Sci Technol 45(22):9473-9483

Minowa T, Kondo T, Sudirjo ST (1998) Thermochemical liquefaction of indonesian biomass residues. Biomass Bioenergy 14(5-6):517-524

Mo WY, Cheng Z, Choi WM, Man YB, Liu Y, Wong MH (2014) Application of food waste based diets in polyculture of low trophic level fish: effects on fish growth, water quality and plankton density. Mar Pollut Bull 85(2):803-809

Mo WY, Cheng Z, Choi WM, Lun CHI, Man YB, Wong JTF, Chen XW, Lau SCK, Wong MH (2015) Use of food waste as fish feeds: effects of prebiotic fibers (inulin and mannanoligosaccharide) on growth and non-specific immunity of grass carp (Ctenopharyngodon idella). Environ Sci Pollut Res 22(22):17663-17671

Mohan D, Pittman CU, Steele PH (2006) Pyrolysis of wood/ biomass for bio-oil: a critical review. Energy Fuels 20(3):848-889

Mohan D, Sarswat A, Ok YS, Pittman CU Jr (2014) Organic and inorganic contaminants removal from water with biochar, a renewable, low cost and sustainable adsorbent-a critical review. Bioresour Technol 160:191-202

Molino A, Chianese S, Musmarra D (2016) Biomass gasification technology: the state of the art overview. J Energy Chem 25(1):10-25

Möller K, Müller T (2012) Effects of anaerobic digestion on digestate nutrient availability and crop growth: a review. Eng Life Sci 12(3):242-257

Moon S-K, Wee Y-J, Choi G-W (2014) Utilization of byproducts derived from bioethanol production process for cost-effective production of lactic acid. J Ind Microbiol Biotechnol 41(10):1525-1531

Moqsud MA, Yoshitake J, Bushra QS, Hyodo M, Omine K, Strik D (2015) Compost in plant microbial fuel cell for bioelectricity generation. Waste Manag 36:63-69

Murugan S, Gu S (2015) Research and development activities in pyrolysis-contributions from Indian scientific community-a review. Renew Sustain Energy Rev 46:282-295
Mussatto SI, Dragone G, Guimarães PMR, Silva JPA, Carneiro LM, Roberto IC, Vicente A, Domingues L, Teixeira JA (2010) Technological trends, global market, and challenges of bio-ethanol production. Biotechnol Adv 28(6):817-830

Mwampamba TH, Owen M, Pigaht M (2013) Opportunities, challenges and way forward for the charcoal briquette industry in Sub-Saharan Africa. Energy Sustain Dev 17(2): $158-170$

Myers HM, Tomberlin JK, Lambert BD, Kattes D (2008) Development of black soldier fly (Diptera: Stratiomyidae) larvae fed dairy manure. Environ Entomol 37(1):11-15

Nagpure AS, Ramaswami A, Russell A (2015) Characterizing the spatial and temporal patterns of open burning of municipal solid waste (MSW) in Indian cities. Environ Sci Technol 49(21):12911-12912

Nanda S, Dalai AK, Berruti F, Kozinski JA (2016) Biochar as an exceptional bioresource for energy, agronomy, carbon sequestration, activated carbon and specialty materials. Waste Biomass Valoriz 7(2):201-235

Ndegwa PM, Thompson SA, Das KC (2000) Effects of stocking density and feeding rate on vermicomposting of biosolids. Bioresour Technol 71(1):5-12

Newton GL, Sheppard DC, Thomson SA, Savage SI (1995) The soldier fly, a beneficial insect: house fly control, manure volume reduction and nutrient recycling. In: Van Horn $\mathrm{HH}$ (ed) Nuisance concerns in animal manure management: odors and flies, proceedings of conference, March 21-22 1995. University of Florida, Gainesville, pp 106-116

Newton GL, Sheppard DC, Watson DW, Burtle GJ, Dove CR, Tomberlin JK, Thelen EE (2005) The black soldier fly, Hermetia illucens, as a manure management/resource recovery tool. In: Nowak P (ed) Symposium on the state of the science of animal manure and waste management, San Antonio, Texas

Nguyen TTX, Tomberlin JK, Vanlaerhoven S (2015) Ability of black soldier fly (Diptera: Stratiomyidae) larvae to recycle food waste. Environ Entomol 44(2):406-410

Nigam PS, Singh A (2011) Production of liquid biofuels from renewable resources. Prog Energy Combust Sci 37(1):52-68

Njenga M, Karanja N, Prain G, Malii J, Munyao P, Gathuru K, Mwasi B (2009) Community-based energy briquette production from urban organic waste at Kahawa Soweto informal settlement, Nairobi. Urban Harvest Working Paper Series, No 5. International Potato Center, Lima, p 26

Nunes LJR, Matias JCO, Catalão JPS (2014) Mixed biomass pellets for thermal energy production: a review of combustion models. Appl Energy 127:135-140

Nzila C, Dewulf J, Spanjers H, Tuigong D, Kiriamiti H, van Langenhove H (2012) Multi criteria sustainability assessment of biogas production in Kenya. Appl Energy 93:496-506

OECD/IEA (2015) Global Energy Outlook-executive summary. International Energy Agency, Paris

Okello C, Pindozzi S, Faugno S, Boccia L (2013) Development of bioenergy technologies in Uganda: a review of progress. Renew Sustain Energy Rev 18:55-63

Olowolafe EA (2008) Effects of using municipal waste as fertilizer on soil properties in Jos area, Nigeria. Resour Conserv Recycl 52(11):1266-1270 
Onodera T, Kim CK (2006) BSE situation and establishment of Food Safety Commission in Japan. J Vet Sci 7(1):1-11

Pandyaswargo AH, Premakumara DGJ (2014) Financial sustainability of modern composting: the economically optimal scale for municipal waste composting plant in developing Asia. Int J Recycl Org Waste Agric 3(3):1-14

Papargyropoulou E, Lozano R, Steinberger JK, Wright N, Ujang $\mathrm{Zb}$ (2014) The food waste hierarchy as a framework for the management of food surplus and food waste. J Clean Prod 76:106-115

Parawira W (2009) Biogas technology in sub-Saharan Africa: status, prospects and constraints. Rev Environ Sci Bio/ Technol 8(2):187-200

Park J-Y, Lee J-S, Wang Z-M, Kim D-K (2010) Production and characterization of biodiesel from trap grease. Korean $\mathrm{J}$ Chem Eng 27(6):1791-1795

Park YK, Kim W, Jo YM (2013) Release of harmful air pollutants from open burning of domestic municipal solid wastes in a metropolitan area of Korea. Aerosol Air Qual Res 13(4):1365-1372

Parra Paz AS, Carrejo NS, Gómez Rodríguez CH (2015) Effects of larval density and feeding rates on the bioconversion of vegetable waste using black soldier fly larvae Hermetia illucens (L.) (Diptera: Stratiomyidae). Waste Biomass Valoriz 6(6):1059-1065

Pérez RA, Sánchez-Brunete C, Albero B, Miguel E, Tadeo JL, Alonso J, Lobo MC (2016) Quality assessment of three industry-derived organic amendments for agricultural use. Compost Sci Util 24(3):190-202

Peterson AA, Vogel F, Lachance RP, Froling M, Antal JMJ, Tester JW (2008) Thermochemical biofuel production in hydrothermal media: a review of sub- and supercritical water technologies. Energy Environ Sci 1(1):32-65

Pham TPT, Kaushik R, Parshetti GK, Mahmood R, Balasubramanian R (2015) Food waste-to-energy conversion technologies: current status and future directions. Waste Manag 38:399-408

Polprasert C (2007) Organic waste recycling-technology and management. IWA Publishing, London

Prasad Raju H, Partheeban P (2014) Mobile monitoring of air pollution emanating from burning of MSW: impact on human health - a case study. Int $J$ Earth Sci Eng 7(5):1799-1805

Puig-Arnavat M, Bruno JC, Coronas A (2010) Review and analysis of biomass gasification models. Renew Sustain Energy Rev 14(9):2841-2851

Qian K, Kumar A, Zhang H, Bellmer D, Huhnke R (2015) Recent advances in utilization of biochar. Renew Sustain Energy Rev 42:1055-1064

Quintero JA, Moncada J, Cardona CA (2013) Techno-economic analysis of bioethanol production from lignocellulosic residues in Colombia: a process simulation approach. Bioresour Technol 139:300-307

Rajendran K, Aslanzadeh S, Taherzadeh MJ (2012) Household biogas digesters-a review. Energies 5(8):2911

Ramirez J, Brown R, Rainey T (2015) A review of hydrothermal liquefaction bio-crude properties and prospects for upgrading to transportation fuels. Energies 8(7):6765

Reckerzügl T (2013) Bali: combating climate change and poverty-recycling used cooking oil and transforming it into biodiesel. REPIC final report. St. Ursen, Caritas
Reddy PS, Nandini N (2011) Leachate characterization and assessment of groundwater pollution near municipal solud waste landfill site. Nat Environ Pollut Technol $10(3): 415-418$

Reiche A, Kirkwood KM (2012) Comparison of Escherichia coli and anaerobic consortia derived from compost as anodic biocatalysts in a glycerol-oxidizing microbial fuel cell. Bioresour Technol 123:318-323

Reinecke AJ, Viljoen SA (1990) The influence of feeding patterns on growth and reproduction of the vermicomposting earthworm Eisenia fetida (Oligochaeta). Biol Fertil Soils 10(3):184-187

Reinecke AJ, Viljoen SA, Saayman RJ (1992) The suitability of Eudrilus eugeniae, Perionyx excavatus and Eisenia fetida (Oligochaeta) for vermicomposting in southern Africa in terms of their temperature requirements. Soil Biol Biochem 24(12):1295-1307

Rhén C, Gref R, Sjöström M, Wästerlund I (2005) Effects of raw material moisture content, densification pressure and temperature on some properties of Norway spruce pellets. Fuel Process Technol 87(1):11-16

Riding MJ, Herbert BMJ, Ricketts L, Dodd I, Ostle N, Semple KT (2015) Harmonising conflicts between science, regulation, perception and environmental impact: the case of soil conditioners from bioenergy. Environ Int 75:52-67

Rizal Y, Mahata ME, Wu G, Maryudi H, Andriani M (2015) Improving the nutrient quality of carrot and fruit juice wastes mixture for poultry diet through utilization of ricehull ash filtrate. Pak J Nutr 14(3):126-130

Romero-Güiza MS, Vila J, Mata-Alvarez J, Chimenos JM, Astals S (2016) The role of additives on anaerobic digestion: a review. Renew Sustain Energy Rev 58:1486-1499

Roth C (2014) Micro-gasification: cooking with gas from dry biomass, 2nd revised edition ed. Eschborn, Germany: On behalf of Ministry for Economic Cooperation and Development (BMZ), p 175

Rothenberger S, Zurbrügg C, Enayetullah I, Sinha AHMM (2006) Decentralized composting for cities of low- and middle-income countries-a user's manual: Sandec/ Eawag and Waste Concern, Dhaka

Roy MM, Corscadden KW (2012) An experimental study of combustion and emissions of biomass briquettes in a domestic wood stove. Appl Energy 99:206-212

Rozkosny R (1982) A biosystematic study of the European Stratiomyidae (Diptera), vol I. Dr W. Junk, The Hague, p 401

Ruiz JA, Juárez MC, Morales MP, Muñoz P, Mendívil MA (2013) Biomass gasification for electricity generation: review of current technology barriers. Renew Sustain Energy Rev 18:174-183

Sánchez A, Artola A, Font X, Gea T, Barrena R, Gabriel D, Sánchez-Monedero MÁ, Roig A, Cayuela ML, Mondini C (2015) Greenhouse gas emissions from organic waste composting. Environ Chem Lett 13(3):223-238

Santos FT, Goufo P, Santos C, Botelho D, Fonseca J, Queirós A, Costa MSSM, Trindade H (2016) Comparison of five agroindustrial waste-based composts as growing media for lettuce: effect on yield, phenolic compounds and vitamin C. Food Chem 209:293-301

Sarkar N, Ghosh SK, Bannerjee S, Aikat K (2012) Bioethanol production from agricultural wastes: an overview. Renew Energy 37(1):19-27 
Sarris D, Papanikolaou S (2016) Biotechnological production of ethanol: biochemistry, processes and technologies. Eng Life Sci 16(4):307-329

Sawatdeenarunat C, Surendra KC, Takara D, Oechsner H, Khanal SK (2015) Anaerobic digestion of lignocellulosic biomass: challenges and opportunities. Bioresour Technol 178:178-186

Scheinberg A, Wilson DC, Rodic L (2010) Solid waste management in the World's cities. In: UN-Habitat's third global report on the state of water and sanitation in the World's cities. Earthscan for UN Habitat, London

Schmid MR, Gutzwiler S, Zellweger H (2015) Pulpa Pyro Peru-clean generation of biochar and energy from coffee pulp. REPIC, final report. Swiss State Secretariat for Economic Affairs SECO, Swiss Agency for Development and Cooperation SDC, Swiss Federal Office of Energy SFOE, Bern

Scotti R, Pane C, Spaccini R, Palese AM, Piccolo A, Celano G, Zaccardelli M (2016) On-farm compost: a useful tool to improve soil quality under intensive farming systems. Appl Soil Ecol 107:13-23

Shahmansouri MR, Pourmoghadas H, Parvaresh AR, Alidadi H (2005) Heavy metals bioaccumulation by Iranian and Australian earthworms (Eisenia fetida) in the sewage sludge vermicomposting. J Environ Health Sci Eng 2(1):28-32

Sheppard DC, Newton GL, Thompson SA, Savage S (1994) A value-added manure management-system using the black soldier fly. Bioresour Technol 50(3):275-279

Sim EYS, Wu TY (2010) The potential reuse of biodegradable municipal solid wastes (MSW) as feedstocks in vermicomposting. J Sci Food Agric 90(13):2153-2162

Singh RP, Singh P, Araujo ASF, Hakimi Ibrahim M, Sulaiman O (2011) Management of urban solid waste: vermicomposting a sustainable option. Resour Conserv Recycl 55(7):719-729

Smith JU, Fischer A, Hallett PD, Homans HY, Smith P, AbdulSalam Y, Emmerling HH, Phimister E (2015) Sustainable use of organic resources for bioenergy, food and water provision in rural Sub-Saharan Africa. Renew Sustain Energy Rev 50:903-917

Srirangan K, Akawi L, Moo-Young M, Chou CP (2012) Towards sustainable production of clean energy carriers from biomass resources. Appl Energy 100:172-186

Srivastava V, Ismail SA, Singh P, Singh RP (2014) Urban solid waste management in the developing world with emphasis on India: challenges and opportunities. Rev Environ Sci Bio/Technol 14(2):317-337

Stamer A (2015) Insect proteins - a new source for animal feed. EMBO Rep 16:676-680

Stelte W, Holm JK, Sanadi AR, Barsberg S, Ahrenfeldt J, Henriksen UB (2011a) Fuel pellets from biomass: the importance of the pelletizing pressure and its dependency on the processing conditions. Fuel 90(11):3285-3290

Stelte W, Holm JK, Sanadi AR, Barsberg S, Ahrenfeldt J, Henriksen UB (2011b) A study of bonding and failure mechanisms in fuel pellets from different biomass resources. Biomass Bioenergy 35(2):910-918

St-Hilaire S, Cranfill K, McGuire MA, Mosley EE, Tomberlin JK, Newton GL, Sealey W, Sheppard DC, Irving S (2007) Fish offal recycling by the black soldier fly produces a foodstuff high in omega-3 fatty acids. J World Aquacult Soc 38(2):309-313

Stohl A, Aamaas B, Amann M, Baker LH, Bellouin N, Berntsen TK, Boucher O, Cherian R, Collins W, Daskalakis N et al (2015) Evaluating the climate and air quality impacts of short-lived pollutants. Atmos Chem Phys 15(18):10529-10566

Stolarski MJ, Szczukowski S, Tworkowski J, Krzyżaniak M, Gulczyński P, Mleczek M (2013) Comparison of quality and production cost of briquettes made from agricultural and forest origin biomass. Renew Energy 57:20-26

Strassen HE (1995) Small-scale gasifiers for heat and power. A global review. World Bank technical paper, No 296: Energy Series. The World Bank, Washington

Sukumaran RK, Surender VJ, Sindhu R, Binod P, Janu KU, Sajna KV, Rajasree KP, Pandey A (2010) Lignocellulosic ethanol in India: prospects, challenges and feedstock availability. Bioresour Technol 101(13):4826-4833

Surendra KC, Olivier R, Tomberlin JK, Jha R, Khanal SK (2016) Bioconversion of organic wastes into biodiesel and animal feed via insect farming. Renew Energy 98:197-202

Suryawanshi PC, Chaudhari AB, Kothari RM (2010) Mesophilic anaerobic digestion: first option for waste treatment in tropical regions. Crit Rev Biotechnol 30(4):259-282

Taiwo AM, Gbadebo AM, Oyedepo JA, Ojekunle ZO, Alo OM, Oyeniran AA, Onalaja OJ, Ogunjimi D, Taiwo OT (2016) Bioremediation of industrially contaminated soil using compost and plant technology. J Hazard Mater 304:166-172

Tan X, Liu Y, Zeng G, Wang X, Hu X, Gu Y, Yang Z (2015) Application of biochar for the removal of pollutants from aqueous solutions. Chemosphere 125:70-85

Tang J, Zhu W, Kookana R, Katayama A (2013) Characteristics of biochar and its application in remediation of contaminated soil. J Biosci Bioeng 116(6):653-659

Tomberlin JK, Sheppard DC (2002) Factors influencing mating and oviposition of black soldier flies (Diptera: Stratiomyidae) in a colony. J Entomol Sci 37(4):345-352

Tomberlin JK, Adler PH, Myers HM (2009) Development of the black soldier fly (Diptera: Stratiomyidae) in relation to temperature. Environ Entomol 38(3):930-934

Toor SS, Rosendahl L, Rudolf A (2011) Hydrothermal liquefaction of biomass: a review of subcritical water technologies. Energy 36(5):2328-2342

Tran KQ (2016) Fast hydrothermal liquefaction for production of chemicals and biofuels from wet biomass-the need to develop a plug-flow reactor. Bioresour Technol 213:327-332

Tripathi M, Sahu JN, Ganesan P (2016) Effect of process parameters on production of biochar from biomass waste through pyrolysis: a review. Renew Sustain Energy Rev 55:467-481

Troschinetz AM, Mihelcic JR (2009) Sustainable recycling of municipal solid waste in developing countries. Waste Manag 29(2):915-923

Tryner J, Willson BD, Marchese AJ (2014) The effects of fuel type and stove design on emissions and efficiency of natural-draft semi-gasifier biomass cookstoves. Energy Sustain Dev 23:99-109

Tumuluru JS, Wright CT, Hess JR, Kenney KL (2011) A review of biomass densification systems to develop uniform feedstock commodities for bioenergy application. Biofuels Bioprod Biorefin 5(6):683-707 
UNEP (2007) Guidelines on best available techniques and provisional guidance on best environmental practicesopen burning of waste, including burning of landfill sites. Relevant to Article 5 and Annex $\mathrm{C}$ of the Stockholm Convention on Persistent Organic Pollutants. United Nations Environmental Programme, Geneva, p 29

UNEP (2011) UNEP Year Book 2011: emerging issues in our global environment. United Nations Environment Programme, Nairobi

UNF (2016) Global alliance for clean cookstoves. United Nations Foundation, Washington

United Nations Development Programme (2015) Table 1: Human Development Index and its components. http://hdr. undp.org/en/composite/HDI. Last Accessed 2 Feb 2017

Vamvuka D (2011) Bio-oil, solid and gaseous biofuels form biomass pyrolysis processes-an overview. Int $\mathrm{J}$ Energy Res 35:835-862

van der Stelt MJC, Gerhauser H, Kiel JHA, Ptasinski KJ (2011) Biomass upgrading by torrefaction for the production of biofuels: A review. Biomass Bioenergy 35(9):3748-3762

Van Fan Y, Lee CT, Klemeš JJ, Bong CPC, Ho WS (2016) Economic assessment system towards sustainable composting quality in the developing countries. Clean Technol Environ Policy 18(8):2479-2491

Vandevivere P, De Baere L, Verstraete W (2003) Types of anaerobic digester for solid wastes. In: Mata-Alvarez J (ed) Biomethanization of the organic fraction of municipal solid wastes. IWA Publishing, Cornwall, pp 111-137

Velis CA, Longhurst PJ, Drew GH, Smith R, Pollard SJT (2010) Production and quality assurance of solid recovered fuels using mechanical-biological treatment (MBT) of waste: a comprehensive assessment. Crit Rev Environ Sci Technol 40(12):979-1105

Venderbosch RH, Prins W (2010) Fast pyrolysis technology development. Biofuels Bioprod Biorefin 4(2):178-208

Vergara SE, Tchobanoglous G (2012) Municipal solid waste and the environment: a global perspective. Annu Rev Environ Resour 37(1):277-309

Verma P, Sharma MP (2016) Review of process parameters for biodiesel production from different feedstocks. Renew Sustain Energy Rev 62:1063-1071

Vijay VK, Kapoor R, Trivedi A, Narale P (2015) Biogas upgrading and bottling technology for vehicular and cooking applications. In: Raju JN, Gossel W, Sudhakar M (eds) Management of natural resources in a changing environment. Springer, Cham, pp 135-153

Vögeli Y, Lohri CR, Gallardo A, Diener S, Zurbrügg C (2014) Anaerobic digestion of biowaste in developing countriespractical information and case studies. Swiss Federal Institute of Aquatic Science and Technology (Eawag), Dübendorf

Vohra M, Manwar J, Manmode R, Padgilwar S, Patil S (2014) Bioethanol production: feedstock and current technologies. J Environ Chem Eng 2(1):573-584

Walsh E, McDonnell KP (2012) The influence of added organic matter on soil physical, chemical, and biological properties: a small-scale and short-time experiment using straw. Arch Agron Soil Sci 58(sup1):S201-S205

Wang LK, Hung Y-T, Li KH (2007) Vermicomposting Process. In: Wang LK, Shammas NK, Hung Y-T (eds) Biosolids treatment processes. Humana Press, Totowa, pp 689-703
Wang Z-M, Lee J-S, Park J-Y, Wu C-Z, Yuan Z-H (2008) Optimization of biodiesel production from trap grease via acid catalysis. Korean J Chem Eng 25(4):670-674

Weiland P (2010) Biogas production: current state and perspectives. Appl Microbiol Biotechnol 85(4):849-860

Werther J, Saenger M, Hartge EU, Ogada T, Siagi Z (2000) Combustion of agricultural residues. Prog Energy Combust Sci 26(1):1-27

WHO (2014) WHO indoor air quality guidelines: household fuel combustion. World Health Organization, Geneva

Wilson DC (ed) (2015) Global Waste Management Outlook. International Solid Waste Association (ISWA) and United Nations Environmental Programme (UNEP), United Nations Environment Programme, Nairobi

Wilson DC, Rodic L, Scheinberg A, Velis CA, Alabaster G (2012) Comparative analysis of solid waste management in 20 cities. Waste Manag Res 30(3):237-254

Witjes S, Lozano R (2016) Towards a more Circular Economy: proposing a framework linking sustainable public procurement and sustainable business models. Resour Conserv Recycl 112:37-44

World Bank (2015) GNI per capita, PPP (current international \$). http://data.worldbank.org/indicator/NY.GNP.PCAP.PP.CD. Last Accessed on 2 Feb 2017[ZC1]

Xi B, He X, Dang Q, Yang T, Li M, Wang X, Li D, Tang J (2015) Effect of multi-stage inoculation on the bacterial and fungal community structure during organic municipal solid wastes composting. Bioresour Technol 196:399-405

Xie T, Reddy KR, Wang C, Yargicoglu E, Spokas K (2015) Characteristics and applications of biochar for environmental remediation: a review. Crit Rev Environ Sci Technol 45(9):939-969

Xiu S, Shahbazi A (2012) Bio-oil production and upgrading research: a review. Renew Sustain Energy Rev 16(7):4406-4414

Xu G, Lv Y, Sun J, Shao H, Wei L (2012) Recent advances in biochar applications in agricultural soils: benefits and environmental implications. CLEAN Soil Air Water 40(10):1093-1098

Xue Y, Chen H, Zhao W, Yang C, Ma P, Han S (2016) A review on the operating conditions of producing bio-oil from hydrothermal liquefaction of biomass. Int J Energy Res 40(7):865-877

Yaakob Z, Mohammad M, Alherbawi M, Alam Z, Sopian K (2013) Overview of the production of biodiesel from waste cooking oil. Renew Sustain Energy Rev 18:184-193

Yaman S (2004) Pyrolysis of biomass to produce fuels and chemical feedstocks. Energy Convers Manag 45(5):651-671

Yang F, Hanna MA, Sun R (2012) Value-added uses for crude glycerol - a byproduct of biodiesel production. Biotechnol Biofuels 5(1):13

Yang L, Xu F, Ge X, Li Y (2015a) Challenges and strategies for solid-state anaerobic digestion of lignocellulosic biomass. Renew Sustain Energy Rev 44:824-834

Yang X, Choi HS, Park C, Kim SW (2015b) Current states and prospects of organic waste utilization for biorefineries. Renew Sustain Energy Rev 49:335-349

Yank A, Ngadi M, Kok R (2016) Physical properties of rice husk and bran briquettes under low pressure densification for rural applications. Biomass Bioenergy 84:22-30 
Yenigün O, Demirel B (2013) Ammonia inhibition in anaerobic digestion: a review. Process Biochem 48(5-6):901-911

Yu G, Cheng P, Chen Y, Li Y, Yang Z, Chen Y, Tomberlin JK (2011) Inoculating poultry manure with companion bacteria influences growth and development of black soldier fly (Diptera: Stratiomyidae) larvae. Environ Entomol 40(1):30-35

Zabaleta I, Rodic L (2015) Recovery of essential nutrients from municipal solid waste-Impact of waste management infrastructure and governance aspects. Waste Manag 44:178-187

Zhang Q, Chang J, Wang T, Xu Y (2007) Review of biomass pyrolysis oil properties and upgrading research. Energy Convers Manag 48(1):87-92

Zhang DQ, Tan SK, Gersberg RM (2010a) Municipal solid waste management in China: status, problems and challenges. J Environ Manag 91(8):1623-1633

Zhang L, Xu C, Champagne P (2010b) Overview of recent advances in thermo-chemical conversion of biomass. Energy Convers Manag 51(5):969-982

Zhang T, Fiedler H, Yu G, Ochoa GS, Carroll WF, Gullett BK, Marklund S, Touati A (2011) Emissions of unintentional persistent organic pollutants from open burning of municipal solid waste from developing countries. Chemosphere 84(7):994-1001

Zhang L, Liu R, Yin R, Mei Y (2013) Upgrading of bio-oil from biomass fast pyrolysis in China: a review. Renew Sustain Energy Rev 24:66-72

Zhang C, Su H, Baeyens J, Tan T (2014) Reviewing the anaerobic digestion of food waste for biogas production. Renew Sustain Energy Rev 38:383-392
Zhao T, Zhang L, Zhao Y (2010) Study on the inhibition of methane production from anaerobic digestion of biodegradable solid waste. Waste Manag Res 28(4):347-354

Zheng L, Crippen TL, Holmes L, Singh B, Pimsler ML, Benbow ME, Tarone AM, Dowd S, Yu Z, Vanlaerhoven SL et al (2013) Bacteria mediate oviposition by the black soldier fly, Hermetia illucens (L.), (Diptera: Stratiomyidae). Sci Rep 3. doi:10.1038/srep02563

Zhou F, Tomberlin JK, Zheng L, Yu Z, Zhang J (2013) Developmental and waste reduction plasticity of three black soldier fly strains (Diptera: Stratiomyidae) raised on different livestock manures. J Med Entomol 50(6):1224-1230

Zinoviev S, Müller-Langer F, Das P, Bertero N, Fornasiero P, Kaltschmitt M, Centi G, Miertus S (2010) Next-generation biofuels: survey of emerging technologies and sustainability issues. ChemSusChem 3(10):1106-1133

Zurbrügg C (2013) Assessment methods for waste management decision-support in developing countries [Dissertation]. Università degli Studi die Brescia, Facoltà di Ingegneria, Brescia

Zurbrügg C, Drescher S, Patel A, Sharatchandra HC (2004) Decentralised composting of urban waste - an overview of community and private initiatives in Indian cities. Waste Manag 24(7):655-662

Zurbrügg C, Gfrerer M, Ashadi H, Brenner W, Küper D (2012) Determinants of sustainability in solid waste management - the Gianyar Waste Recovery Project in Indonesia. Waste Manag 32(11):2126-2133 